NIST Technical Note 1823

\title{
Additive Manufacturing Technical Workshop Summary Report
}

Christopher Brown

Joshua Lubell

Robert Lipman 


\section{NIST Technical Note 1823}

\section{Additive Manufacturing Technical Workshop Summary Report}

Christopher Brown Joshua Lubell Robert Lipman

Systems Integration Division

Engineering Laboratory

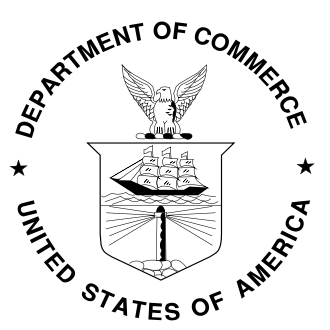

U.S. Department of Commerce Penny Pritzker, Secretary 
Certain commercial entities, equipment, or materials may be identified in this document in order to describe an experimental procedure or concept adequately. Such identification is not intended to imply recommendation or endorsement by the National Institute of Standards and Technology, nor is it intended to imply that the entities, materials, or equipment are necessarily the best available for the purpose.

National Institute of Standards and Technology Technical Note 1823 Natl. Inst. Stand. Technol. Tech. Note 1823, 59 pages (November 2013) CODEN: NTNOEF http://dx.doi.org/10.6028/NIST.TN.1823 


\begin{abstract}
This report summarizes the presentations, discussions, and recommendations from the Additive Manufacturing Technical Workshop held during the PDES, Inc. [1] offsite meeting in Gaithersburg, Maryland in March 2013. The purpose of the Workshop was to identify challenges, research needs, and issues with the quality of additive manufacturing data. This report includes an overview of additive manufacturing, summaries of the Workshop presentations, and conclusions based on the presentations and discussions.
\end{abstract}

\title{
Acknowledgement
}

We thank the presenters for their excellent presentations and those that participated in the workshop.

\section{Keywords}

manufacturing, 3D printing, stereolithography, data quality, STL format, AMF format

\section{Acronym}

$\begin{array}{ll}\text { AM } & \text { Additive Manufacturing } \\ \text { AMF } & \text { Additive Manufacturing File Format } \\ \text { ASTM } & \text { American Society for Testing and Materials } \\ \text { CAD } & \text { Computer-Aided Drawing } \\ \text { DMLS } & \text { Direct Metal Laser Sintering } \\ \text { EL } & \text { Engineering Laboratory } \\ \text { ISO } & \text { International Organization for Standardization } \\ \text { LOTAR } & \text { Long Term Archiving and Retrieval } \\ \text { LTA } & \text { Long Term Archiving } \\ \text { NAMII } & \text { National Additive Manufacturing Innovation Institute } \\ \text { NIST } & \text { National Institute of Standards and Technology } \\ \text { PICAM } & \text { Product Information for Composites and Additive Manufacturing } \\ \text { PDM } & \text { Product Data Management } \\ \text { SIMCA } & \text { Systems Integration for Manufacturing and Construction Applications } \\ \text { STEP } & \text { Standard for the Exchange of Product model data } \\ \text { STL } & \text { Stereolithography File Format } \\ \text { UV } & \text { Ultra-violet } \\ \text { XML } & \text { eXtensible Markup Language }\end{array}$




\section{Introduction}

The NIST (National Institute of Standards and Technology) Engineering Laboratory held a technical workshop titled "Exploring Current State-of-the-Art and Issues in Additive Manufacturing," on March 14, 2013 in Gaithersburg, Maryland. The purpose of the workshop was to review the state-of-the-art in additive manufacturing (AM), identify technical challenges, research issues, and standards' gaps from a manufacturing information perspective. Participants included representatives from Airbus, BAE Systems, Boeing, Honeywell, Lockheed Martin, NASA, Rockwell Collins, Sandia National Laboratories, US Air Force, US Army Research Laboratory, and various government agencies. Table 1 lists the presentations.

The workshop was held in conjunction with the PDES, Inc. Offsite meeting also hosted by the NIST Engineering Laboratory (EL). PDES, Inc. is an industry consortium that supports the digital manufacturing enterprise through the development and implementation of information standards for engineering and manufacturing. Implementation testing and data exchange using ISO 10303 standard for product data exchange are an integral part of PDES, Inc. programs [1].

\section{Table 1 Workshop presentations}

\begin{tabular}{|l|l|}
\hline Speaker & Presentation Title \\
\hline Chris Brown, NIST & Introduction \\
\hline Richard Murrish, Boeing & Additive Manufacturing, Where Complexity is Free \\
\hline Kevin Jurrens, NIST & $\begin{array}{l}\text { NIST Measurement Science Research for Additive } \\
\text { Manufacturing }\end{array}$ \\
\hline Shawn Moylan, NIST & $\begin{array}{l}\text { Proposed Standardized Test Artifact for Additive } \\
\text { Manufacturing }\end{array}$ \\
\hline John Slotwinski, NIST & Material Standards for Additive Manufacturing \\
\hline Hod Lipson, Cornell & ASTM file format for 3D printing - AMF \\
\hline Douglas Thomas, NIST & Economic Trends in US Additive Manufacturing \\
\hline
\end{tabular}

Industry interest in AM is growing as the AM industry has matured. Producing products using AM processes is now becoming more feasible for the industries of interest to PDES, Inc. members. For example, the aerospace industry is interested in using AM processes to make nonstructural components such as radar domes and critical components such as airplane wings. PDES, Inc. member companies are either actively engaged in AM or expect to be in the near future. Companies including Boeing [3], General Electric [4], and Lockheed Martin [5] have active research and development programs investigating AM applications and have identified the need for improving information standards and material standards in this area.

PDES, Inc. is affiliated with Long Term Archiving and Retrieval International (LOTAR). LOTAR's objective is to develop standards for long-term archiving (LTA) of digital data, such as 3D CAD (Computer-Aided Drawing) and PDM (Product Data Management) data [2]. An AM 
data exchange standard suitable for use throughout the product lifecycle would serve the goals of both PDES, Inc. and LOTAR member companies.

This report summarizes presentations, discussions, and recommendations from the AM Workshop. Section 2 provides an overview of AM. Section 3 summarizes each of the five technical workshop presentations. Section 4 provides conclusions and recommendations.

\section{Additive Manufacturing}

AM has been around for over 40 years and is now becoming more widespread as the cost of hardware becomes less expensive and as AM processes improve. An AM process builds parts directly from a CAD design file adding material layer-by-layer. There are several different kinds of processes (discussed in Richard Murrish's presentation - see 3.1) that are considered additive processes because they all involve adding material to create the desired part rather than subtractive processes which involve machining away unnecessary material.

AM parts may have several advantages over traditional subtractive manufacturing techniques. The AM techniques may allow the part to be made with less material for less cost, generating less waste material, and possibly weighing less. Parts may be made with increased strength and with multiple functions, such as embedding an antenna within a wing. Parts may be designed and manufactured in ways that are not possible using traditional subtractive manufacturing techniques.

Modeling and testing approaches are needed to assess the accuracy of AM design models. AM processes are susceptible to errors because of the complexity and fault-sensitivity of AM data. Even the smallest data error can cause process errors that can lead to part defects that are not detectable by visual examination. An AM product is only as good as the data that describes it. Accurate models will improve quality and reduce rework.

\section{Workshop Presentation Summaries}

This section provides summaries of the 6 presentations given during the workshop. Subsection titles are the presentation titles and the author's name, title, and organization is provided in italics. 


\title{
3.1 Additive Manufacturing, Where Complexity is Free
}

\author{
Richard Murrish, Associate Technical Fellow, Boeing
}

This presentation gave an overview of the history of AM and discussed current techniques and materials used (see Appendix 1). AM processes mentioned include stereolithography, laser sintering, fused deposition, direct metal laser sintering, 3D printing, layer object manufacturing, and ballistic particle manufacturing.

In the 1960s Herbert Voelcker considered the possibilities of using computer-aided machine control to run machines that built parts from CAD geometry. In the 1970s, he developed the mathematical tools to describe 3D parts that resulted in the early algorithms for solid modeling. In the 1980s, Carl Deckard formulated the idea of layer based manufacturing. Charles Hull is typically given credit for pioneering rapid prototype technology and patented his concept in 1986 (see Appendix 1). His method, which he called "stereolithography," involved thin consecutive layers of ultraviolet curable liquid photopolymer resin, which was then cured with a concentrated ultraviolet (UV) light. A typical stereolithography process consists of a UV laser that moves over a vat of liquid photopolymer to solidify the surface layer in the cross-sectional geometry. Final curing and some post processing are often required [6]. The layer geometry is extracted from the CAD geometry, and a solid object is built layer by layer relatively quickly compared to other AM processes.

Other additive processes have also been developed. Laser sintering is similar to the stereolithography process of using UV light to cure plastic; however in this case, a laser is used to melt a thermoplastic powder. The powder is spread over the build surface incrementally so that only one layer of powder is added at a time [7]. A laser then moves in the X-Y direction to fuse the powder layer in the form of the cross section of the object. CAD data is used to generate the cross section geometry of the object. Improving the surface finish may require additional work. Porosity can be a concern. Selective laser sintering is the same process but with a highpowered laser to make parts that are denser. Direct metal laser sintering involves metal powder and a higher powered laser then is used with the laser sintering or the selective laser sintering processes.

Fused deposition modeling is a widely used technique. A plastic filament is unwound from a coil and fed into an extrusion nozzle where it is melted. The melted plastic is then directed either by motion of the nozzle or by motion of the table. The plastic cools and hardens immediately and bonds to the lower layer [8]. This concept is similar to a hot glue gun mounted in place of a cutter on a 3-axis numerical control milling machine. The process can be relatively slow and may have poor layer to layer adhesion.

$3 \mathrm{D}$ printing is a relatively quick process compared to other AM processes with low material costs. It is similar to the laser sintering process except that the powder is bonded with liquid 
adhesive instead of a laser. Liquid adhesive is deposited on a layer of powder material and bonds the powder together [9]. A hardener is often added to the part once finished to provide strength and overcome fragility.

Laminated (or layer) object manufacturing involves building layers of an object from paper. Paper is pulled across the build surface using a heated roller. The roller melts the plastic coating on the underside of the paper so the paper bonds to the previous layer. A carbon dioxide laser then cuts the paper cross section. The surface may have a stair-stepping roughness resulting from the paper thickness of each layer, but material costs for this process are low [10]. The process is relatively fast compared to other AM processes but suffers from the paper absorption of moisture which can result in warping.

Ballistic particle manufacturing is a process that builds models by firing micro-droplets of molten wax from a moving nozzle onto a build platform. The platform lowers to allow the wax to be added in consecutive layers. Material costs for this process are low but the parts lack strength.

The aerospace and automotive industries currently use AM to make design prototypes and expect to soon be making non-critical and critical parts such as engine parts and entire aircraft wings [11]. Other industries have also found AM useful. These industries include the construction industry where small structures are made from adding layers of concrete [12]. The fashion industry has printed shoes, clothing, and jewelry [13]. The medical industry uses AM to scan body parts and print replacement structures on which new tissue can grow [14]. Also, printing organs from biological tissue is being developed. The food industry is also working on printing food products [15].

If a user can design a part with CAD software, then it can be "printed." Unlike subtractive manufacturing, the complexity of a designed object does not impact its cost. Additively manufacturing a complex geometry costs the same as manufacturing a simple geometry, thus, "complexity is free." However, since there is no subtractive process, the design model fully specifies the object to be manufactured and therefore must be very accurate. Any errors in the model or loss of integrity of the design information during transfer to an AM machine will produce errors in the part which may be difficult to detect. 


\subsection{NIST Measurement Science for Additive Manufacturing}

Kevin Jurrens, Deputy Division Chief, Intelligent Systems Division, National Institute of Standards and Technology

In 2009, the National Science Foundation and Office of Naval Research sponsored an AM roadmap development workshop [16]. Barriers to AM adoption were determined to be insufficient understanding of material types and properties, part accuracy, the need for qualification and certification, and the lack of AM standards and data formats. NIST proposed a suite of AM standards to focus on areas identified as needing attention (see Appendix 2). The proposed standards hierarchy has a top level, focusing on fundamental standards defining general concepts and common requirements. Below the top level is a tier containing three specialized groups of standards specific to machines: raw materials, process/equipment, and finished parts. NIST's current focus is on developing a standardized test artifact to characterize the performance of a metal-based AM machine or process, and developing standard test methods for raw metal powder characterization and material properties of AM parts.

NIST is active in ASTM Standards Committee F42. The purpose of F42 is to address high priority needs for AM technologies [17]. Subcommittees have been formed for terminology, test methods, processes and materials, and design including data formats. NIST's Intelligent Systems Division hosted a requirements-gathering workshop in December 2012 for metal-based additive manufacturing, which resulted in a measurement science roadmap [18]. The objectives of the workshop were to build on previous AM roadmaps with additional details on barriers, challenges, and gaps; provide direction to ASTM F42 planning; and begin coordination with the National Additive Manufacturing Innovation Institute (NAMII).

\subsection{Proposed Standardized Test Artifact for Additive Manufacturing}

Shawn Moylan, Mechanical Engineer, Intelligent Systems Division, National Institute of Standards and Technology

NIST developed an AM standardized test artifact to characterize the performance of an AM machine or process (see Appendix 3). The focus on developing a standard test artifact addresses one of the requirements from the measurement science roadmap mentioned previously in Jurrens' presentation. The test artifact is designed to test the AM machine's or process's ability to accurately build features such as straight or round features, parallel and perpendicular features, holes, and bosses. The artifact then may serve to verify the machine performance for a user or vendor. The artifact can also be used to compare the capabilities between machines. It can also highlight a specific machine defect and compare the performance of a machine before and after a machine or process improvement is made. 
Three stainless steel artifacts were built by NIST's direct metal laser sintering (DMLS) machine to determine repeatability. An average repeatability of approximately $30 \mu \mathrm{m}$ was determined using several feature measurements such as pin and hole diameters and positions, z-heights on staircases, and straightness, roundness, and flatness measurements. Process improvements were made with adjusted scaling that resulted in an improved repeatability of pin and hole positions.

\subsection{Material Standards for Additive Manufacturing}

John Slotwinski, Physicist, Intelligent Systems Division, National Institute of Standards and Technology

The NIST Engineering Laboratory is developing standard test methods for raw metal powder characterization, and standard test methods to obtain material properties of AM parts (see Appendix 4). The test methods will be part of the proposed suite of standards discussed in Jurrens' presentation. Currently, the AM industry cannot verify that the same type of metal powder is identical, resulting in unconfirmed powder properties. Therefore, the parts made from these powders may not have the same properties either. Mechanical tests are also being conducted to determine properties of test specimens made from different metal powders.

Additionally, NIST is developing test protocols, procedures, and analysis methods for industry round-robin testing of AM materials for contributing to a material property database. A material database will assist AM adoption for aerospace components. NIST has been conducting tensile tests on stainless steel specimens made using the DMLS process. Results indicate that the stressstrain behavior of the tensile bars is repeatable, and similar to the values reported by vendors. Specimens were found to have a slightly different strength depending on the build direction. Residual thermal stress is an issue due to the DMLS process involving the rapid melting and cooling of the material. Images of test specimens are being examined to view residual thermal stress. Porosity hiding within AM parts can also effect their mechanical behavior. A sensor system was designed to monitor the porosity during the DMLS process.

\subsection{ASTM File Format for 3D Printing - AMF}

Hod Lipson, Associate Professor of Mechanical and Aerospace Engineering and Computing and Information Science, Cornell University

ASTM developed a standard specification (F2915-12) for the Additive Manufacturing File Format (AMF) [19]. This eXtensible Markup Language (XML) format is intended to replace the 
STL (STereoLithography) file format commonly used for transferring information between design programs and additive manufacturing equipment. Although STL is simple to read, write, and process, it does have some shortcomings and fails to meet the needs of newer AM equipment (see Appendix 5). The STL format allows duplicate information and inconsistencies, and it does not scale well to high resolution. STL also does not support color, blending different materials, and different build orientations.

The time is right for the adoption of the AMF format since 3D printers are becoming smaller, cheaper, and more commonplace among hobbyists, home users, and small businesses. This proliferation of 3D printers is resulting in more users exchanging files with one another. Technology independence, ease of understanding and use, and scalability with complex objects are key requirements the AMF file format meets.

AMF is designed to have a manageable file size, efficient read and write time, processing, and accurate representation of information to address AM performance needs. Volumes are defined using a triangular mesh and materials are defined by properties. Colors and graphics can be specified. Materials can be mixed and grading between materials is possible. The format is backwards compatible with the STL format and, because of the extensibility of XML, it has the potential to include new features in the future.

\subsection{Economic Trends in US Additive Manufacturing}

Doug Thomas, Economist, Applied Economics Office, National Institute of Standards and Technology

NIST's Applied Economics Office is investigating AM trends in the US and the AM supply chain (see Appendix 6). AM is playing a significant role in global manufacturing including the US. In 2011, the US made \$246 million in AM shipments which is $38 \%$ of all the global shipments made. Based on the research data, it can be more cost effective to manufacture parts using AM than traditional manufacturing processes when the number of parts to be manufactured is small. However, if a large number of identical parts are needed, traditional manufacturing processes are still more cost effective. There are several consistent cost advantages of AM including lighter part weight, less transportation costs, and a rapid design-to-product phase. The adoption and diffusion of AM may occur at a faster rate as material costs decrease and the number of users increases. 


\section{Conclusions}

The following conclusions emerged from the Workshop presentations and the discussion among PDES, Inc. members that occurred after the presentations.

\subsection{AM is an important industry that is gaining momentum}

The AM industry is expanding and becoming a larger portion of US manufacturing (Thomas Appendix 6 slides). It is important that companies consider how their industry will be using AM and plan for the future accordingly. AM has the potential to transform various industries with innovations such as lighter weight aircraft, more fuel efficient cars, and improved medical treatments. Complexity in the AM part design is not more costly than less complex parts (Murrish Appendix 1 slides). NIST is playing an important role in standardizing AM raw materials and test artifacts, which will in turn help the certification process and acceptance of AM parts (Slotwinski Appendix 4 slides). As new materials and AM processes are introduced, NIST's work will continue.

\subsection{Data quality will increase in importance}

Current research appears to be focused on improving the AM machines and processes rather than data quality, the development of AMF file format being the exception. This may be because currently machine errors more than data errors contribute to part errors. As the AM machines improve, data quality will become more important. Conducting research to improve data quality, anticipating continued advancement of machine and process technology, could help reduce data quality errors in the future.

\subsection{The AMF file format is a step in the right direction}

AMF is an improvement over STL. Although STL remains the dominant AM file format in the industry, AMF use could grow as lower cost AM machines, AM manufacturers, and AM users become more commonplace (Lipson Appendix 5 slides). Because AMF is extensible, increased AMF use would likely drive further improvements in the form of enhancements to the format, some of which could appear in new editions of the ASTM AMF standard.

AMF however does not solve the problem of information exchange pertaining to the slicing of a CAD model into layers, nor was long-term archiving of AM information considered as a requirement for AMF. These use cases require a far richer information model. Patil et al. [20] have demonstrated the feasibility of ISO 10303, an international standard for the exchange of 
product data in a neutral format among CAD systems, as a basis of transferring slicing information in a neutral file format among different AM processes. Since STEP is also suitable for long-term archiving [2], additional research building upon the results of Patil et al. could contribute to solving problems beyond the scope of AMF and STL. 


\section{References}

[1] PDES, Inc. public webpage, About PDES, Inc., Available:

http://www.pdesinc.org/index.html. [Accessed: 1-Aug-2013].

[2] LOTAR webpage, Why LOTAR? Mission, Objectives and Scope, Available: http://www.lotarinternational.org/why-lotar/mission-objectives-scope.html. [Accessed: 1-Aug-2013].

[3] Zelinski, P., Modern Machine Shop, April 16, 2012, Available:

http://www.mmsonline.com/articles/the-aircraft-imperative. [Accessed: 29-Oct-2013].

[4] General Electric webpage, Additive manufacturing is reinventing the way we work, Available:

http://www.ge.com/stories/additive-manufacturing. [Accessed: 1-Aug-2013].

[5] Lockheed Martin webpage, Aeronautics, Laboratories, Rapid Prototyping Center, Available: http://www.lockheedmartin.com/us/aeronautics/labs/rapid_prototyping_center.html. [Accessed: 1-Aug-2013].

[6] Worldwide Guide to Rapid Prototyping, stereolithography, Available:

http://www.additive3d.com/sl.htm. [Accessed: 1-Aug-2013]

[7] Worldwide Guide to Rapid Prototyping, laser sintering, Available:

http://www.additive3d.com/sls.htm. [Accessed: 1-Aug-2013].

[8] Worldwide Guide to Rapid Prototyping, fused deposition modeling, Available:

http://www.additive3d.com/fdm.htm. [Accessed: 1-Aug-2013].

[9] Worldwide Guide to Rapid Prototyping, 3D printing, Available:

http://www.additive3d.com/3dp.htm. [Accessed: 1-Aug-2013].

[10] Worldwide Guide to Rapid Prototyping, Laminated Object Manufacturing, Available:

http://www.additive3d.com/lom.htm. [Accessed: 1-Aug-2013].

[11] Dillow, C. (2011, Feb, 14). Using 3-D Printing Tech, British Airbus Engineers Aim to Print Out an Entire Aircraft Wing. Popular Science. Available:

http://www.popsci.com/technology/article/2011-02/using-3-d-printing-tech-eads-wants-printout-entire-aircraft-wing. [Accessed: 21-Aug-2013].

[12] Lim, S., Buswell, R.A., Le, T.T., Austin, S.A., Gibb, A.G.F., and Thorpe, T., 2012, Developments in Construction-Scale Additive Manufacturing Processes, Automation in Construction, 21, pp. 262-268.

[13] Craddock, F., 2013, New Technology Opens Horizons at a Lesser Cost, The New York Times, published May 15, 2013. 
[14] Melchels, F.P.W., Domingos, M.A.N., Klein, T.J., Malda, J., Bartolo, P.J., and Hutmacher, D.W., 2012, Additive Manufacturing of Tissues and Organs, Progress in Polymer Science, 37(8), pp. 1079-1104.

[15] Lipson, H. 2012, Frontiers in Additive Manufacturing: The Shape of Things to Come, Spring Issue, The Bridge Linking Engineering and Society, Frontiers of Engineering, National Academy of Engineering, 42(1), pp. 5-12.

[16] Bourell, D.L., Leu, M.C., and Rosen, D.W., ed. 2009, Roadmap for Additive Manufacturing, Identifying the Future of Freeform Processing, ed The University of Texas at Austin, Austin, TX.

[17] ASTM Committee F42 on Additive Manufacturing Technologies, Available:

http://www.astm.org/COMMITTEE/F42.htm. [Accessed: 1-Aug-2013].

[18] Measurement Science Roadmap for Metal-Based Additive Manufacturing Workshop Summary Report, May 2013, prepared by Energetics Inc., Columbia MD, Available:

http://events.energetics.com/NIST-AdditiveMfgWorkshop/. [Accessed: 1-Aug-2013].

[19] ASTM F2915-12: F42 Committee, Standard Specification for Additive Manufacturing File Format (AMF) Version 1.1, ASTM International, West Conshohocken, PA, 2012.

[20] Patil, L., Dutta, D., Bhatt, A.D., Jurrens, K., Lyons, K., Pratt, M.J., and Sriram, R.D., 2002, A Proposed Standards-Based Approach for Representing Heterogeneous Objects for Layered Manufacturing, Rapid Prototyping Journal, 8(3), pp. 134-146. 


\section{Appendix: Slides}

The following appendices contain the slides from the six presentations during the workshop.

Some slides were removed if they were determined to be content-free (e.g., "Thank you" or "Any Questions?").

With the exception of the presentations given by NIST staff, inclusion in this Appendix implies neither endorsement nor approval by the National Institute of Standards and Technology. 
Appendix 1

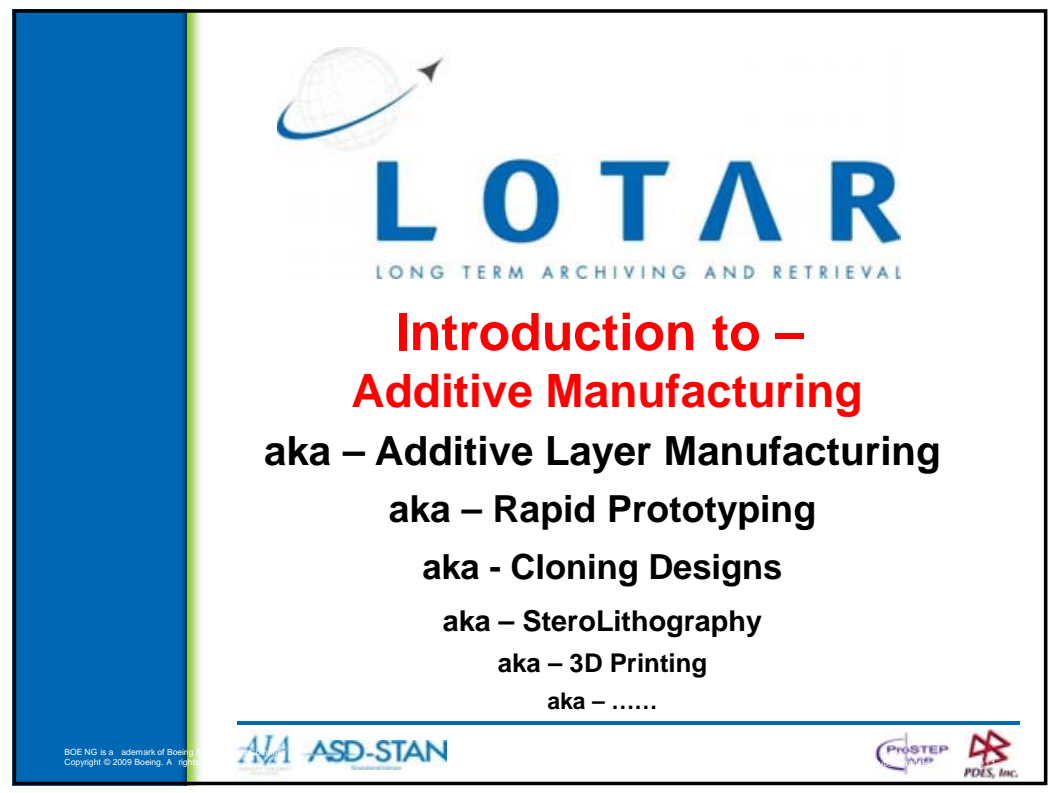

\section{Outline}

1.Technology Overview

2.Hardware and Material

3.Applications

4.STL - Creation/Processing

5.Use Cases

6.Out of the Box

\section{Technology Overview - Definitions}

- Additive Manufacturing consists of a class of technologies that can automatically construct physical models from Computer-Aided Design files.
- Improve communication
- Improve collaboration
- Shorten design cycles
- Stretch R\&D dollars
- Improve accuracy
- Eliminate mistakes
- Trigger innovation
- Accelerate Production
$-\ldots . .$.
- Save your Life?

\section{Technology Overview - Importance}

- Additive manufacturing was named number one in Aviation Week \& Space Technology magazine's May list of "Top Technologies to Watch," is a rapidly growing manufacturing technology being touted for its cost savings and waste reduction. By 2015, the sale of additive manufacturing products and services worldwide is expected to grow to $\$ 3.7$ billion from $\$ \mathbf{1 . 7 1}$ billion in 2011, according to independent consultants Wohlers Associates. 


\section{Objective -}

- Insight into being able to recognize use cases that would benefit from the use of Additive Manufacturing (ADDM)

- Insight into how to effectively initiate and integrate the use ADDM into a standard engineering process.

- Insight into the benefits and limitations found in each of the component disciplines found in the overall the use of ADDM.

- A perspective on future directions the use of ADDM might go

\section{History -}

- The term "stereolithography" was coined by Charles W. Hull, in his US Patent 4,575,330, entitled "Apparatus for Production of ThreeDimensional Objects by Stereolithography" issued in 1986.
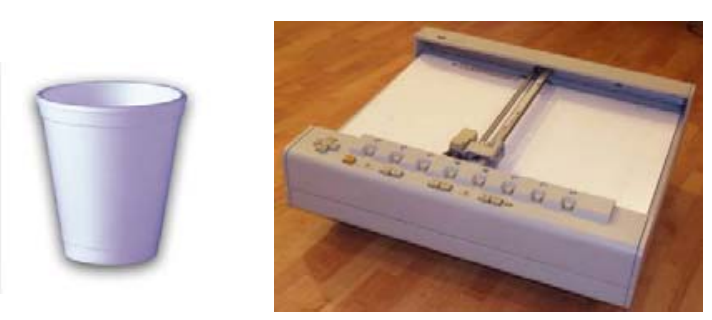

\section{History -}

- In the 60s Herbert Voelcker had thoughts of the possibilities of using computer aided machine control to run machines that build parts from CAD geometry.

- In the 70s he developed the mathematics to describe 3D aspects that resulted in the first algorithms for solid modeling

- in the 80s Carl Deckard came up with the idea of layer based manufacturing

- And while there are several people that have pioneered the Rapid Prototyping technology, the industry generally gives credit to Charles Hull -

\section{History -}

- Stereolithography was originally defined as a method and apparatus for making solid objects by successively "printing" thin layers of the curable material, e.g., a UV-curable material, one on top of the other.

\section{(Video)}




\section{Processes - Stereolithography}

Stereolithography (SLA) (Exerpted from Worldwide Guide to Rapid Prototyping)

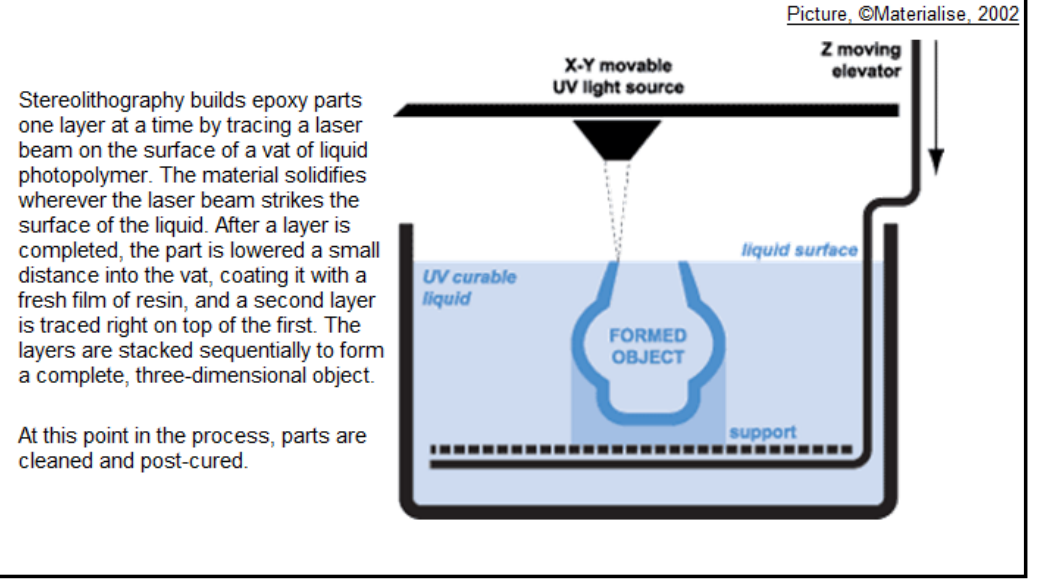

Picture, @Materialise, 2002

\section{Processes - Fused Deposition}

FDM is the second most widely used rapid prototyping

echnology, after

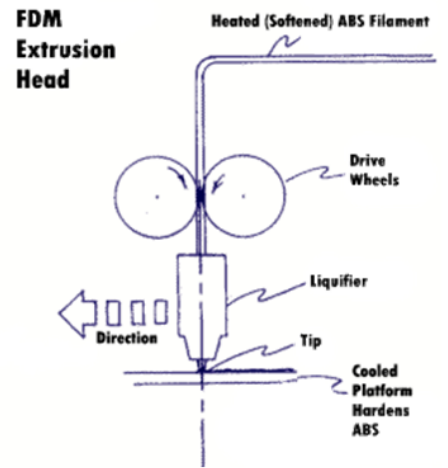

filament is unwound from a

plastic and has a mechanism

which allows the flow of the

melted plastic to be turned on

both horizontal and vertical

directions. The concept can

best be described as a hot

glue gun mounted in place of

As the nozzle is moved over the table in the required geometry, it deposits a thin bead of extruded plastic to form each layer. The plastic hardens immediately after being squirted from the nozzle and warm during the build process to prevent internal stresses from distorting the geometry.

\section{Processes - Laser Sintering}

Selective Laser Sintering (SLS)

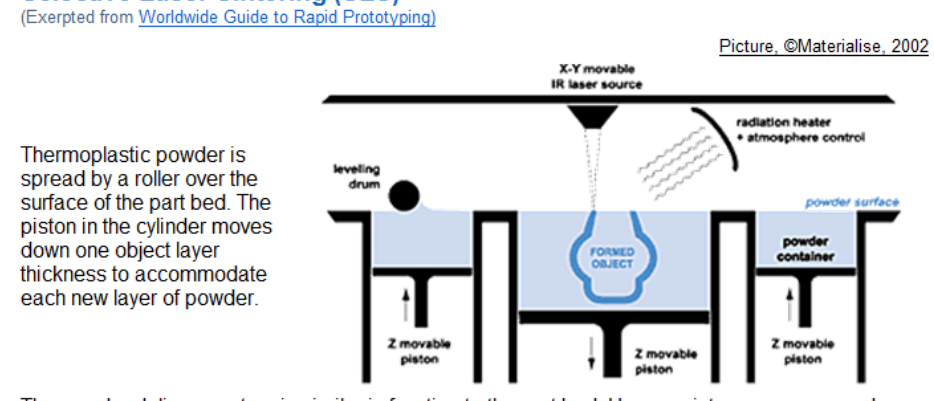

The powder delivery system is similar in function to the part bed. Here, a piston moves upward maintained at a temperature just below the melting point of the powder so that heat from the laser need only elevate the temperature slightly to cause sintering. This greatly speeds up the process.

A computer-directed infrared laser is then traced over the surface of the powder to selectively melt and bond a cross secion of the part to form one layer of the object. The process is repeated layer by

\section{Processes - Direct Metal Laser Sintering}

DMLS on the M270 is also similar to SLS but metal powders are fused directly with a fiber laser Complex metal pats int shap detall down to .012 inch can be built from mild steel, a bronze/stee alloy, or 17.4 pats wish
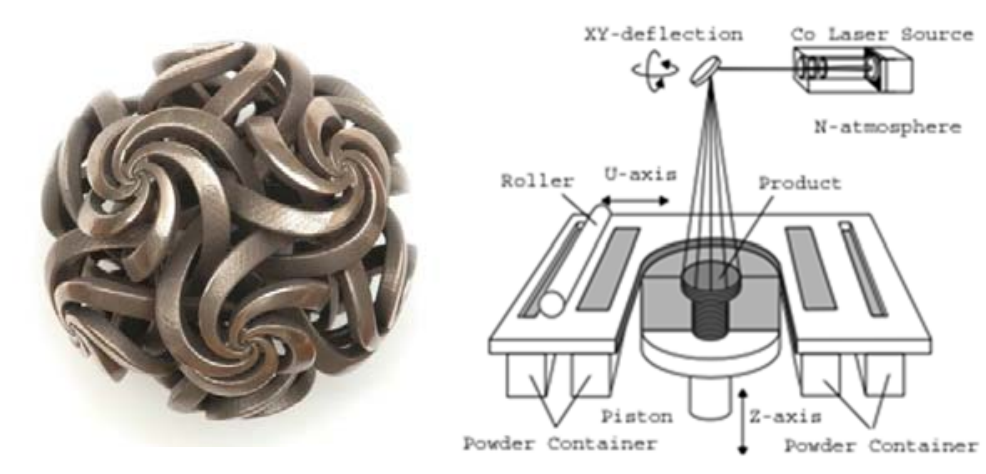


\section{Technology Overview - 3D Printing}

3D Printing on RPM's Z-Corporation Z810 is similar to SLS except the plaster powder is stuck together with binders delivered through ink-jet print heads on an XY plotter. The main advantages of $3 \mathrm{DP}$ are high speed and low cost with the added bonuses of a large build envelope and the capability to print in color. However, 3DP parts are fragile and don't have fine feature detail.

After printing, the parts are allowed to dry within the powder bed. Once removed, they are generally infused with cyanoacrylate (super glue) or epoxy to toughen them up

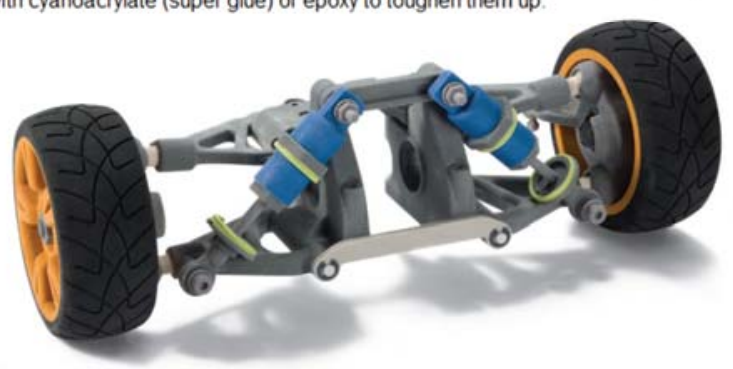

\section{Technology Overview - Layer Object Manufacturing}

A manufacturing process that uses a carbon-dioxide laser to

create successive cross-sections of a three-dimensional object

from layers of paper with a polyethylene coating on the backside.

A sheet of paper is fed through with the aid of small rollers. As the paper is fed through, a heated roller is used to melt the coating on the paper so that each new layer will adhere to the previous layer.

SOLIDO

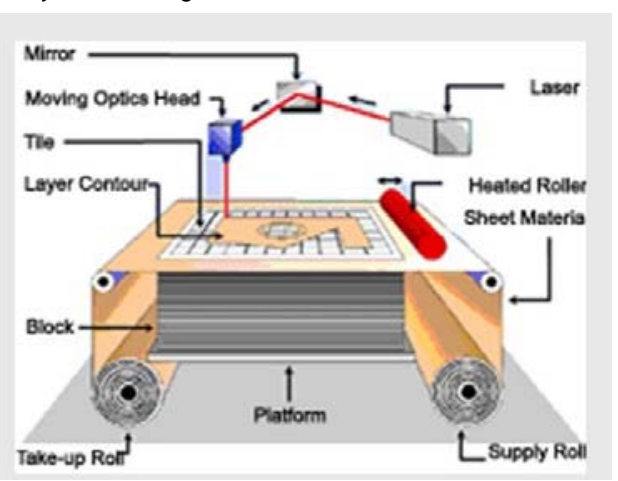

\section{Applications - Prototypes}

Physical and Digital Prototyping By L. Stephen Wolfe, P.E.

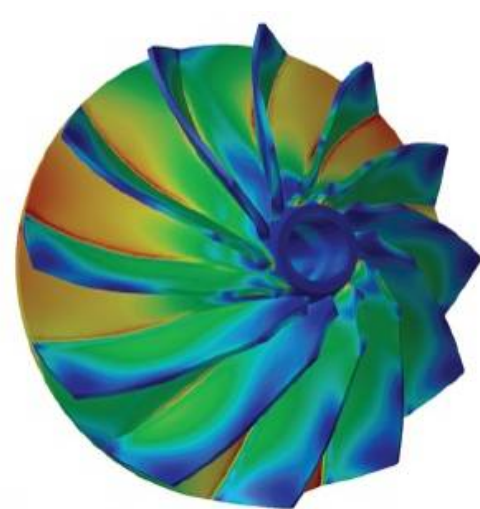

Flgure 8. Plot of stresses produced by centripetal forces In a turbine Impeller generated by Dassault Systèmes Abaqus software.

\section{Processes - Ballistic Particle Manufacturing}

Ballistic Particle Manufacturing utilizes ink jet or droplet based manufacturing techniques, where it builds the models by firing micro-droplets of molten wax material from a moving nozzle or jet onto a stationary platform, the platform then lowers and the process is repeated for each layer of the model.

Bill Masters (the BPM inventor) first described BPM as a spit wad.

"When you shoot a lot

of wads," he said, "they begin to take shape,

and if you can control

the direction of the

wads and the motion of the device that's

shooting them, you can

produce any desired

shape."

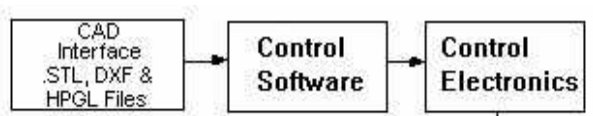
$\underset{\mathrm{STL} \text {, DXF \& }}{\mathrm{S}} \rightarrow$ Software $\rightarrow$ Electronics

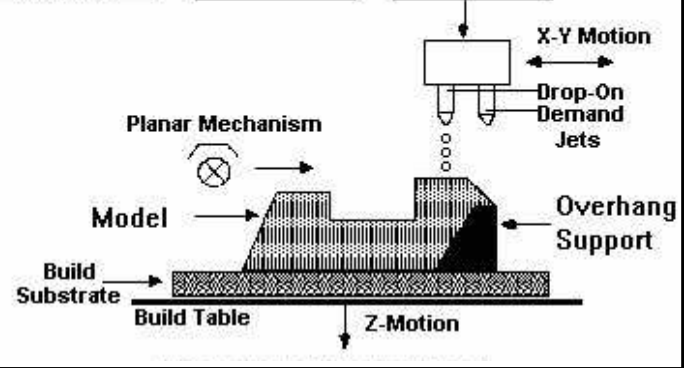




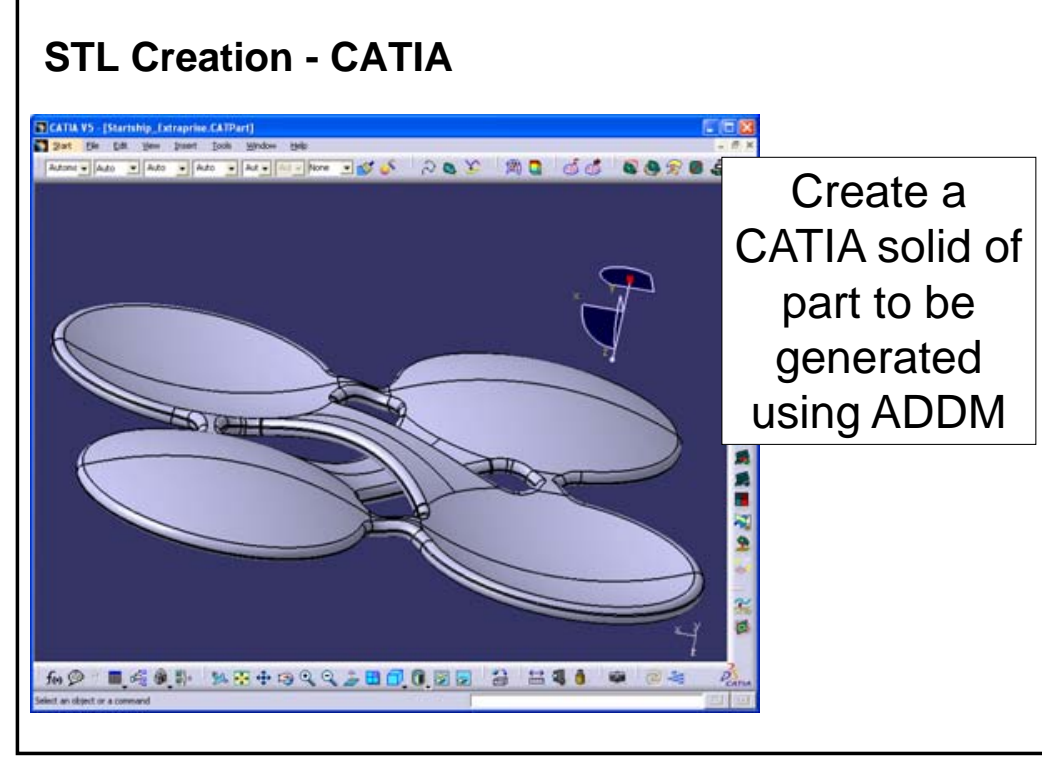

STL Creation - Tessellation

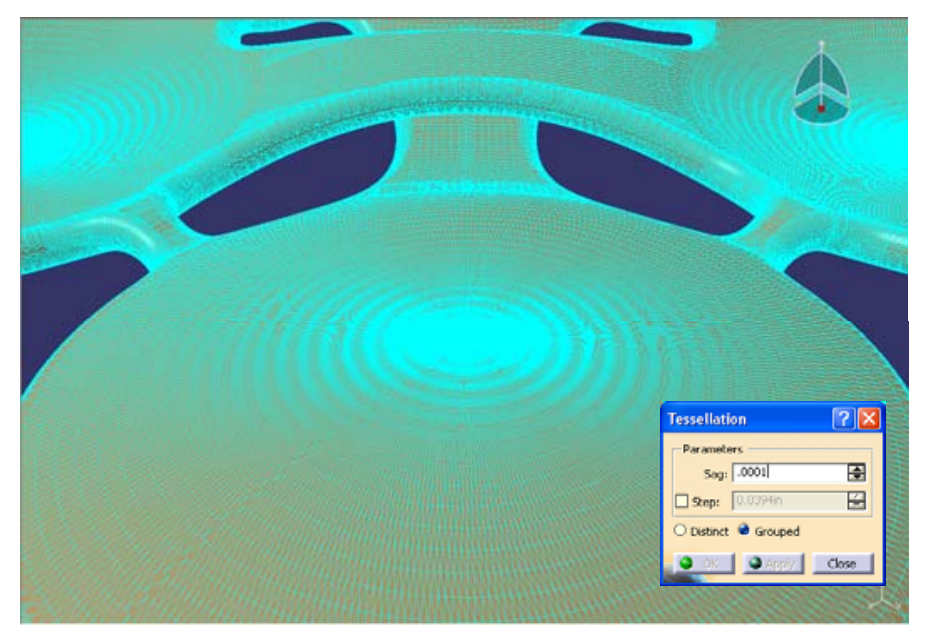

\section{Creation}

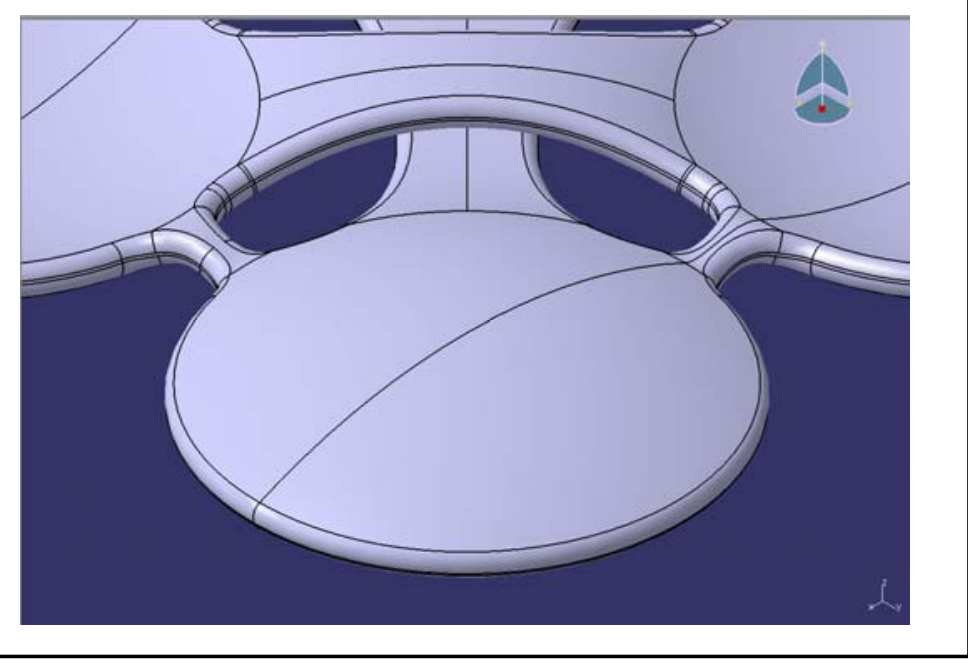

\section{Technology Overview - Considerations}

Speed Surface Finish Color

Office Environment Setup

Flight Certified

Material Properties

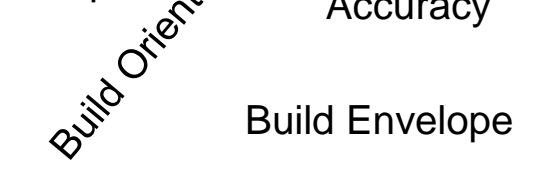

Pre-Processing

Waste

Accuracy

Capital Cost Post Build Processes Support

And on and on ... Material Cost Envelope Utilization 

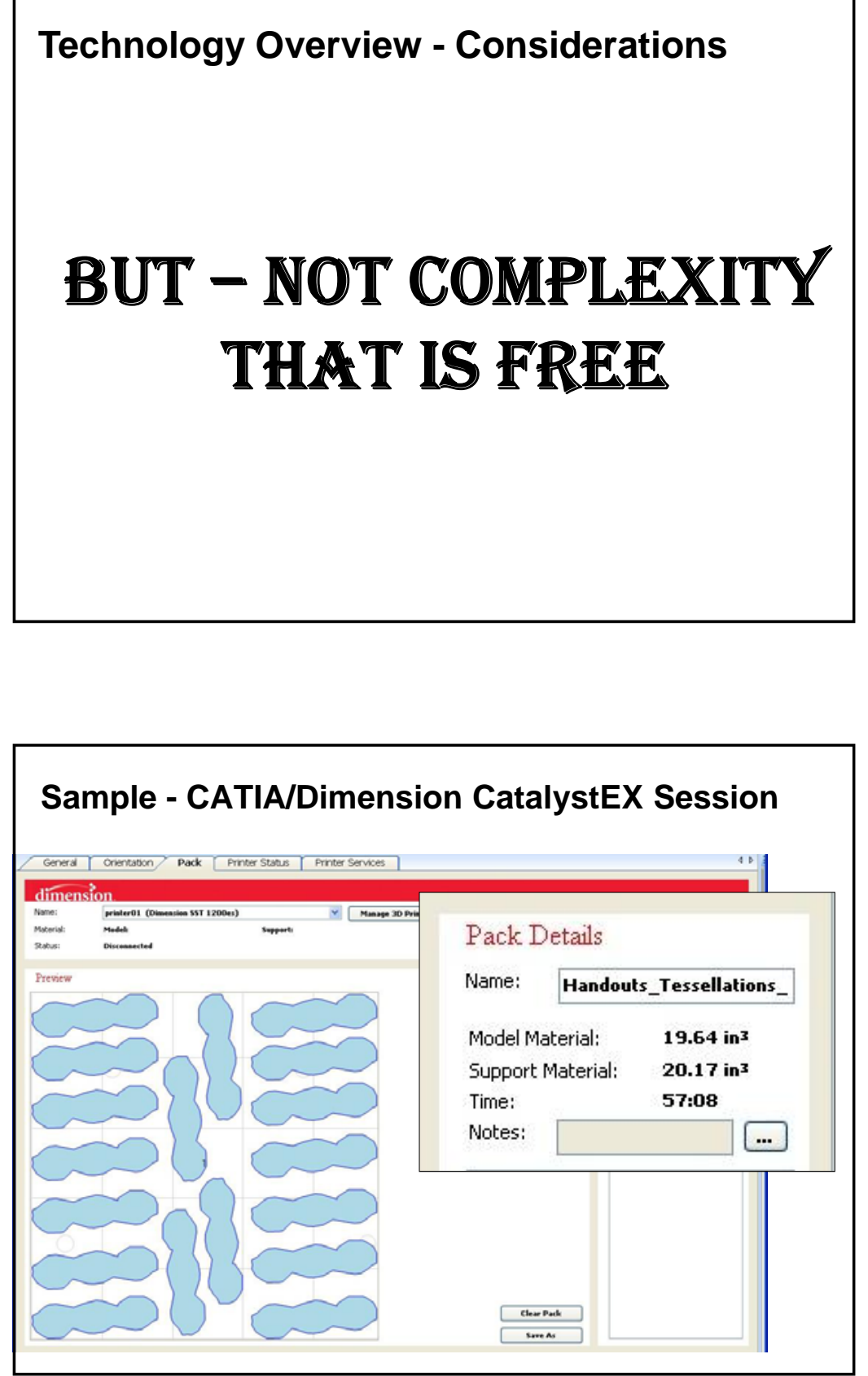

\section{Sample - CATIA/Dimension CatalystEX Session}
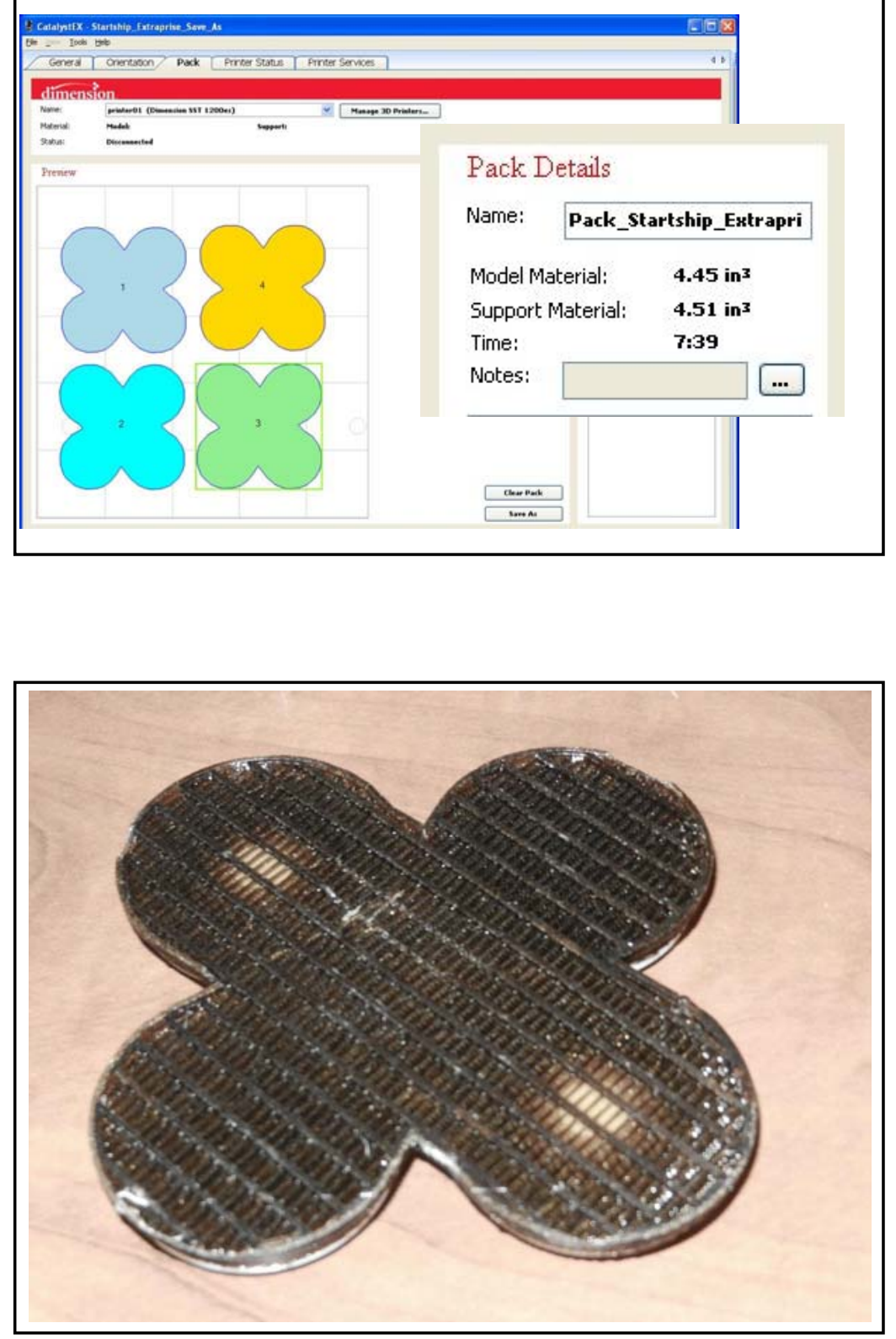

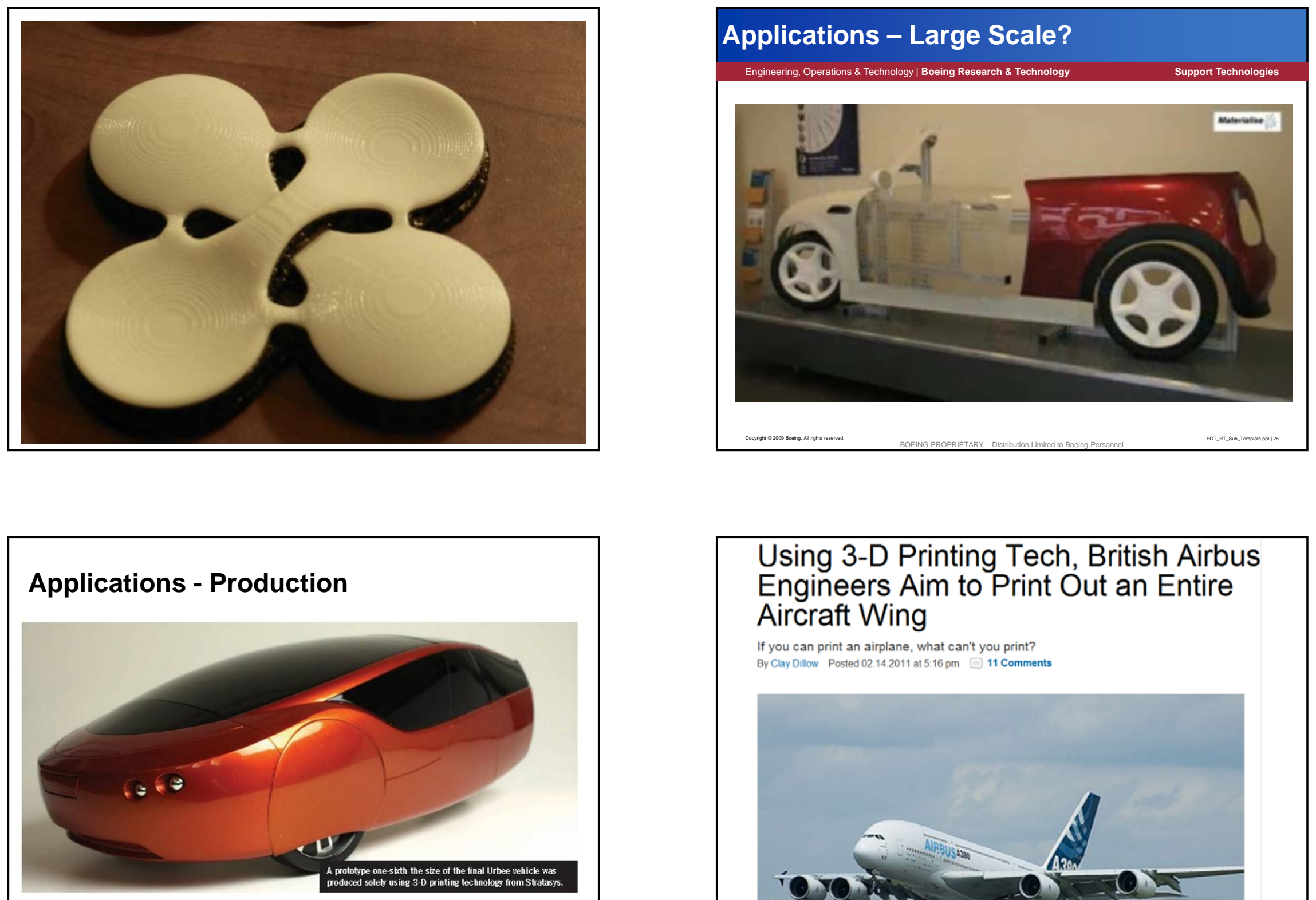

Urbee to Be First 3-D Printed Car

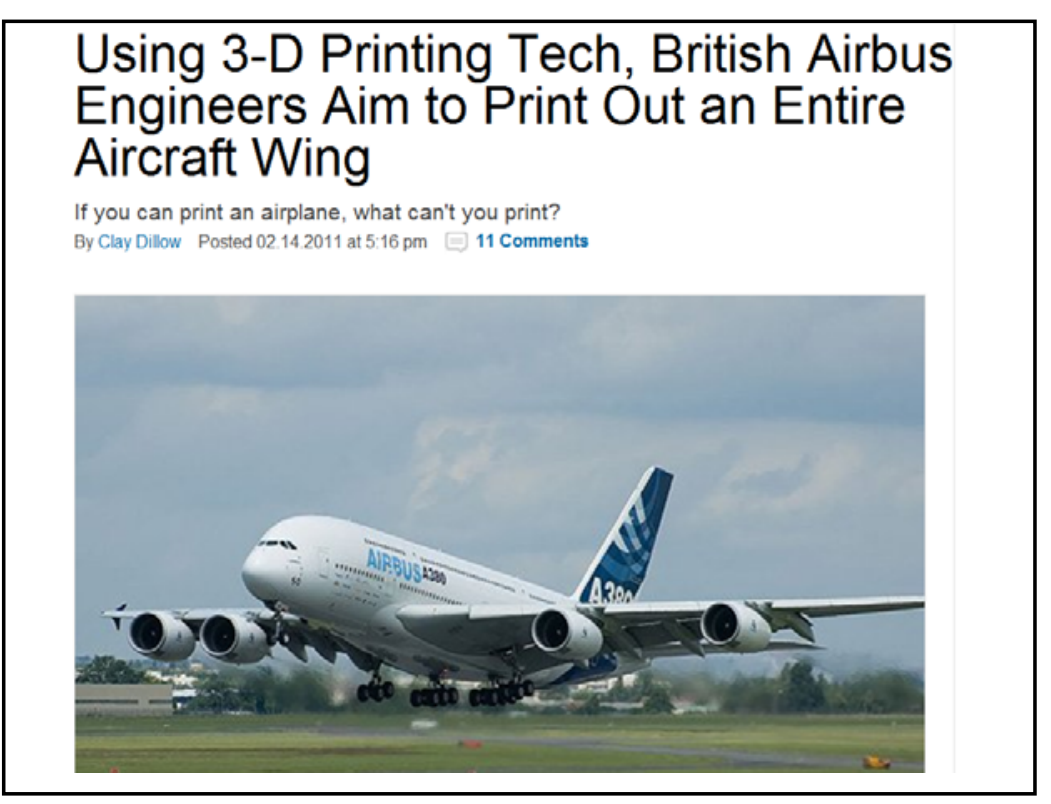




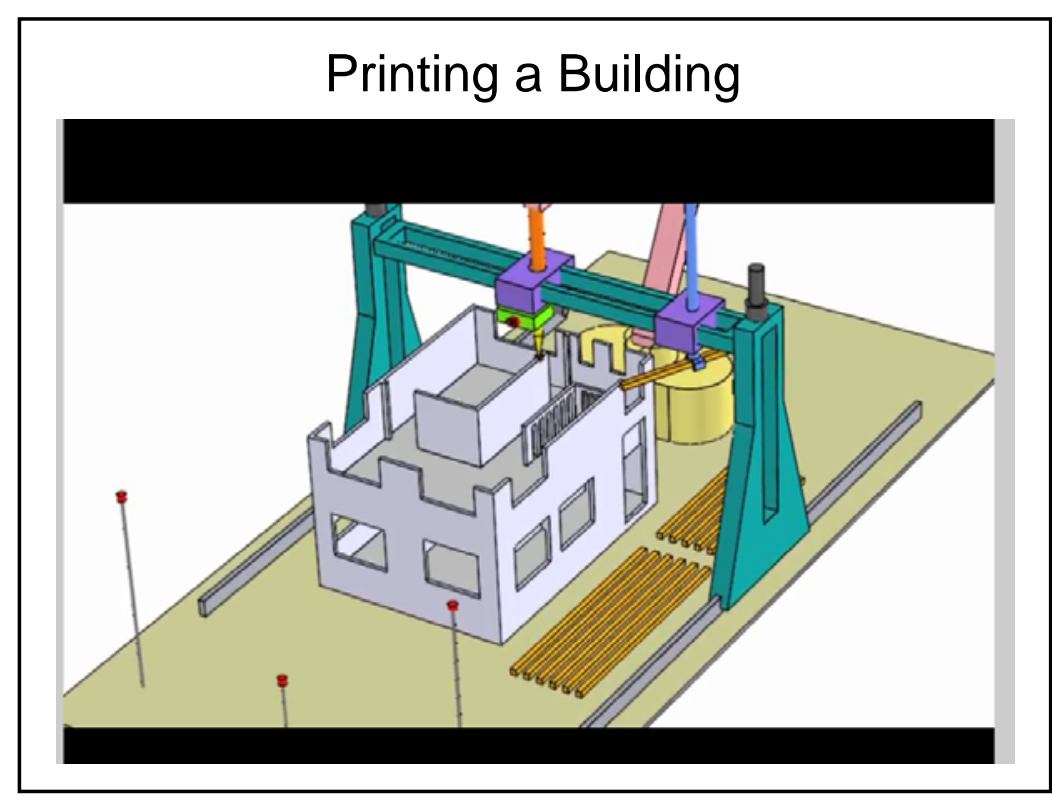

\section{Applications - Sales and Marketing}

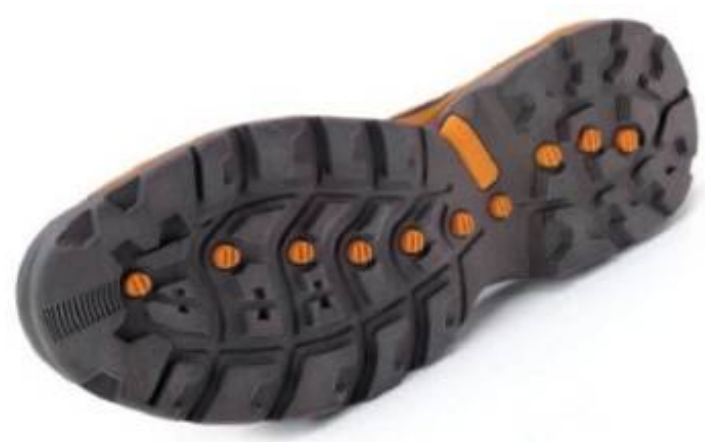

Flgure 7. Prototypes of TImberland Company footwear made on Z Corporatlon's color ZPinter appear remarkably llfell lke.

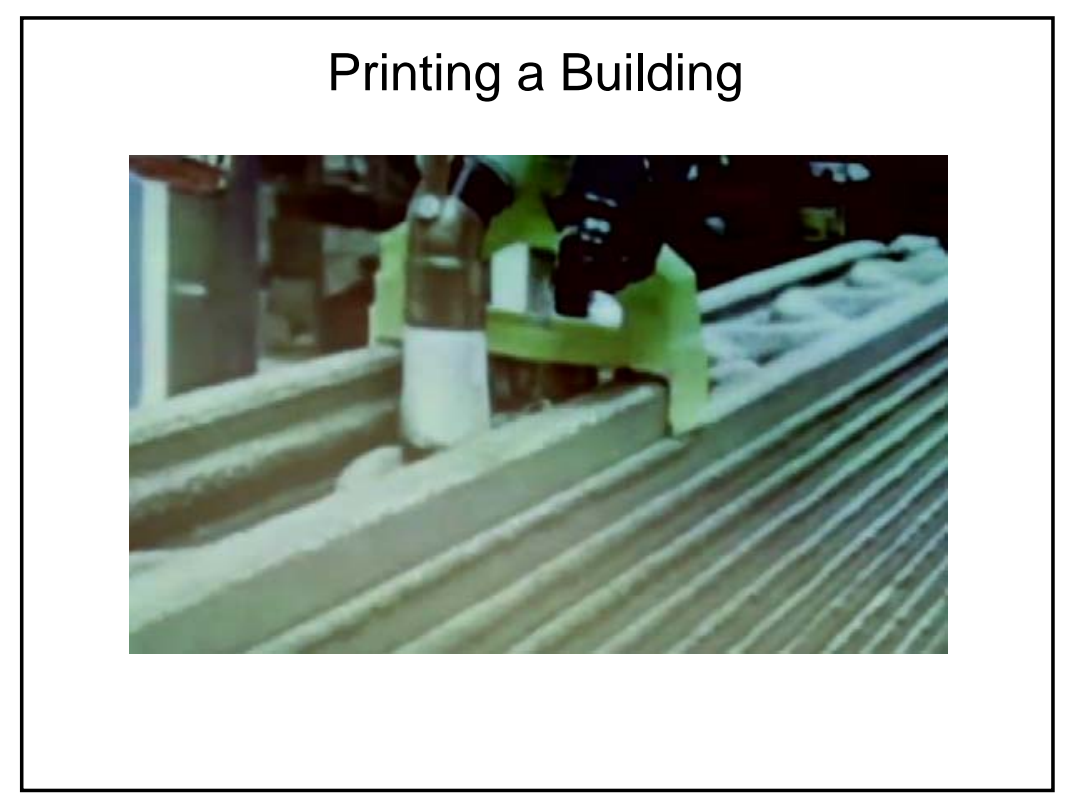

\section{Applications - Medical}

3D Printed Jaw Used in Transplant 2/27/2012

A team of doctors in The Netherlands performed successful jaw transplant surgery recently that showcases just how far the power and potential of 3D printing has come as key asset in medical development of custom prosthesis.

An 83-year-old woman suffering from a chronic bone infection received a lower jaw transplant of a 3D-printed jaw made out of titanium powder as opposed to undergoing reconstructive surgery, which the medical team deemed too risky because mandible. Using a ab dom in the palients lower metal additive manufacturing provider LayerWise, constructed and 3D-printed a metal jaw implant structure that incorporates articulated joints and dedicated features, becoming one of the first complete patient-specific implants, according

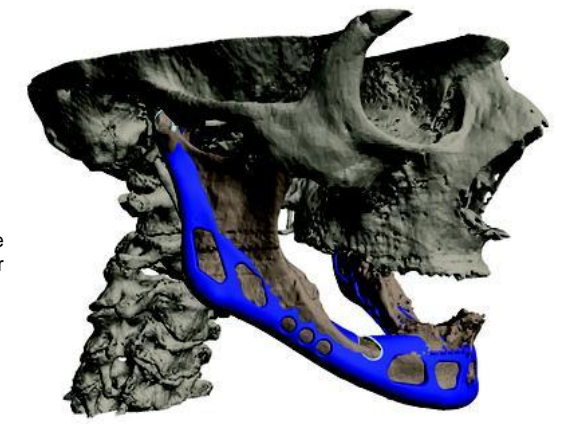



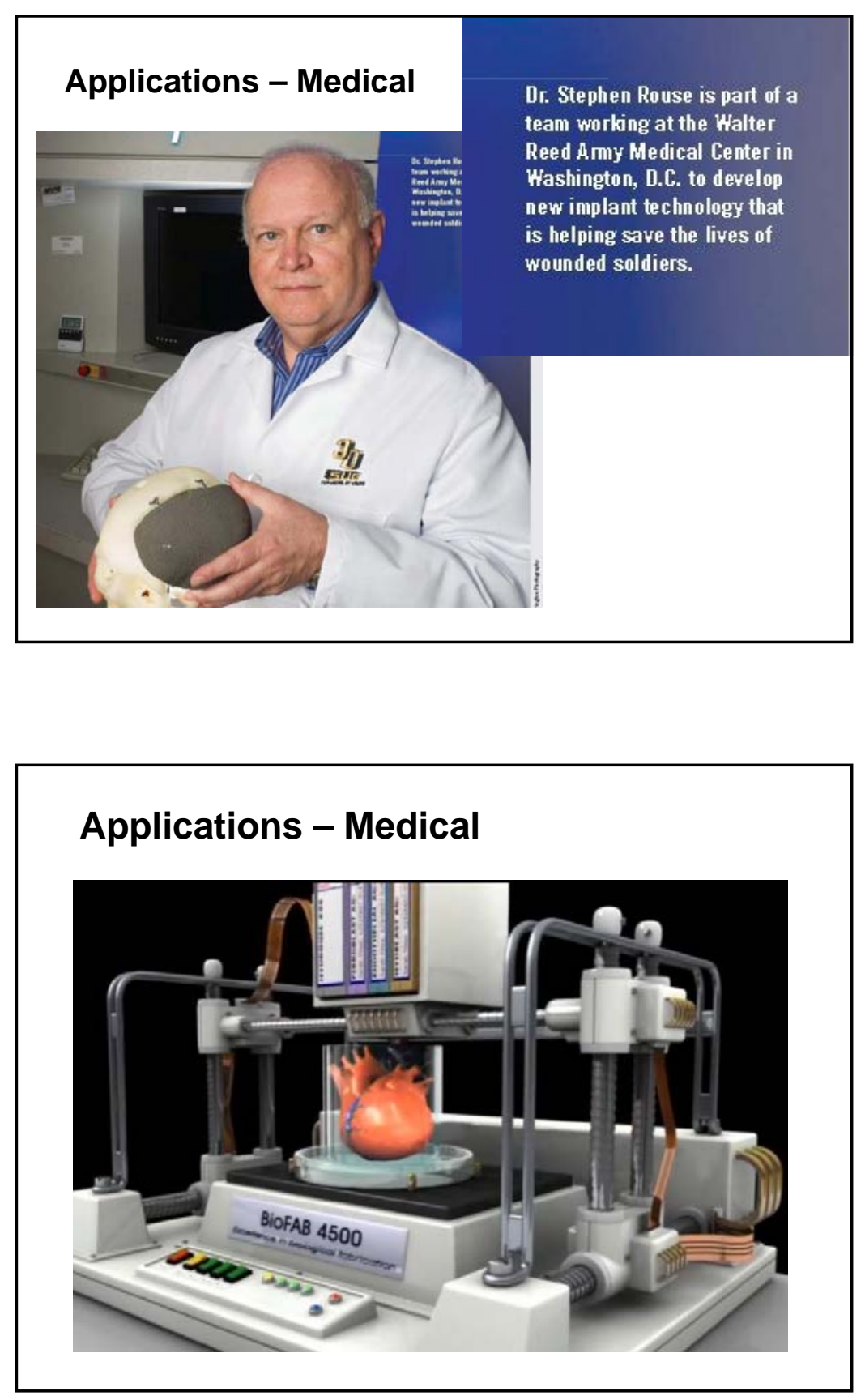

\section{Applications - Medical}

Penn Researchers Improve Living Tissues With 3D Printed Vascular Networks Made From Sugar
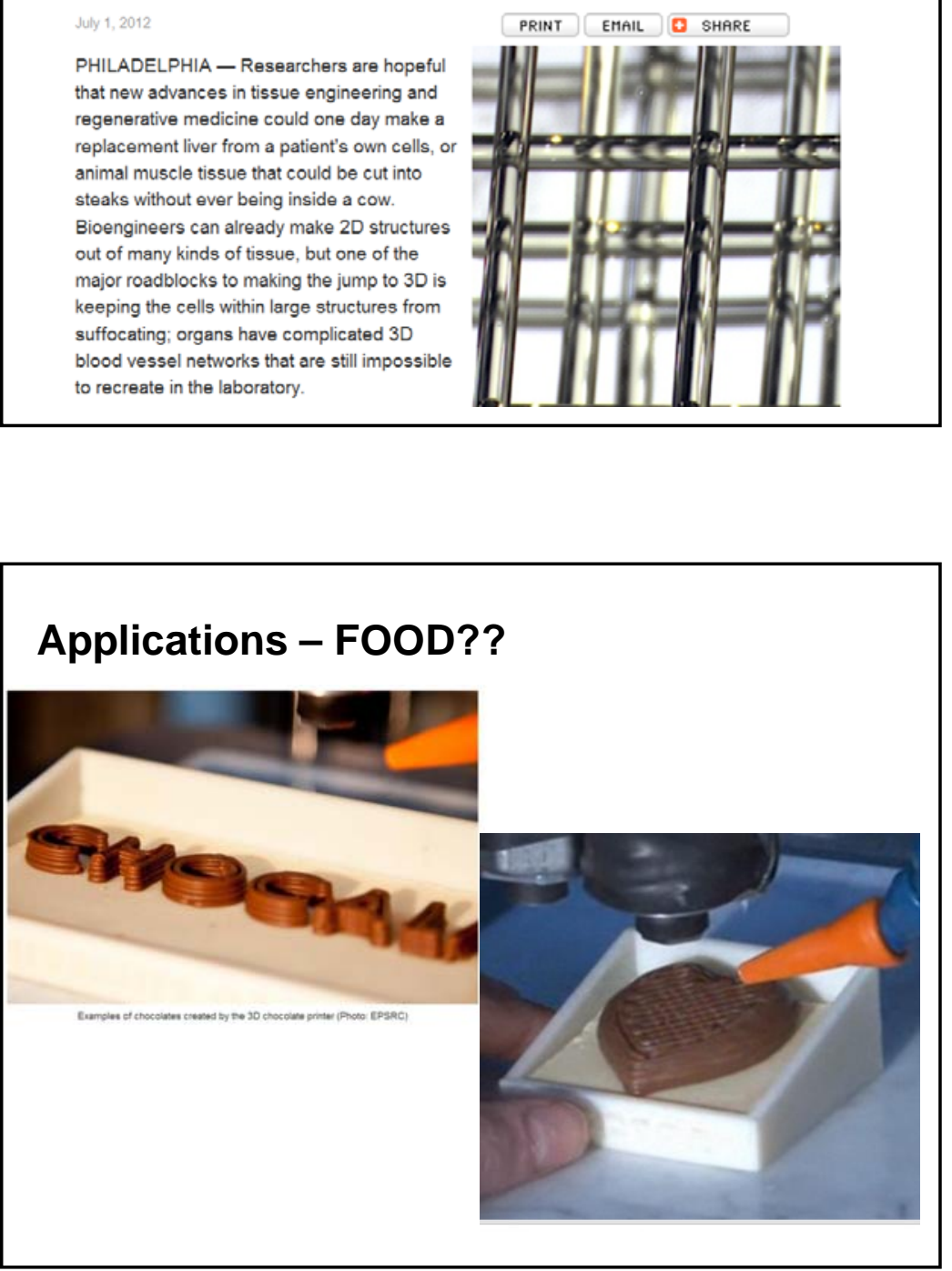
Peter Thiel Backs Start-up Making 3D Printed Meat

Inc.

Published: Friday, 17 Aug 2012 | 2:57 PM ET

By: Abigall Tracy, INC

$\square$ Twitter $70 \quad \Sigma+1 \sqrt{2}$ in Linkedln $0 \quad$ Share

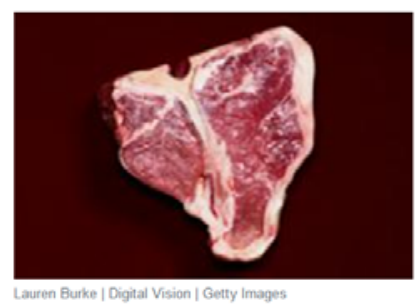

eakout Labs, eccentric billionaire Peter

Thiel's biotech foundation, announced an

eyebrow-raising investment in a start-up that

makes 3D printed meat (yes, really). 
Appendix 2

engineering laboratory

\section{(1) Engineering Laboratory}

NIST Measurement Science for Additive Manufacturing

Kevin Jurrens

NIST Intelligent Systems Division kevin.jurrens@nist.gov

NUT

NUT

PDES, Inc. Workshop

March 14, 2013

\section{Interest and Opportunities in Additive} Manufacturing Continue to Grow

- Recent events and media visibility have generated much emphasis on AM, including attention at the highest levels of corporate management and the federal government

- Much synergy and momentum - the AM industry seems poised for growth, innovations, and advancements

- Examples:

- Publicity in mainstream media

- AM industry roadmaps

- AM industry consortiums and collaborations

- ASTM F42 and ISO TC261 standards committees

- National Additive Manufacturing Innovation Institute (NAMII)

- Federal emphasis on manufacturing

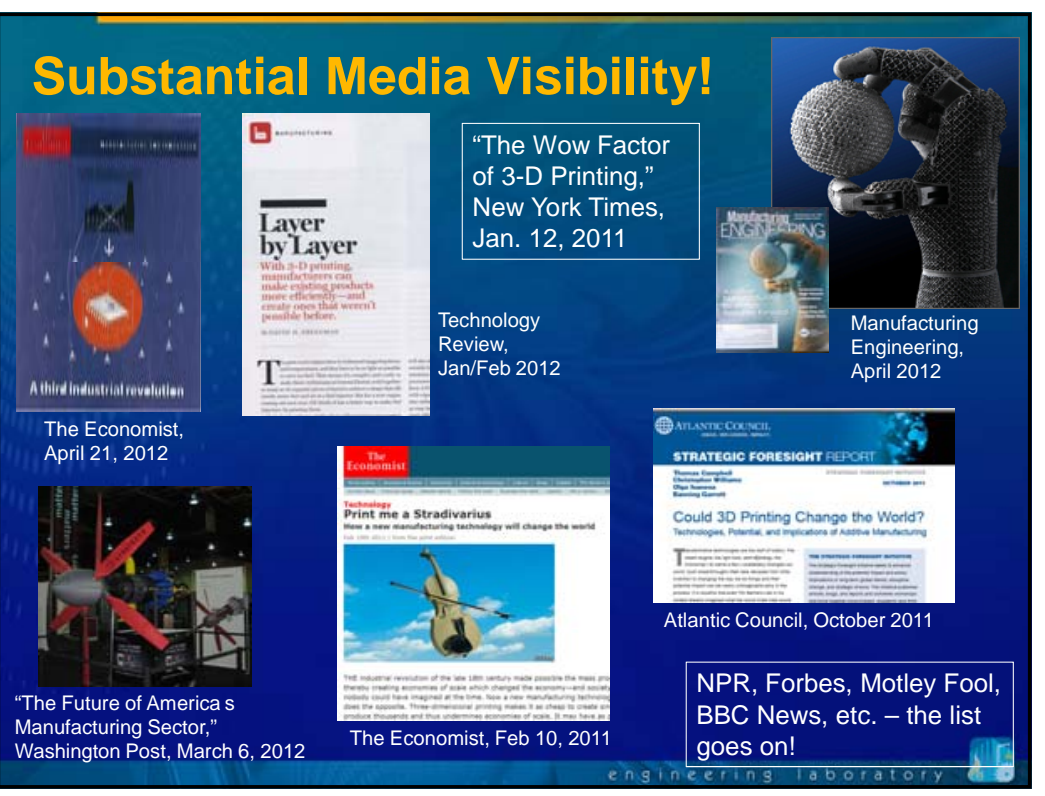

2009 AM Industry Roadmap

- Roadmap Development Workshop sponsored by National Science Foundation (NSF) and Office of Naval Research (ONR)

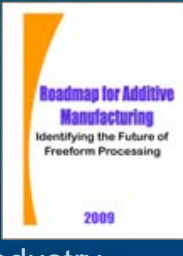

- Expert participants from AM system vendors, industry users, technology suppliers, academia, government

- Focused on needs, priorities, and a research roadmap for AM over next $10-12$ years

- Roadmap recommends several high-priority developments that are needed to advance the AM industry; grouped in the following categories:

- Research

- Education and Outreach

- Development and Community

- National Testbed Centers 
A Sampling of Recommended Developments Identified in the AM Industry Roadmap

- Process-structure-property relationships for each material and process

- Closed-loop and adaptive AM systems with feed-forward and feedback capabilities

- A much better understanding for the basic physics and chemistry of AM processes

- Conceptual design methods to aid designers in defining and exploring design spaces enabled by AM

- A new foundation for CAD systems that overcomes limitations in representing very complex geometries and multiple materials

- Sustainable (green) materials to reduce environmental impact, including recyclable, reusable, and biodegradable materials

- University courses and materials, and training programs for industry practitioners

- Development and adoption of robust standards for AM

- Establishment of a national testbed center to leverage equipment and serve as a highly visible showcase facility (or network of facilities)

\section{Additive Manufacturing Consortium (AMC)}

\section{Consortium Priority Needs*}

- Property Database

- Quality Control

- Distortion Control

- Equipment Development

- Feedstock / Input Materials

- Design Rules

- Standards

- Process Modeling / Optimization

- AM Knowledge Base

$$
\text { * Focus: precompetitive technology development }
$$

\section{Barriers to Broad Adoption of AM}

- Material Types and Properties

- Process Understanding and Performance

- Part Accuracy

- Surface Finish of Contoured Surfaces

- Fabrication Speed

- Build Volumes / Part Size

- Need for Qualification and Certification

- Lack of AM Standards

- Data Formats

\section{NIST Focus on Additive Manufacturing}

- Major thrust within NIST Smart Manufacturing Processes and Equipment (SMPE) program

- Substantial EL expertise in manufacturing domains is being applied to AM

- equipment and process metrology, process optimization and control, remote sensing, materials characterization, data formats, standards development, etc.

- Primary focus is metal-based AM processes

- Improved measurements and standards can help overcome existing AM limitations and barriers 
Unique Role of NIST Laboratory Research

Programs - Measurements and Standards

- Emphasis on infrastructural metrology and non-proprietary, standardized metrology methods that address a broad class of measurement challenges

- Emphasis on rigorous and generic procedures to characterize measurement uncertainty that comply with international standards

- Long-term commitment, expertise, and neutrality essential for harmonized and unbiased national and international standards

- Leverage NIST core competences in measurement science, rigorous traceability, and development and use of standards as well as specific expertise in measurements and standards for manufacturing systems, processes, and equipment

\section{NIST Projects in Additive Manufacturing}

Powder

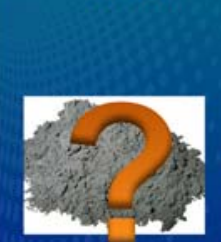

Uncertainties

in the Input Materials

1. Fundamental Measurement Science for Additive Processes 2. Materials Standards for Additive Manufacturing

\section{Primary Outputs of NIST Research Laboratories}

- Measurement methods

- Performance test methods and metrics

- Documentary standards

- Standard reference data

- Standard reference materials

- Calibration services

- Technology transfer: technical publications, industry workshops, collaborations

\section{Technical Focus for NIST Projects}

Fundamental Measurement Science for Additive Processes

$>$ Technical Focus:

- Standard test methods to evaluate and improve AM equipment performance

- Standard test methods to evaluate fundamental process characteristics

- Standard test artifacts to determine the accuracy and capabilities of AM processes

- Physics-based modeling of AM processes and material transformation

- In-situ measurements of AM parts

Materials Standards for Additive Manufacturing

$>$ Technical Focus:

- Standard test methods for metal powder characterization

- Standard test methods to obtain material properties of AM parts

- Test protocols, procedures, and analysis methods for industry round robin testing of AM materials for consensus material property data 


\section{In-house Metal-Based AM Research Platform}

\section{EOS M270 System}

- Direct Metal Laser Sintering (DMLS)

- Standard STL data input from 3D CAD model

- Build volume: $250 \mathrm{~mm} \times 250 \mathrm{~mm} \times 215 \mathrm{~mm}$

- Metal powders: stainless steel, titanium, aluminum, Inconel, cobalt-chrome

- Powder size: 5 micron to 60 micron, with 30 micron median (for stainless steel)

- Layer thickness: 20 micron (for stainless steel)

- Laser : Yb-fiber, 200 W, 1060 - 1100 nm wavelength

- Safety interlocks: Class 1 laser while in operation

- Built-in oxygen sensors and warning system

- Dual-mode: nitrogen or argon environments

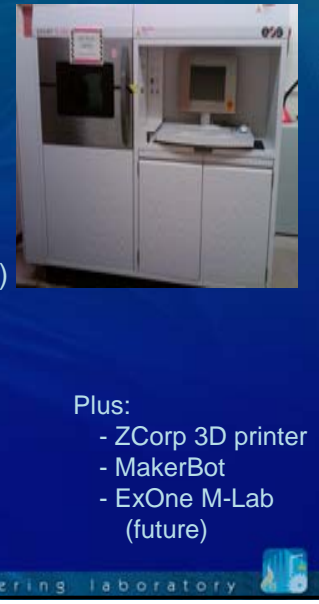

\section{NIST Role in ASTM F42 Standards Development}

- Substantial NIST technical presence and contributions to ASTM F42

- Test Methods, U.S. TAG, Terminology, ballot comments

- Leadership of task groups

- Developed and presented "Future Vision of AM Standards" at January 2012 meeting

- Strategic approach and vision; focused on maximizing impact of F42 standards

- NIST now member of F42 Executive Committee, and tasked to lead the strategic planning for F42

\section{ASTM Standards Committee F42}

- Established in January 2009 to address high-priority needs for standards in Additive Manufacturing Technologies

- Initiated with Society of Manufacturing Engineers (SME), Rapid Technologies \& Additive Manufacturing community

- F42 subcommittees formed for:

- Terminology

- Test Methods

- Processes and Materials

- Design (including data formats)

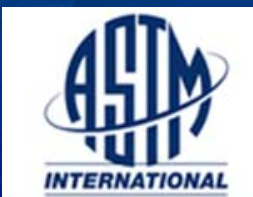

- Many candidate standards identified: multiple standards developed in parallel; rapid pace; much AM system user and vendor support

- Formal agreement with ISO TC261 committee on Additive Manufacturing
Strategic Approach for Development of AM Standards

- Needed to establish the overall structure and give guidance to the task teams, helping with planning and prioritization

- Where do we want to be in 5 years? What standards are needed to get there? What steps can be taken now to maximize future impact?

- Will maximize the impact of the standards by:

- Preventing overlap and contradiction among F42 standards

- Ensuring that future F42 standards work together as an integrated and cohesive set

- Improving usability and acceptance for future users of all types 


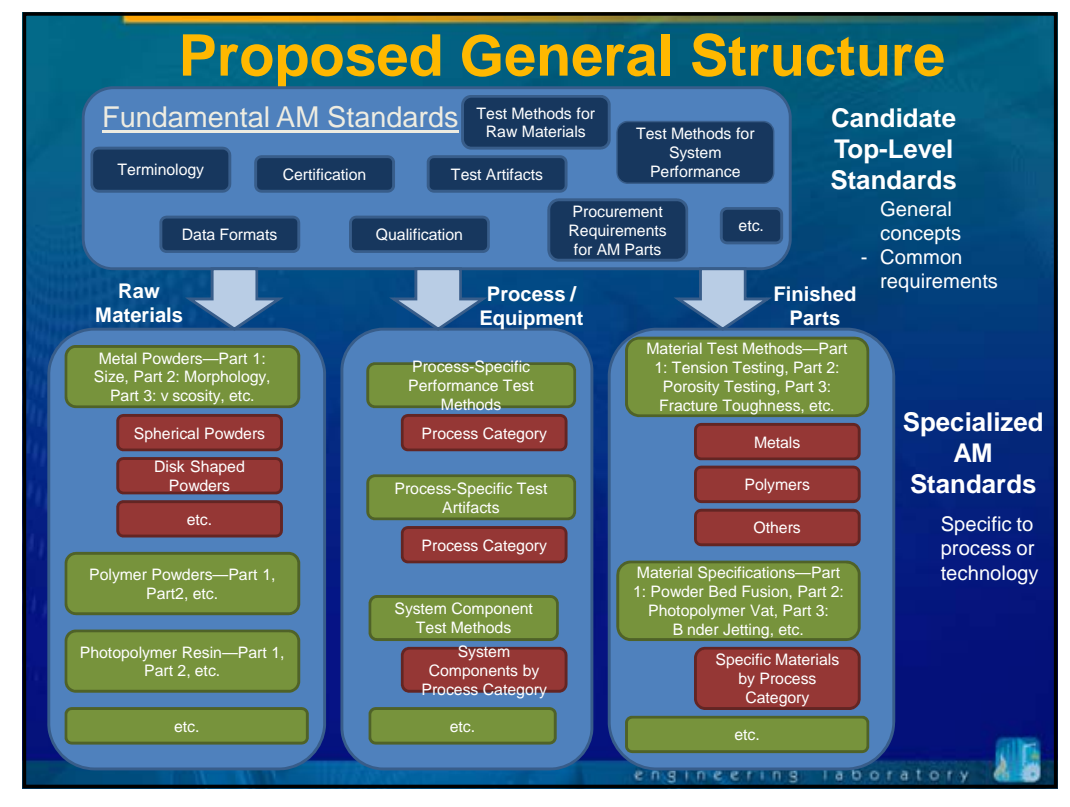

\section{Workshop Results}

- Workshop Final Report and AM Measurement Science Roadmap

- Summary of results, including recommendations, presentation slides, white papers, break-out group results, etc.

- Actionable plan: beyond a list of research needs

- Addresses one slice of overall AM roadmap

- To be integrated with NAMII national AM roadmap

- Foundation for ASTM F42 Strategic Plan

- Establish consensus needs and priorities, and influence the national research agenda for metal-based additive manufacturing
NIST Roadmapping Workshop: Measurement Science for Metal-Based Additive Manufacturing

- Held at NIST on December 4-5, 2012, with 88 AM experts

- Workshop objectives:

1. Build on prior AM roadmaps

$>$ In-depth coverage of measurement science barriers, challenges, and gaps that prevent the broad use of metal-based AM

$>$ Create actionable plans: what's needed and how to get there

2. Provide direction and input to ASTM F42 strategic planning

3. Influence and coordinate with NAMII development of national AM roadmap

- Plenary Talks, Industry Panel, Moderated Break-Out Groups AM Materials, AM Processes and Equipment, AM Modeling and Simulation, Qualification and Certification of AM Materials, Processes, and Products

http://events.energetics.com/NIST-AdditiveMfgWorkshop/index.html

\section{Substantial NIST Interactions with Stakeholders}

- Additive Manufacturing Consortium (AMC)

- National Additive Manufacturing Innovation Institute (NAMII)

- Interagency Working Group on AM (OSTP, NASA, Army, Navy, Air Force, DOE, NIST)

- Federal agencies: DARPA, AFRL, ARL, NRL, NSF, NASA, DOE, LLNL, ORNL, FBI, CRS

- Industry: Morris Technologies (OH), GE Aviation and GE Global Research, Pratt \& Whitney, Carpenter Powder, ExOne, others

- Universities: Univ. of Louisville, CMU, Virginia Tech, NCSU

- Events: ASTM F42, SME RAPID, SFF Symposium, JDMTP Metals AM Roadmap Workshop 


\section{National Additive Manufacturing Innovation Institute (NAMII)}

- Public-private partnership launched in August 2012 to accelerate AM innovation bridges the critical gap between basic research and widespread industry use

- Managed and operated by NCDMM, the National Center for Defense Manufacturing and Machining

- 30-month federal award: DOD, DOE, NASA, NSF, NIST

- Substantial cost-share by $70+$ members: industry users, AM vendors, universities

- Technology Development, Technology Transition, Advanced Manufacturing Enterprise, Workforce / Educational Outreach

- NAMII Innovation Hub located in Youngstown, $\mathrm{OH}$

- First project call in December; project kick-off is imminent

\section{Partnering with NIST}

NIST partners with industrial consortia, individual companies, other government agencies, and universities

The NIST stake in partnerships tends to focus on issues that can benefit industry sectors in a broad sense typically relating to measurements and standards

Several mechanisms available:

e.g., cooperative agreements, contracts, MOUs, guest researchers, letters of agreement, grants,

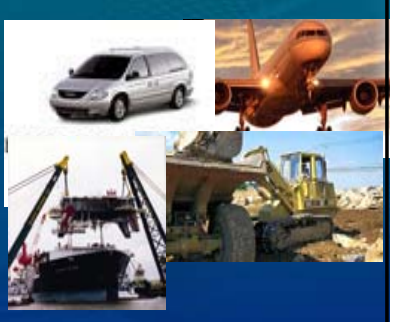
sabbaticals

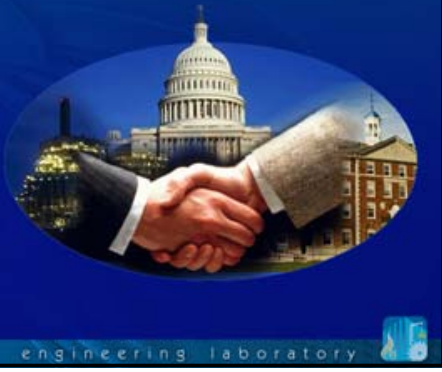

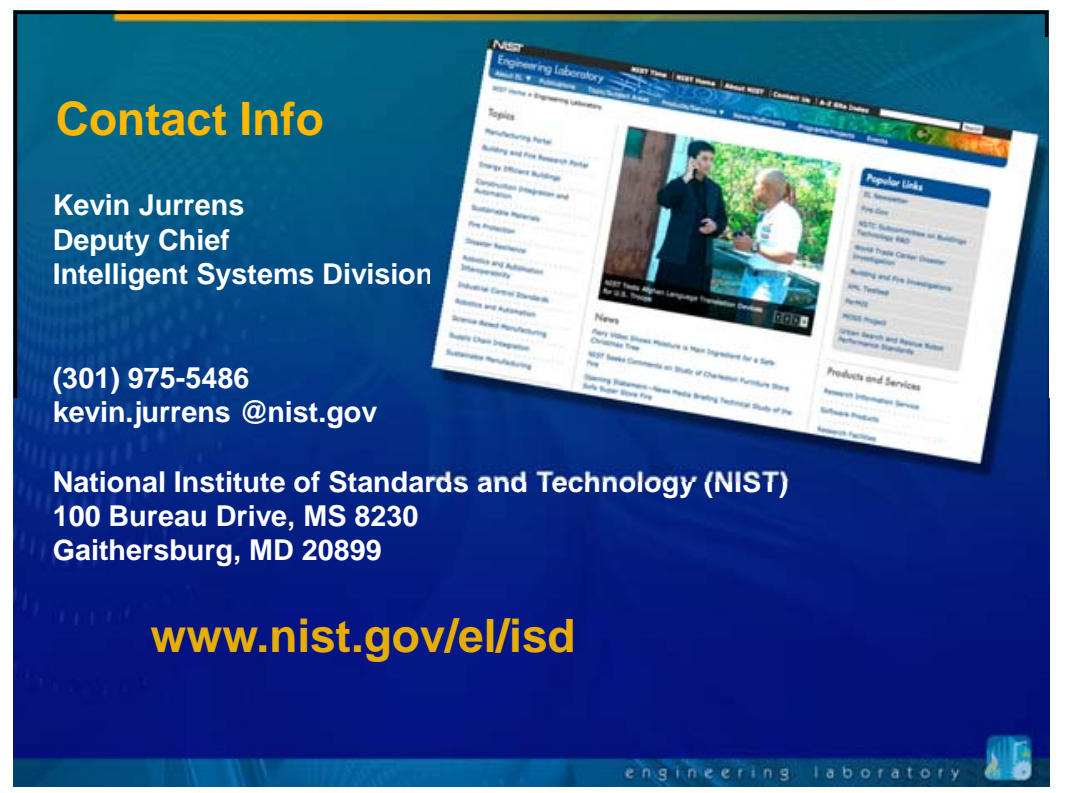


Appendix 3

\section{engineering laboratory

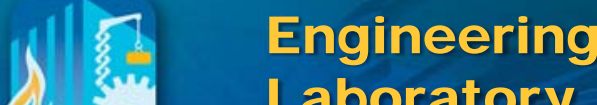

Proposed Standardized Test Artifact for Additive Manufacturing

Shawn Moylan, Ph.D.

NIST Intelligent Systems Division

shawn.moylan@nist.gov

NUT

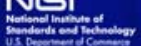

PDES, Inc. Workshop

March 14, 2013
NIST Projects in Additive Manufacturing

Powder

Process

Part

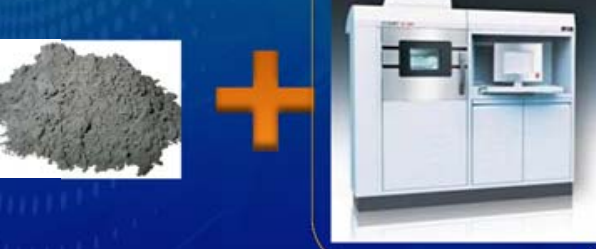

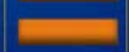

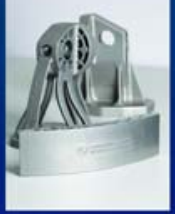

- Two primary methodologies of performance characterization of a machine or process

- Series of direct measurements of machine or process characteristics

- Measurement on manufactured test pieces

- Direct measurement of AM machines difficult

- Lack of access and control over positioning axes

- Sensors interfere with process or safety interlocks

- Test pieces play a larger role in AM than in traditional manufacturing 


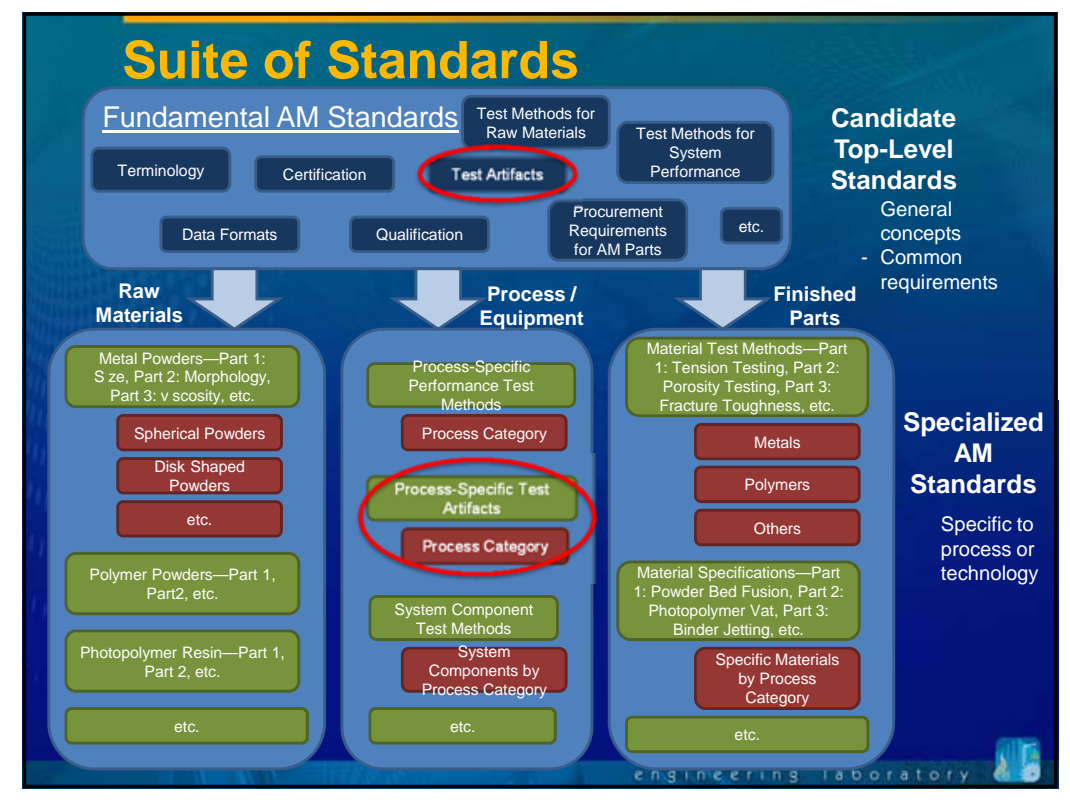

\section{Prior Work}

- Reviewed more than 40 test artifacts previously described in literature.

- Four categories of test artifacts

- Comparing different processes

- Evaluating individual processes

- Evaluating metal-based processes

- Other uses

- NISTIR 7858, "A Review of Test Artifacts for Additive Manufacturing," May 2012.

\section{Suite of Standards}

- 1 top level Test Method, 7 process level standard practices (1 for each process category)

- Test Method generally describes - potential uses of test artifact

- test artifact geometry

- measurements to be taken on the test artifact

- reporting of results

- Standard Practices provide

- links to download specific test artifact geometries (different processes may use different size scales)

- guidance in preparing a build (not a process prescription)

- specific process parameters to be reported.

\section{Prior Work $\rightarrow$ Design Criteria}

- The intent of most test artifacts falls into one of two main categories

- Intended to demonstrate the capabilities of the machine or process

- Intended to highlight specific machine defects to allow iterative process improvement

- We seek to design a test artifact that will accomplish both. 


\section{Design Criteria}

- Test part should demonstrate machine's or process's ability to build features with proper form, orientation, size and location

- Straight features (paraxial and askew)

- Parallel and perpendicular features

- Round features

- Concentric circles or arcs

- Fine features

- Holes and bosses

- Features in planes orthogonal to build plane

\section{Design Criteria}

- Design should link specific part defects to specific machine or process errors

- Geometric errors of beam positioning axes

- Geometric errors of build platform (z-axis)

- Alignment errors between axes

- Beam size

\section{Design Criteria}

- General Considerations

- Easily measurable with low measurement uncertainty

- Trade off between testing full work volume and the time and material cost. We try to find balance, but side with faster, smaller builds

- Minimize other variables

- Support structures

- Post processing

- Minimize impact on recoating arm

- Allow testing of surface roughness along with mechanical and physical properties

\section{Description of Proposed Artifact}

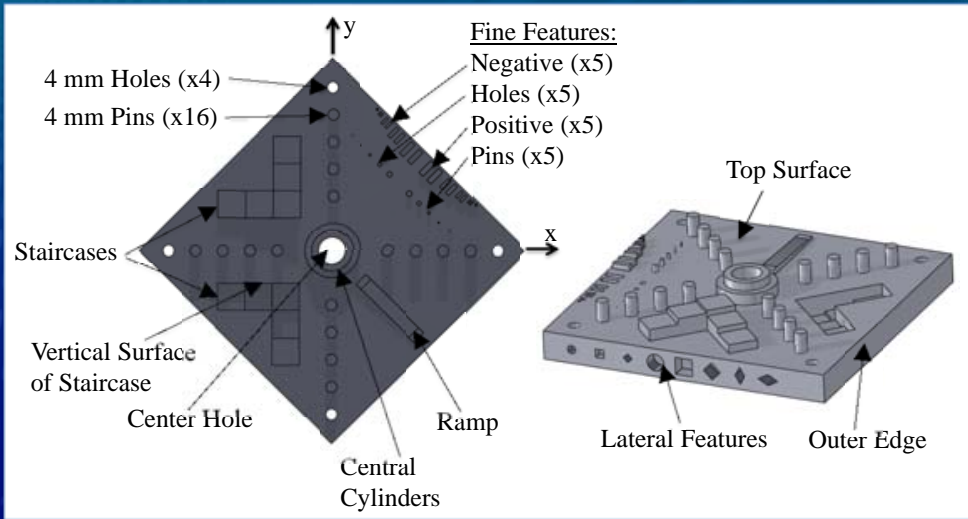




\section{Results—Repeatability}

- Multiple builds by DMLS in stainless steel show average repeatability of approximately $30 \mu \mathrm{m}$ ( $2 x$ average standard deviation using several feature measurements)

- Pin and hole diameters

- Pin and hole positions

- Z-heights on staircases

- Straightness measurements

- Roundness measurements

- Flatness measurements

Straightness

\section{Process Improvement}

- Use measured deviations of build 1 to calculate improved beam offset and $x$ - and $y$-scaling

- Pins and holes were too close to center; scaling was too small

- Scaling = slope of best fit line to position deviation of pins and holes (represented as \%)

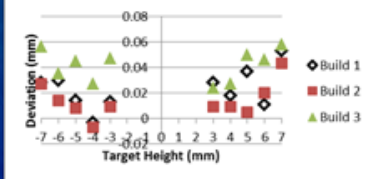

Rebuild with adjusted scaling produced pins and holes with

position deviations no greater than $52 \mu \mathrm{m}$ ( 8 of 10 better than $25 \mu \mathrm{m}$ )

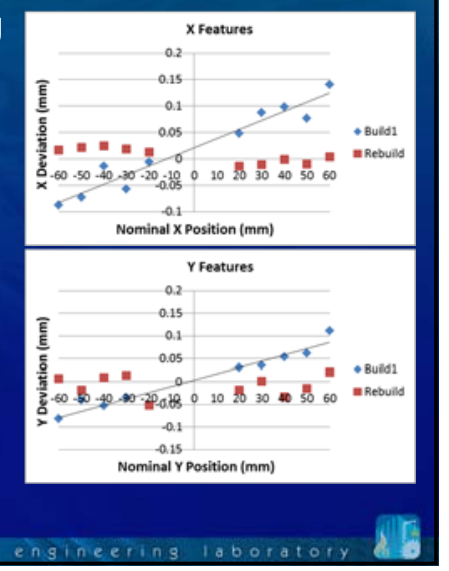


Appendix 4

ensineering laboratory

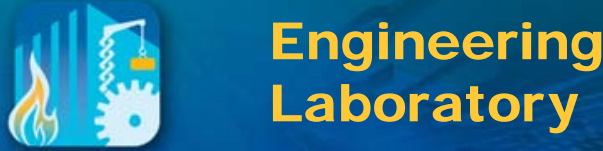

Materials Standards for Additive Manufacturing

John A. Slotwinski, Ph.D.

PDES, Inc. Workshop

Nढ̆T

March 14, 2013

\section{Material Standards for Additive} Manufacturing

Powder

Process

Part

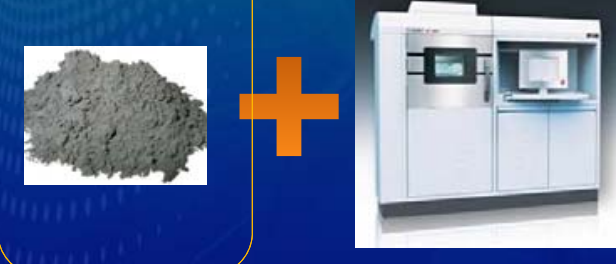

AM Materials is a top priority...

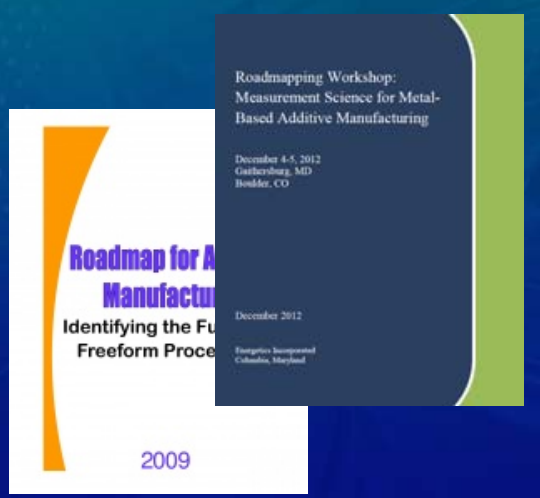

\section{AM\#2: Project Overview}

- Materials Properties and Qualification remains a significant barrier to more widespread adoption of AM technologies

- Currently, the additive manufacturing (AM) industry does not have the confidence, and is unable to rigorously verify, that nominally identical AM powders are in fact identical, resulting in unconfirmed powder properties.

- This lack of confidence in material properties is also true for parts produced by AM.

- Need publically available, published property data for both powders and AM materials.

- Project's Technical Focus:

- Standard test methods for metal powder characterization

- Standard test methods to obtain material properties of AM parts

- Test protocols, procedures, and analysis methods for industry round robin testing of $\mathrm{AM}$ materials for consensus material property data 


\section{Collaborators}

- Internal:

- Engineering Laboratory Materials and Structural Systems Division

- Material Measurement Laboratory Materials Science and Engineering Division

- Information Technology Laboratory Statistical Engineering Division

- Center for Neutron Research

- External:

- Oak Ridge National Laboratory, Morris Technologies, U. of Louisville, Picatinny Arsenal, Aberdeen Proving Ground, UTEP GE Global Research, Carpenter Powder Products, Oxford Performance Materials, ASTM

\section{Results to Date}

- Background Studies

- Powder Characterization

- Material Properties

- Stress

- Porosity for Process Monitoring

\section{Background Studies}

- NISTIR 7847 assessed current state-of-the-art for material property testing of bulk metal material properties. (Slotwinski, Cooke, Moylan)

- NISTIR 7873 assessed current state-of-the-art methods for characterizing metal powder. (Cooke, Slotwinski)

- Determined the applicability of current state-of-the-art methods for AM parts and AM powder and documented conclusions in internal report, results to be published in 2013. (Slotwinski, Moylan, Cooke)

\section{Powder Characterization}

- Current Foci:

Variability of nominally identical powder, effects of recycling (e.g., exposure of powder to multiple builds), documented properties of round robin pouder

- Characteristics of Interest:

Size (and size distribution), morphology, chemical composition, flow, thermal properties.

- Measurement Methods:

SEM (size, morphology), Quantitative $X$ Ray Diffraction (chemical composition), Laser Diffraction (size distribution), X Ray Computed Tomography (morphology), X Ray Photoelectron Spectroscopy (gives photoelectron energy characteristic of elemental chemical states)

- Results:

Recycling reduces austenite, increases ferrite content in Stainless Steel (QXRD), but does not change surface chemistry/atomic concentration (XRPS)

Nominally identical Stain Steel and Round Robin CoCr powder lots have same base chemical composition (QXRD)

CoCr and Stainless Steel powder morphology is "quasi-spherical

Laser diffraction measurements and analysis are currently underway. 


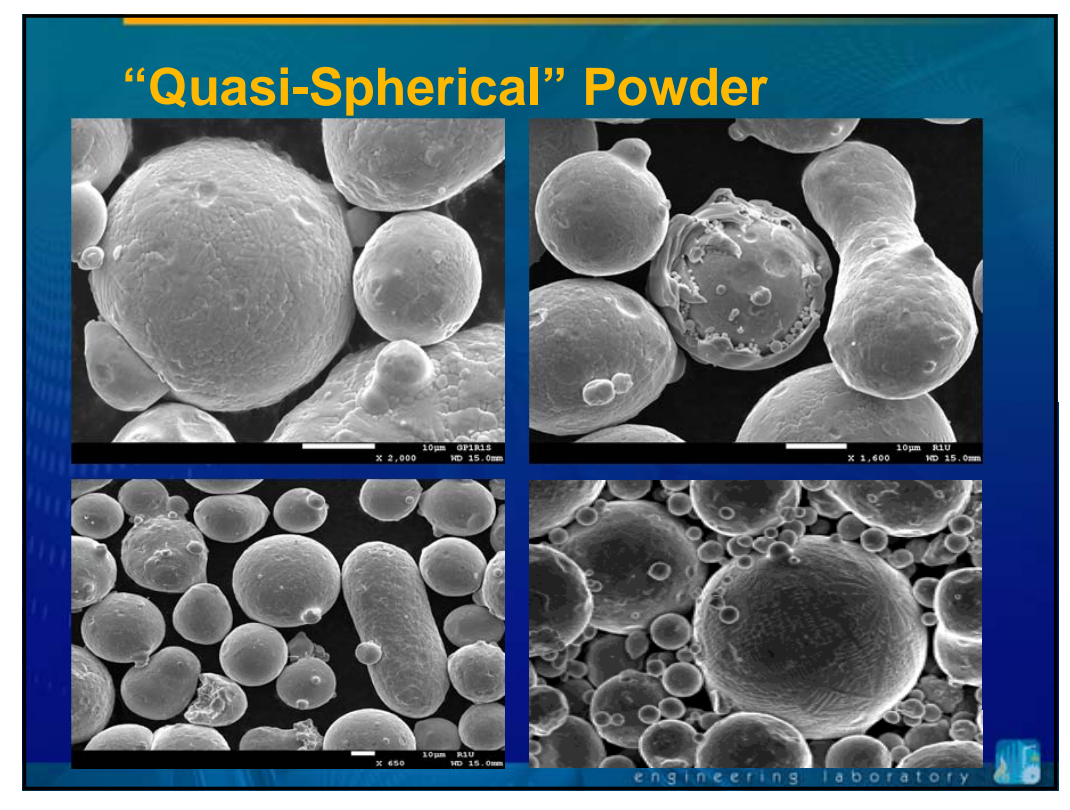

\section{Powder Characterization Laboratory}

- Setting up powder characterization lab to: - Develop appropriate measurement techniques and standards

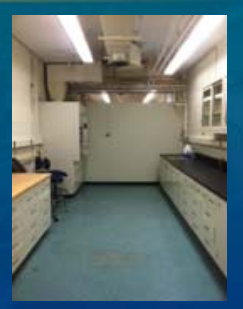

- Compare industrially common benchtop techniques to more advanced measurement methods (such SEM, laser diffraction, energy-dispersive X-ray, X-ray computed tomography...)

- Drafted powder characterization standard, recently submitted to ASTM (WK40606 - Standard Guide for Characterizing Properties of Metal Powders Used for Additive Manufacturing) and chairing task group.

\section{Future Work on Powder Characterization}

- Finalizing WK40606 into ASTM Standard

- Determining effects of customized powder lots (e.g., skewed size distributions, controlled morphologies, etc.) on mechanical properties

- Flow, thermal properties measurements

- More specific AM powder characterization standards

\section{Material Properties Round Robins}

- Two NIST-funded round robin tests (one internally led, one externally led)

- Mainly focused on laser-based DMLS powder bed systems, but internal study also includes two e-beam (ARCAM) AM systems for comparison

- Preparation of test protocols, procedures, test specimens, powder specifications, and analysis methods

- NIST statistical and material science expertise for design of experiments and analysis of internally led round robin

- Both have careful controls and procedures on powder, build parameters, post processing and material property measurements

- "Tests to develop the test" 


\section{Material Properties Round Robins}

\begin{tabular}{|c|c|c|}
\hline & AMC & NIST \\
\hline Material & Inconel 625 & Cobalt Chrome (MP1) \\
\hline Status & Final Planning & Underway \\
\hline Process & 3x DMLS (M270) & $6 \times$ DMLS $(M 270)+2 \times$ ARCAM \\
\hline Types of Specimens & $\begin{array}{l}\text { Tensile, high-cycle fatigue, low- } \\
\text { cycle fatigue (room temperature } \\
\text { and high temperature) }\end{array}$ & Tensile (room temperature) \\
\hline Number of Specimens & 120 & 64 \\
\hline Participants & 5 & 8 \\
\hline Goal & $\begin{array}{l}\text { Establish protocol for making } \\
\text { and testing material coupons for } \\
\text { additive processes; establish } \\
\text { protocol for generating and } \\
\text { reporting DMLS mechanical } \\
\text { property data with the intent of } \\
\text { possible inclusion in a design } \\
\text { allowables database (such as } \\
\text { MMPDS) }\end{array}$ & $\begin{array}{l}\text { Same; baseline study of } \\
\text { material property variability for } \\
\text { nominally identical builds }\end{array}$ \\
\hline
\end{tabular}

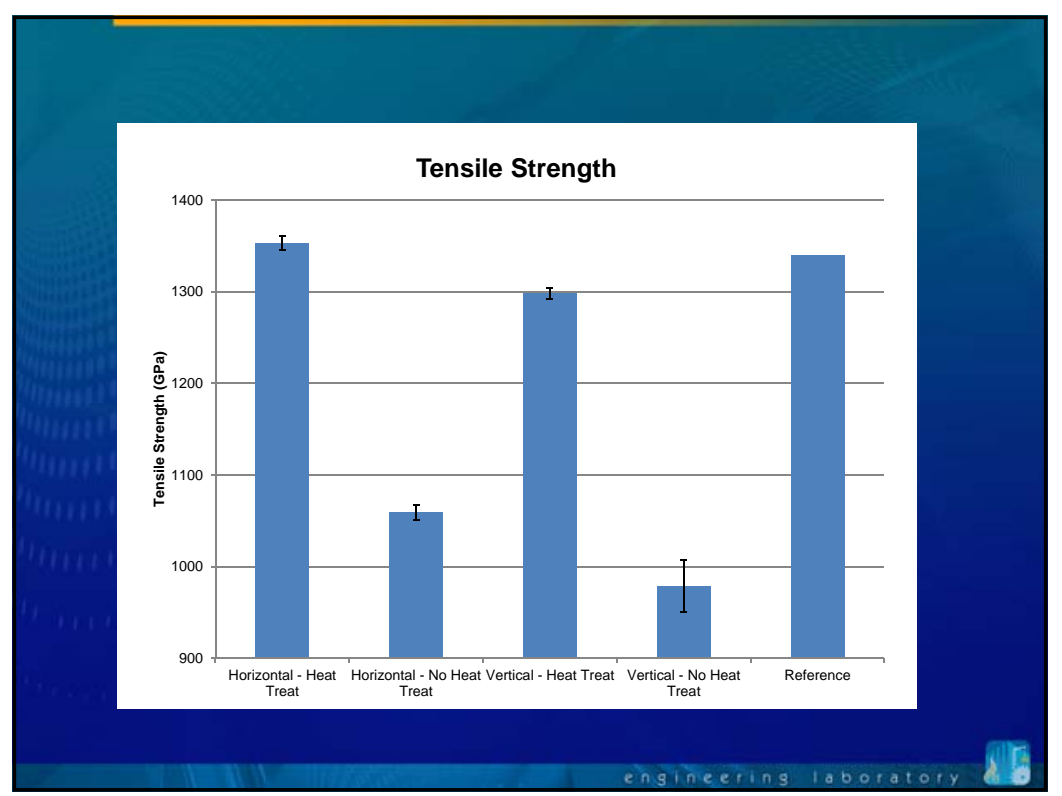

\section{Tensile Properties: EOS GP1} Stainless Steel (17-4)

- Stress-strain behavior of NIST-made tensile bars is very repeatable

- Stress-strain behavior qualitatively is very similar to vendor data and reminiscent of cold steel

- NIST measured Tensile Strength (1000 MPa typical) is generally higher than vendor data (930 MPa $\pm 50 \mathrm{MPa})$ and NIST measured Elastic Modulus (160 GPa typical) is generally in consonance with vendor data (170 GPa $\pm 30 \mathrm{GPa}$ )

- Material exhibits discontinuous yielding, and has significant work hardening (strengthening of material during plastic deformation)

- Vendor-recommend heat-treatment results in increased yield strength (not decreased!) and decreased ductility (not increased!)

- Slight directional-dependent anisotropy present specimens are slightly weaker $(7 \%)$ when build vertically, heat-treatment improves this slightly (4\%).

\section{Additional Mechanical Properties} Work

- A variety of other test specimens made in three different configurations:

- As-built

- Machined to final shape from similarly sized and shaped solids

- Machined to final shape from large blocks

- Compression, high-cycle fatigue, charpy, tension

- Awaiting heat-treatment, removal, and mechanical testing

- Results will feed into development of AM mechanical testing standards 


\section{Thermal Stress}

- The extremely rapid and localized melting and cooling results in residual thermal stresses

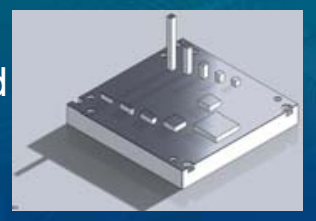

- Interest in residual thermal stresses present after a build, as well as the effects of post-processing (shot-peening, heat treatments) and part removal on stress.

- Working with both ORNL and NCNR for neutron imaging of stress (complimentary capabilities)

- Have delivered test samples to both ORNL and NCNR, awaiting results

\section{AM Thermal Stress Can Be} Significant...

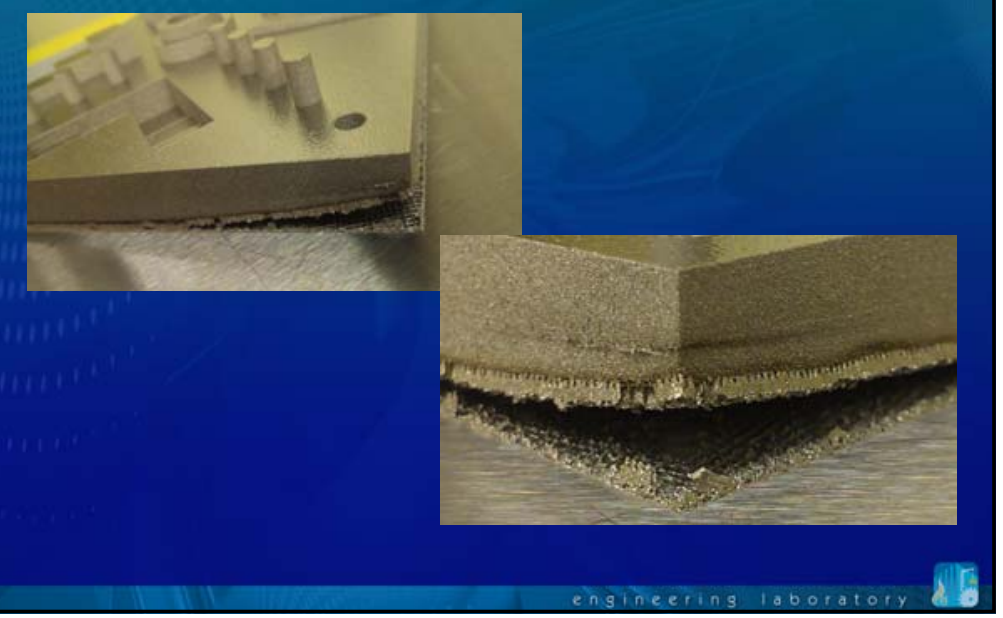

\section{Ultrasonic Porosity Sensor:}

Process Monitoring

- Ultrasonic velocity in material decreases with increasing porosity (models vary, most are linear)

- Different models all predicted that a $0.2 \%$ change in porosity would be detectable ultrasonically $(\Delta \cong 0.02 \mathrm{~mm} / \mu \mathrm{s})$

- Porosity samples

Partnered with Morris Technologies to produce three sets of $\mathrm{CoCr}$ samples with varying porosity $(0 \%-72 \%)$

- Measured ultrasonic velocity with three different techniques

Collaborating with others to determine "final" porosity (Archimedes, X-ray computed tomography, Mass/Volume, Optical) as well as porosity morphology

- Designed sensor system for use in EOS M270 for process monitoring

\section{Ultrasonic Porosity Sensor}

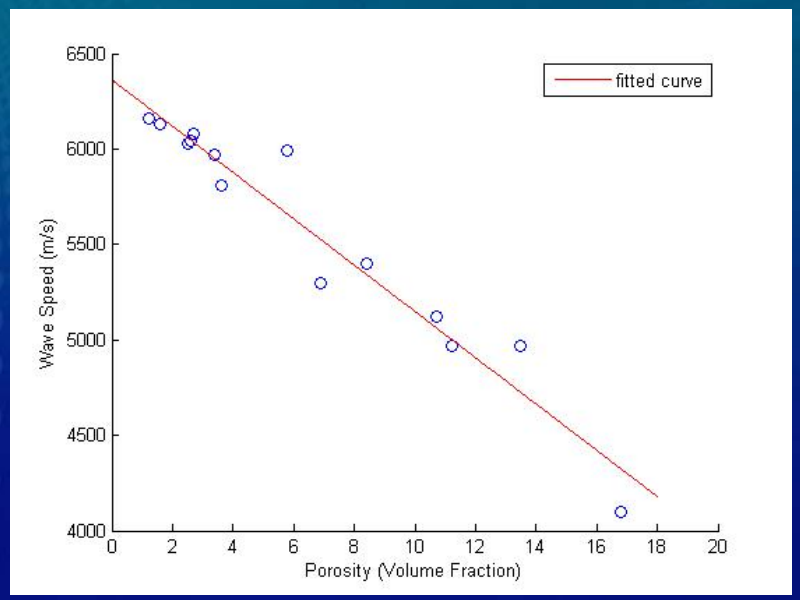


NIST Journal of Research: Special Issue on Additive Manufacturing, Summer 2013

- J. Slotwinski, Guest Editor

- Overview of Additive Manufacturing

- Test Artifact

- Powder Characterization

- Mechanical Properties of AM Parts

- Sustainability of AM Processes

- Theory, laboratory experimentation and sensor design for UT porosity sensor

- Z-Axis Interferometer Measurements

\section{Summary}

- Additive manufacturing is gaining momentum in the US, but there are significant materials-related issues to overcome before gaining wider adoption

- Current methods for mechanical testing and powder characterizatoin assessed, round robins started

- Focus on powder metrology, AM materials mechanical data and standardizing AM materials measurement methods

- Highly inter-disciplinary, with multiple participants and partners.

- Significant publications this year 
Appendix 5

\section{Additive Manufacturing} File Format

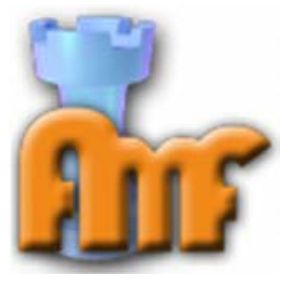

Hod.lipson@cornell.edu

Chair, ASTM F42/Design Task Group on File Formats

Disclaimer: Information in this presentation does not constitute the final standard. Actual specifications is subject to change until finalized by ASTM

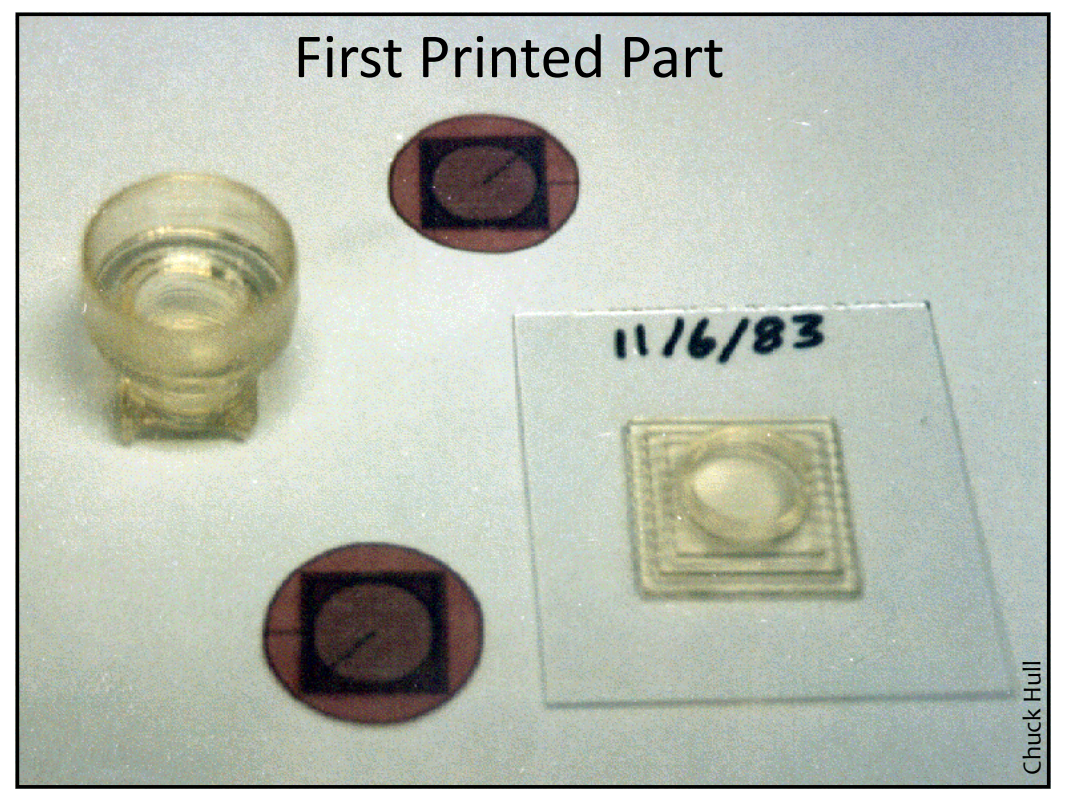

\section{0 principles}

1. Manufacturing complexity is free

2. Variety is free

3. No lead time

4. Zero skill

5. Less waste by-product

6. ...

\section{Open Source 3D Printers}

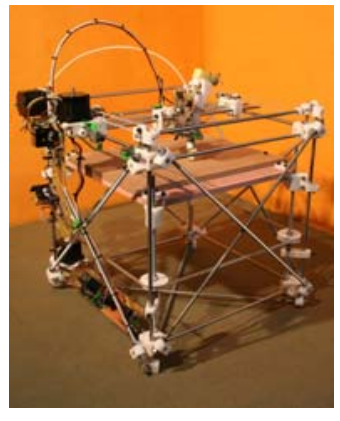

RepRap (2005) University of Bath, UK

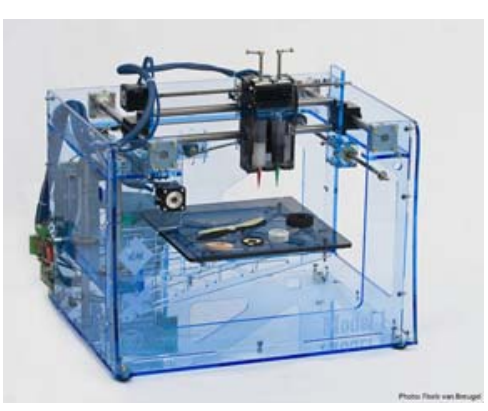

Fab@Home (2006) Cornell University, NY 

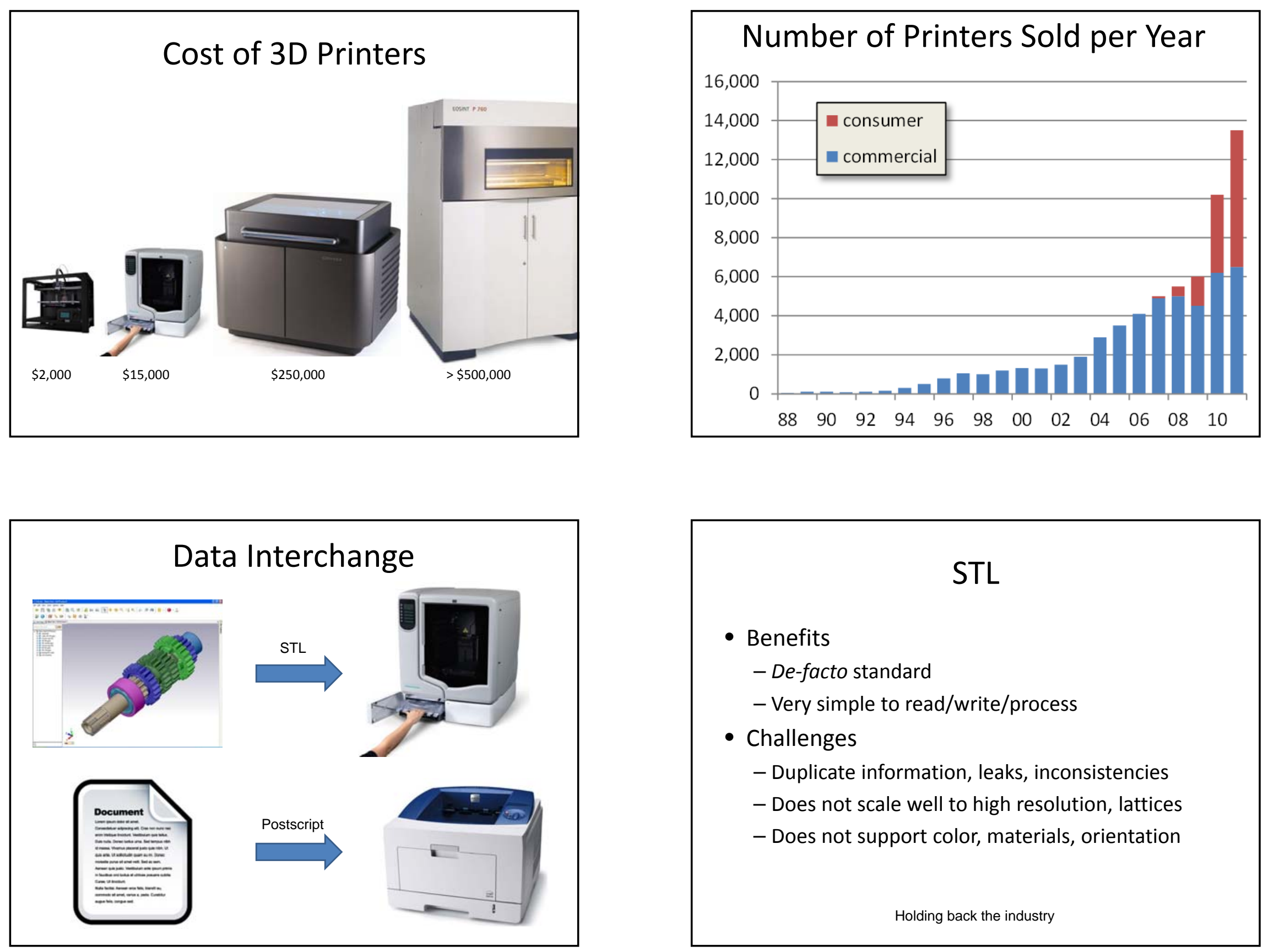

\section{STL}

- Benefits

- De-facto standard

- Very simple to read/write/process

- Challenges

- Duplicate information, leaks, inconsistencies

- Does not scale well to high resolution, lattices

- Does not support color, materials, orientation

Holding back the industry 


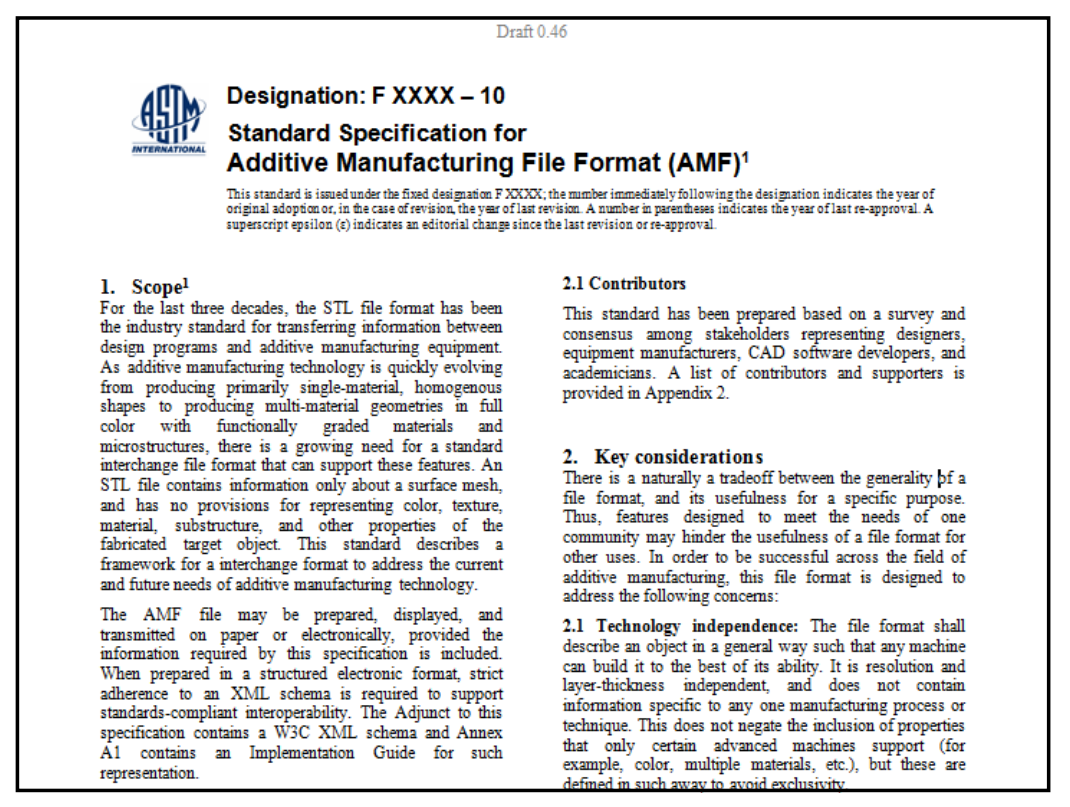

\section{Key considerations}

\section{- Technology independence}

- Describes target object, not how to make it

- Every machine can make it to the best of its ability

- Simplicity

- Easy to understand and implement

- Scalability

- Can handle complex objects, microstructures, repetitions

\section{- Performance}

- File size, read/write time, processing, accuracy

\section{- Backwards compatible}

- Can covert to/from STL without additional info

\section{- Forward compatible}

- Easy to extend new features in the future

\section{Prioritized features from survey}

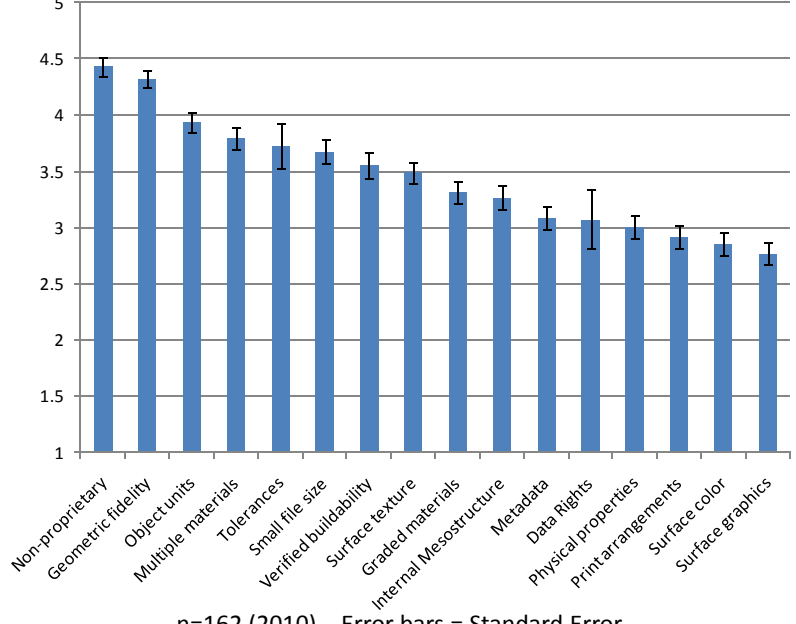

$\mathrm{n}=162$ (2010). Error bars = Standard Error

\section{$\mathrm{XML}$}

- Meta-format: Format of formats

- Text based

- Easy to read/write/parse

- Existing editing tools

- Extensible

- Highly compressible 


\section{General Concept}

- Objects (parts) defined by volumes and materials

- Volumes defined by triangular mesh

- Materials defined by properties/names

- Color properties can be specified

- Color

- Texture mapping

- Materials can be combined

- Graded materials

- Lattice/Mesostructure

- Constellations of Objects can be defined

- Repeated instances, packing, orientation

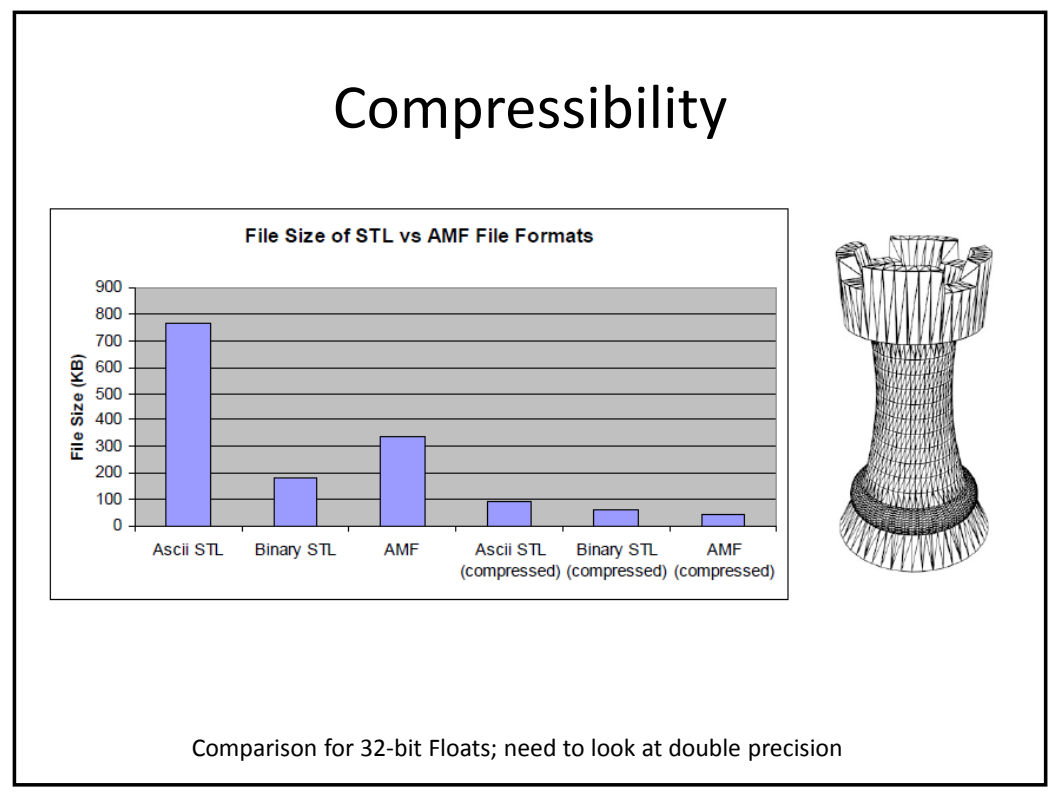

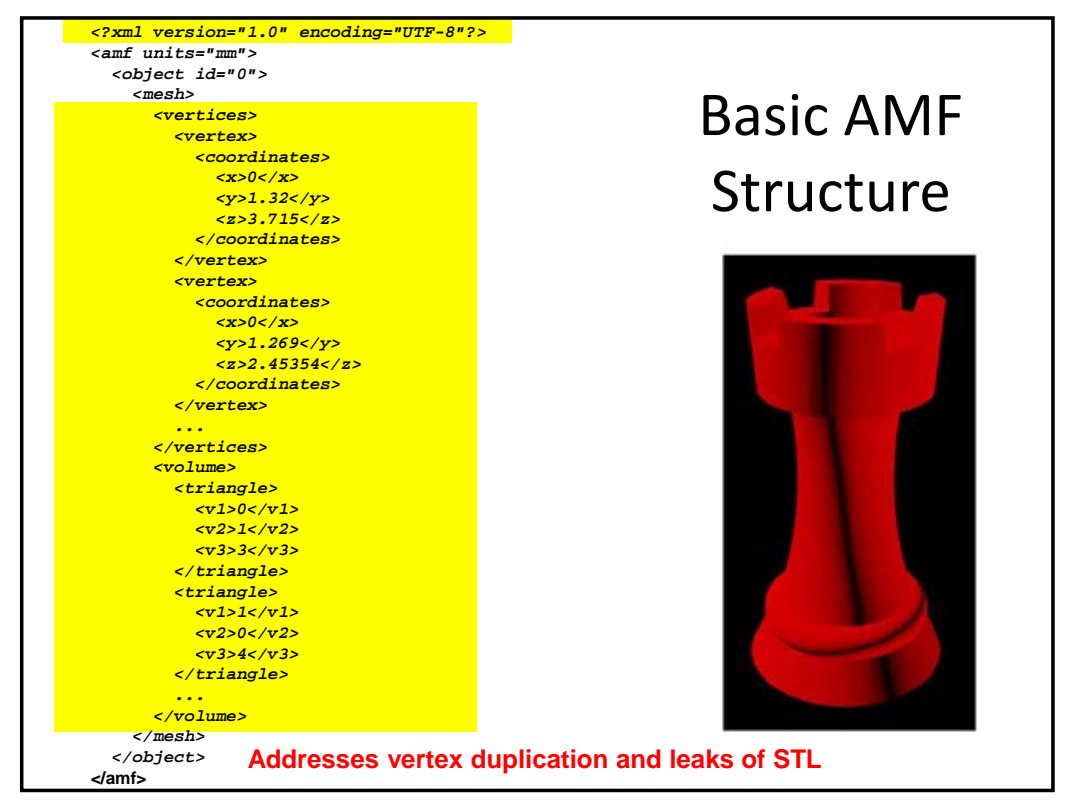

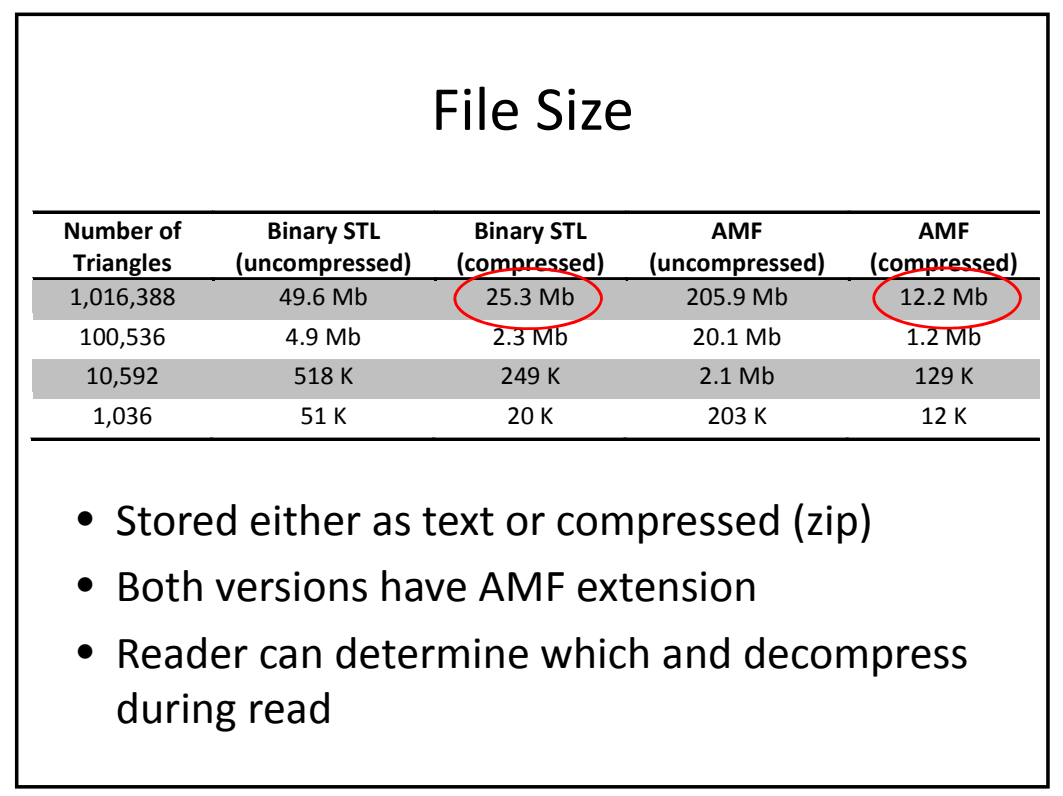




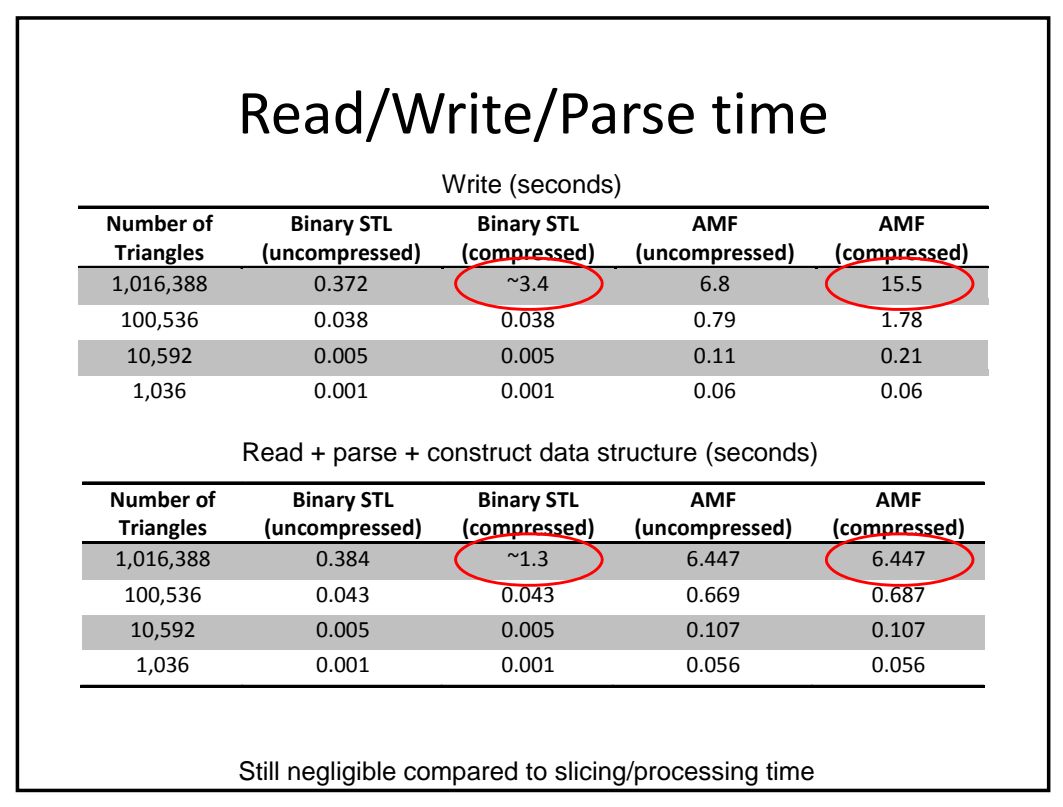

\section{Increasing Geometric Accuracy}

- Flat triangles do not scale well for complex geometry, esepcially:

- Curved surfaces

- Microstructures

- Typical objects require millions of triangles

$-10 \mathrm{M}$ triangles not uncommon

- Likely to get worse with increasing printer resolution

$-10 \mathrm{~cm}$ sphere at $10 \mu \mathrm{m}$ requires 20,000 triangles

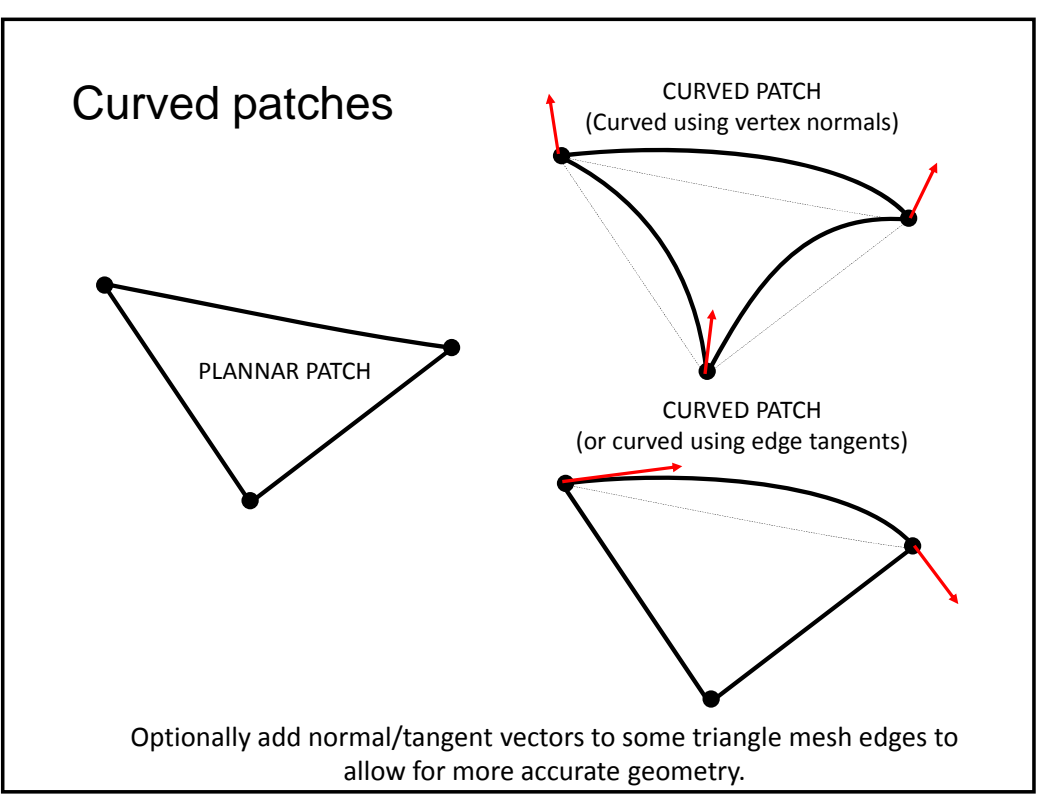



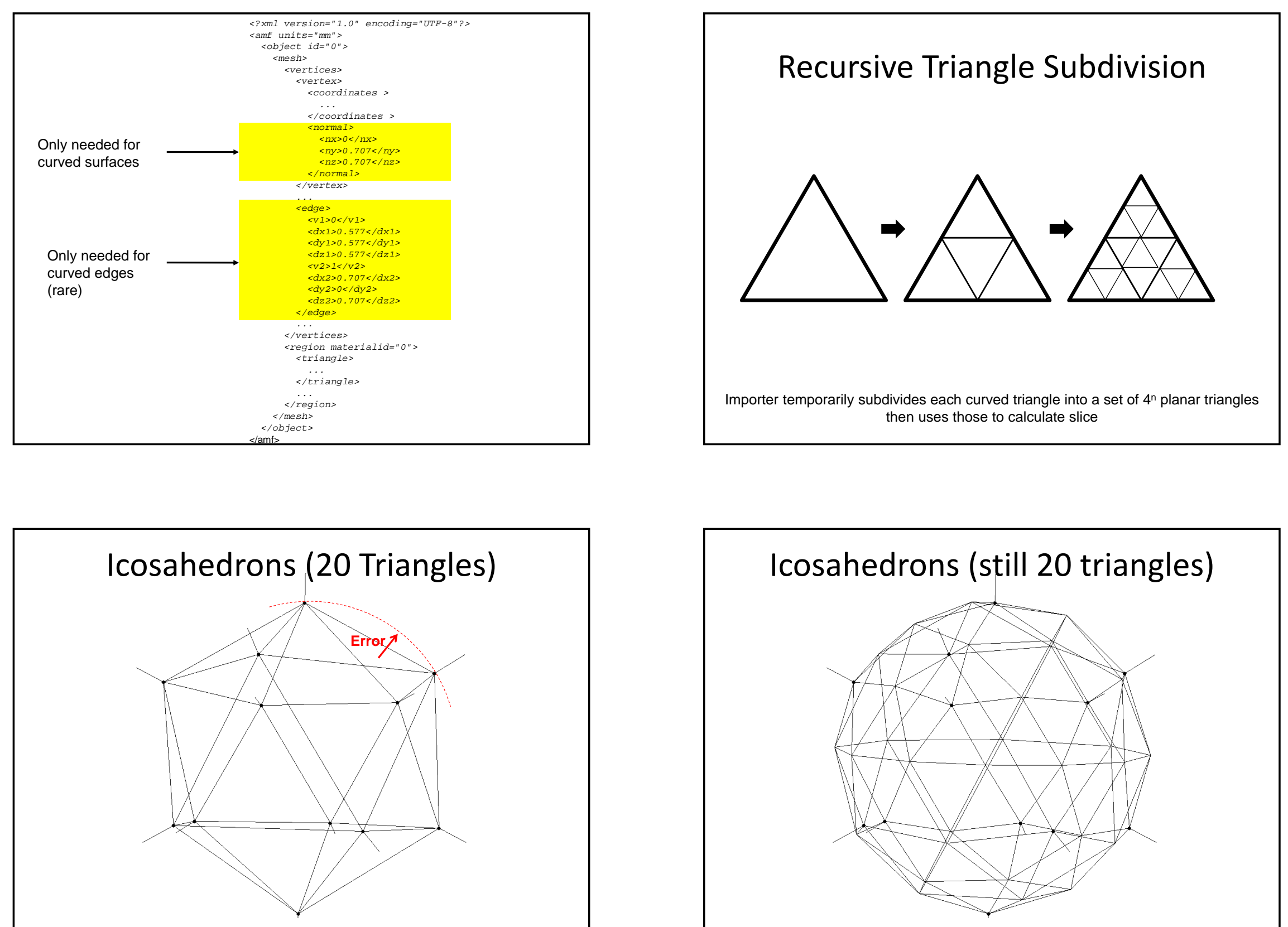

Flat triangles, error $=10.26 \%$ of diameter

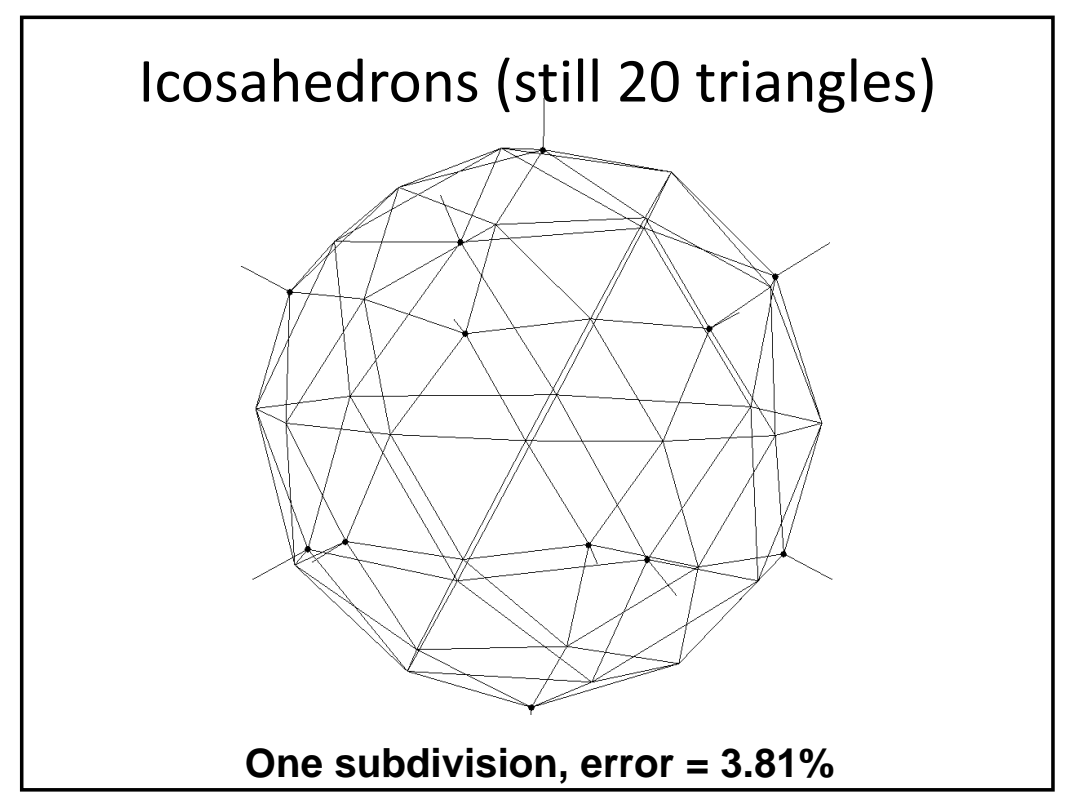




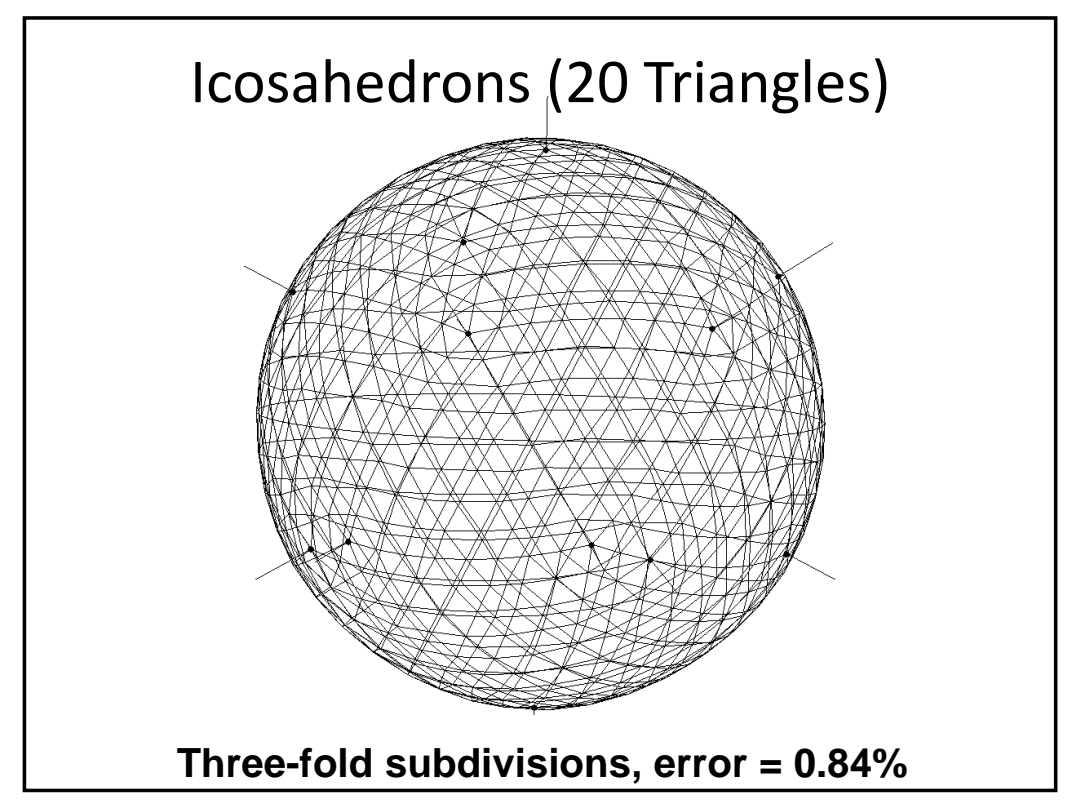

Three-fold subdivisions, error $=0.84 \%$

\section{Icosahedrons (still 20 triangles)}

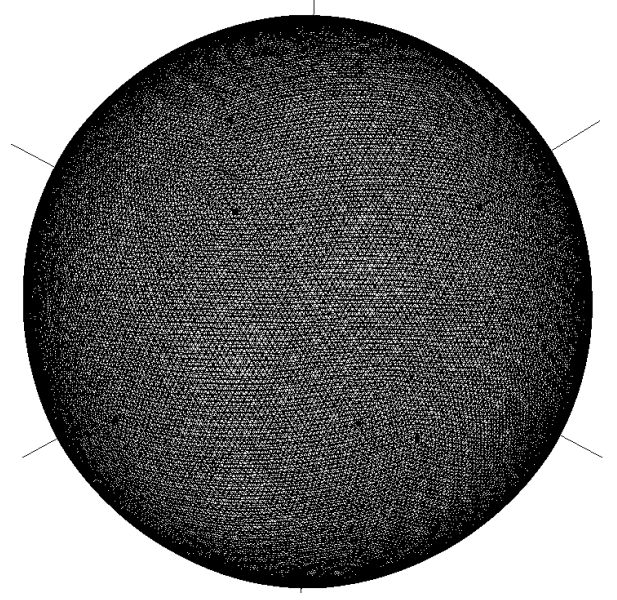

Six-fold subdivisions, error $=0.625 \%$
Icosahedrons (still 20 triangles)

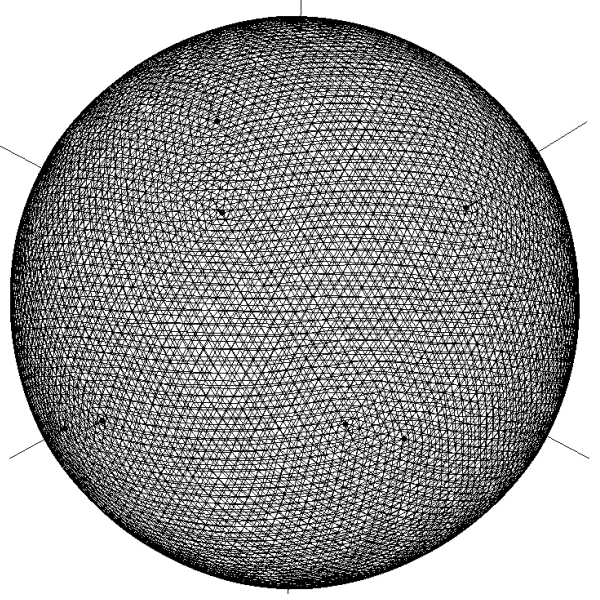

Five-fold subdivisions, error $=0.635 \%$

Curving the triangle patches using surface normal reduces error

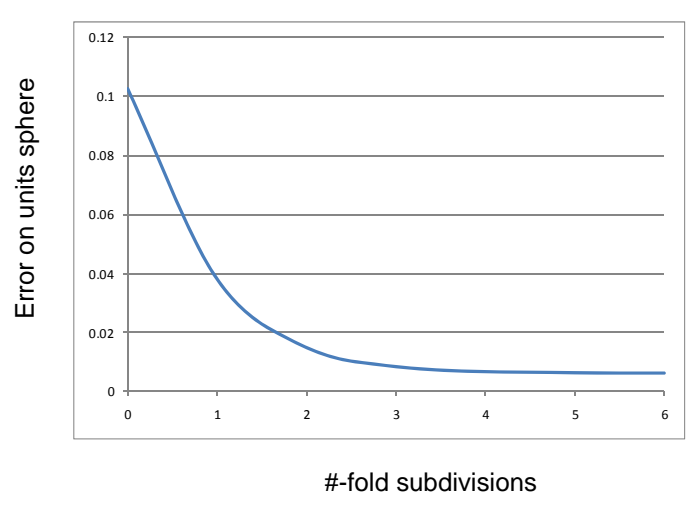



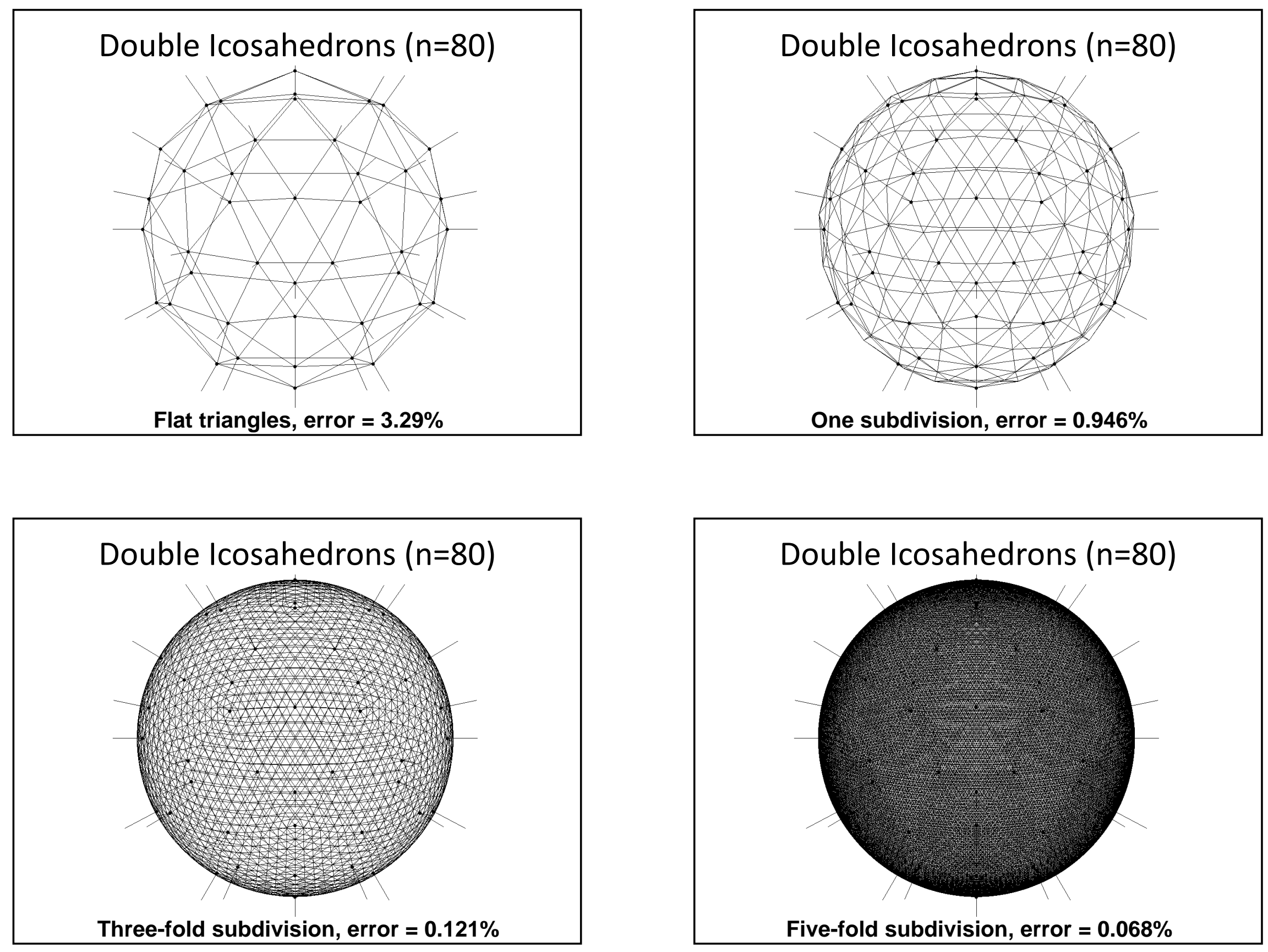


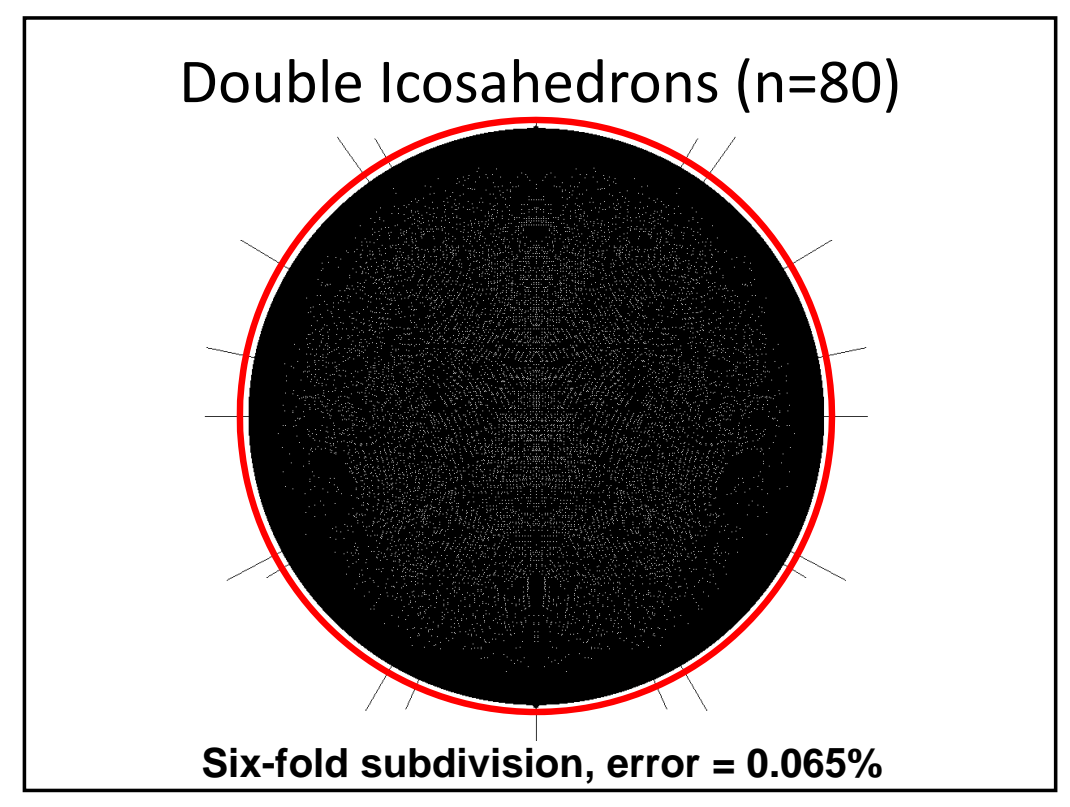

Curving the triangle patches using surface normal reduces error
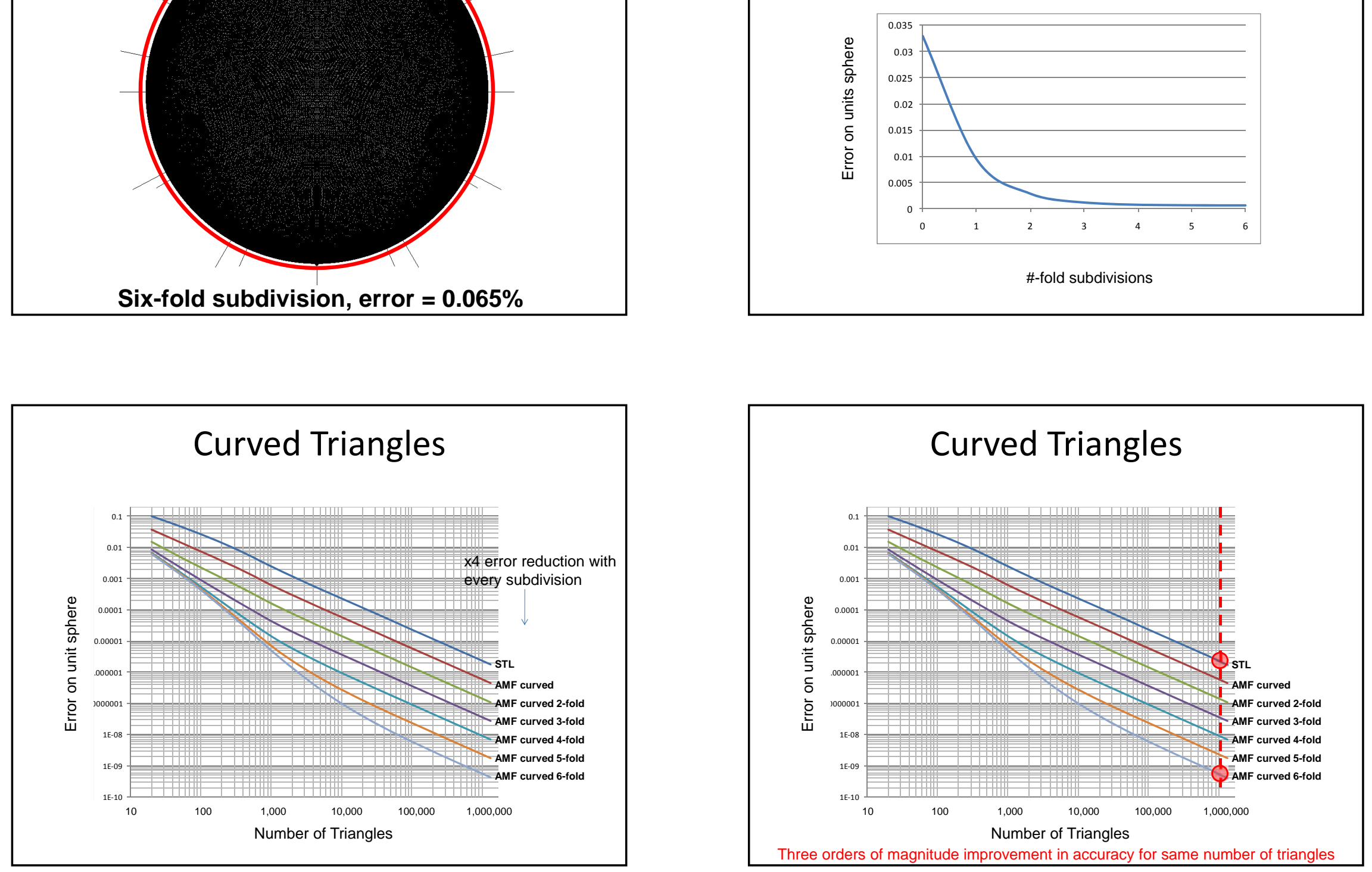


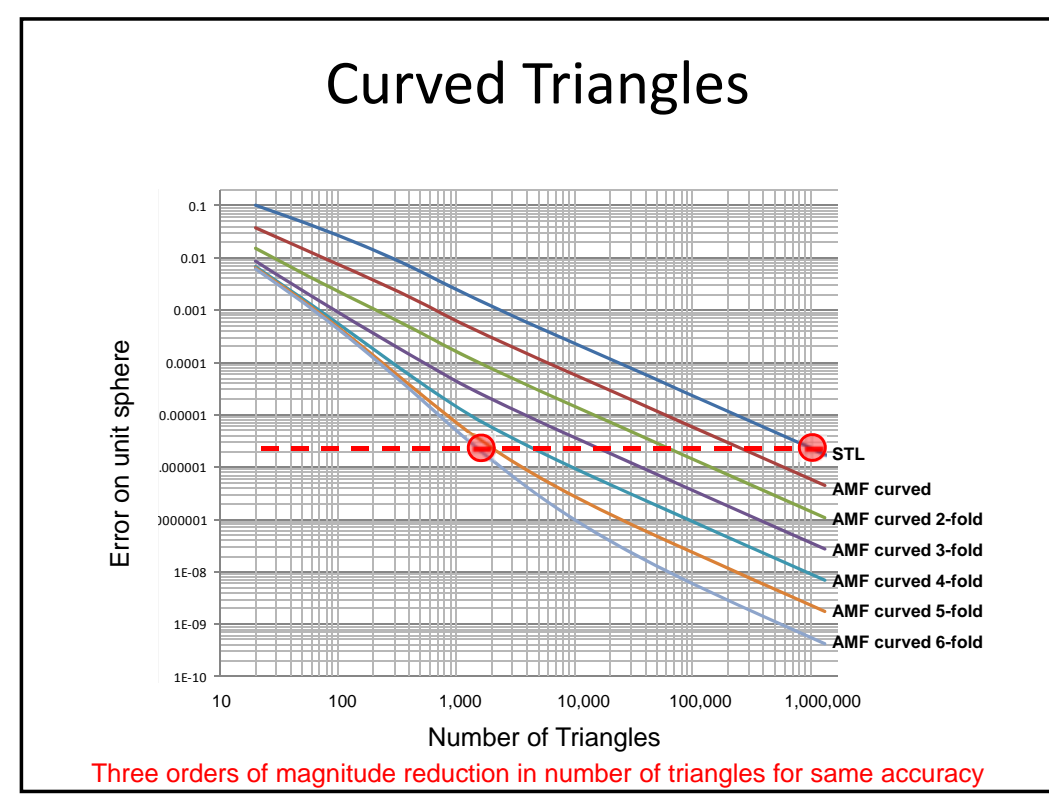

\section{Examples}

- Fabricate $10 \mathrm{~cm}$ diameter sphere

- with 10um Precision

- STL: 20,480 Flat Triangles

- 500K Compressed Binary STL

- AMF: 320 Curved Triangles

- $10 \mathrm{~K}$ Compressed AMF

- Fabricate $1 \mathrm{~m}$ Sphere with $1 \mathrm{~nm}$ precision

- AMF: 1M Triangles

- STL: !?

\section{Accuracy}

\begin{tabular}{ccc}
\hline $\begin{array}{c}\text { Number of } \\
\text { Triangles }\end{array}$ & STL & $\begin{array}{c}\text { AMF } \\
\text { (with normals) }\end{array}$ \\
\hline 20 & 0.102673 & 0.006777 \\
80 & 0.032914 & 0.000788 \\
320 & 0.008877 & $8.28 \mathrm{E}-05$ \\
1,280 & 0.001893 & $1.01 \mathrm{E}-05$ \\
5,120 & 0.000455 & $1.95 \mathrm{E}-06$ \\
20,480 & $1.13 \mathrm{E}-04$ & $4.51 \mathrm{E}-07$ \\
81,920 & $2.81 \mathrm{E}-05$ & $1.11 \mathrm{E}-07$ \\
327,680 & $7.03 \mathrm{E}-06$ & $2.75 \mathrm{E}-08$ \\
$1,310,720$ & $1.76 \mathrm{E}-06$ & $6.87 \mathrm{E}-09$ \\
\hline
\end{tabular}

\section{Simple to implement}

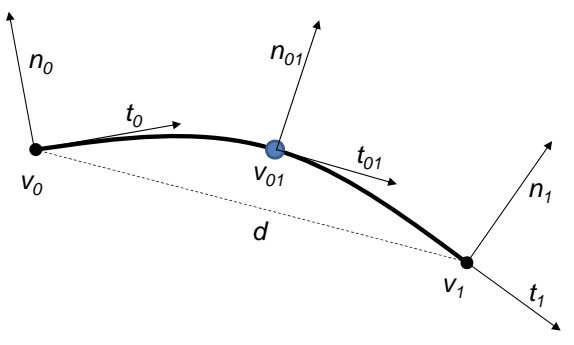

1. If tangents $t_{0}$ or $t_{1}$ not specified, compute tangents from normals

$$
t_{0}=|d| \frac{\left(n_{0} \times d\right) \times n_{0}}{\left\|\left(n_{0} \times d\right) \times n_{0}\right\|}, \quad t_{1}=|d| \frac{\left(n_{1} \times d\right) \times n_{1}}{\left\|\left(n_{1} \times d\right) \times n_{1}\right\|}
$$

2. Compute center point $v_{01}=h(0.5)$ and center tangent $t_{01}$ using Hermite curve $h(s)=\left(2 s^{3}-3 s^{2}+1\right) v_{0}+\left(s^{3}-2 s^{2}+s\right) t_{0}+\left(-2 s^{3}+3 s^{2}\right) v_{1}+\left(s^{3}-s^{2}\right) t_{1}$

3. Repeat for three triangle edges, then split triangle into four

4. Recurse as much as possible (diminishing returns after $\sim 4$ levels)

5. No ambiguities. Detailed procedure in specification. 

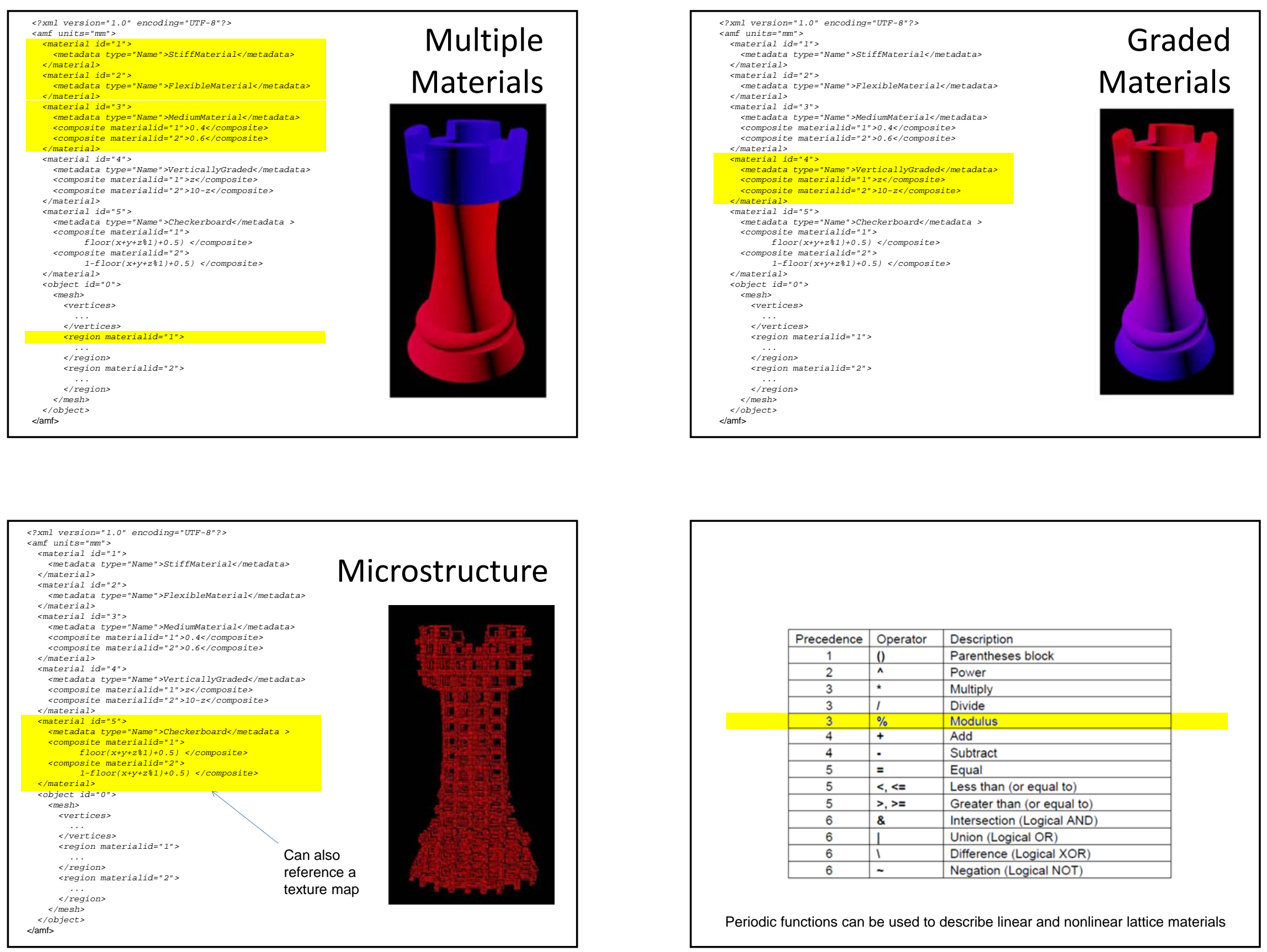


\section{Material properties}

- By name

- <metatdata type="Name" $>$ ABS $<$ /metadata $>$

- <metatdata type="Name" $>$ Nylon 1234</metadata $>$

- By physical property

- <metatdata type="Elastic Modulus" $>\mathbf{2 G P a}</$ metadata $>$

\section{Print Constellation}

- Print orientation

- Duplicated objects

- Sets of different objects

- Efficient packing

- Hierarchical

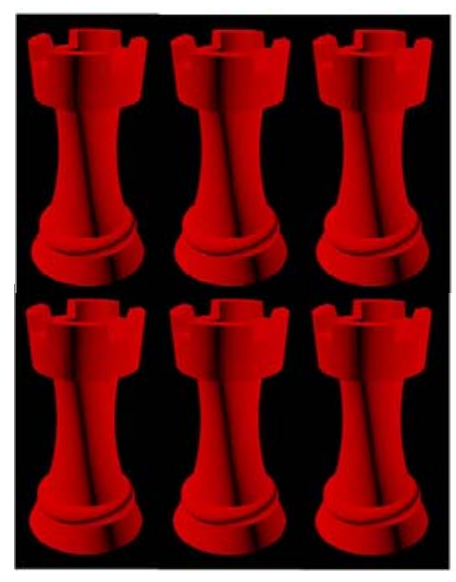

\section{Color and Graphics}

- Can be assigned to

- A material

- A region

- A vertex

- Specified

- Fixed RGBA values

- By formula

- By reference to an image

\section{Metadata}

$<$ metadata type $=$ "Author" $>$ John Doe" $></$ metadata $>$

$<$ metadata type $=$ "Software" $>$ SolidX 2.3" $><$ /metadata $>$

$<$ metadata type $=$ "Name" $>$ Product $1></$ metadata $>$

$<$ metadata type $=$ "Revision" $>12 \mathrm{~A}^{\prime}></$ metadata $>$

<object id="1">

$<$ metadata type $=$ "Name" $>$ Part $A><$ /metadata $>$

$<$ object id="1"> 


\section{Future plans}

- Tolerances

- Surface/depth textures

- Data encryption, copyright

- External references and subassemblies

- Process control

- Non-volumetric support structures

- Non mesh geometry specification methods - Voxel, FRep

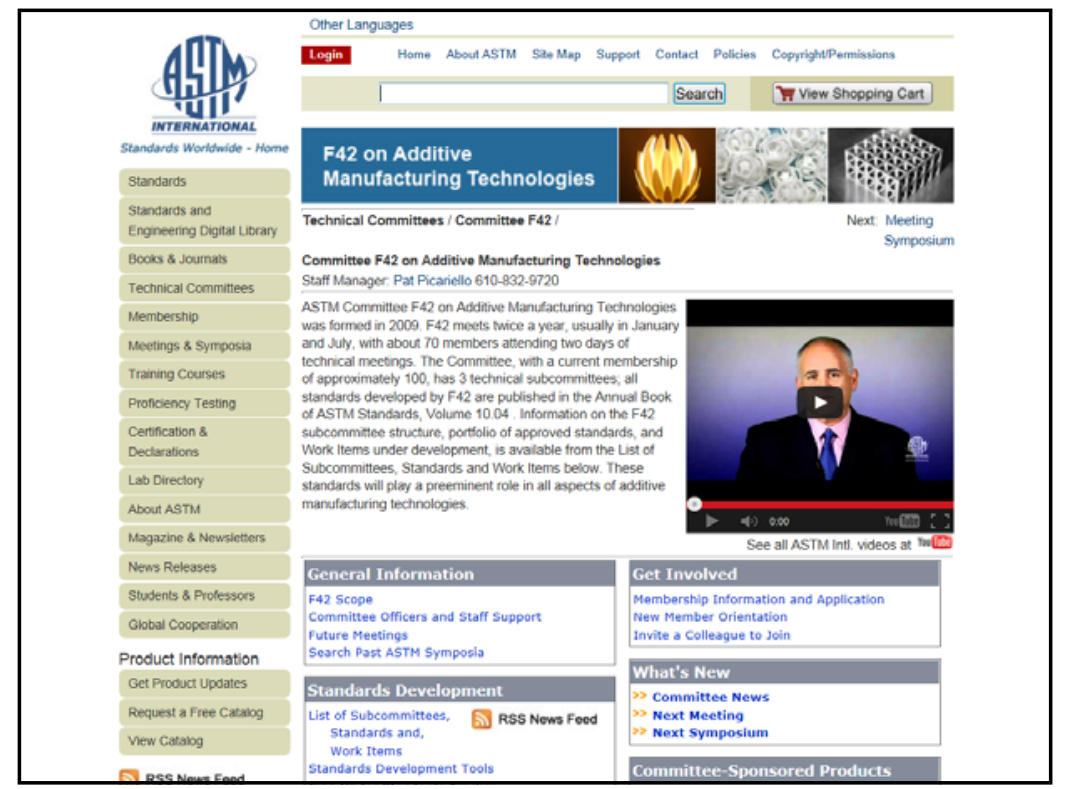

\section{Current Status}

- AMF approved May 2011 as ASTM F2915

- Revision 1.1 in 2012

- Now: The test of adoption
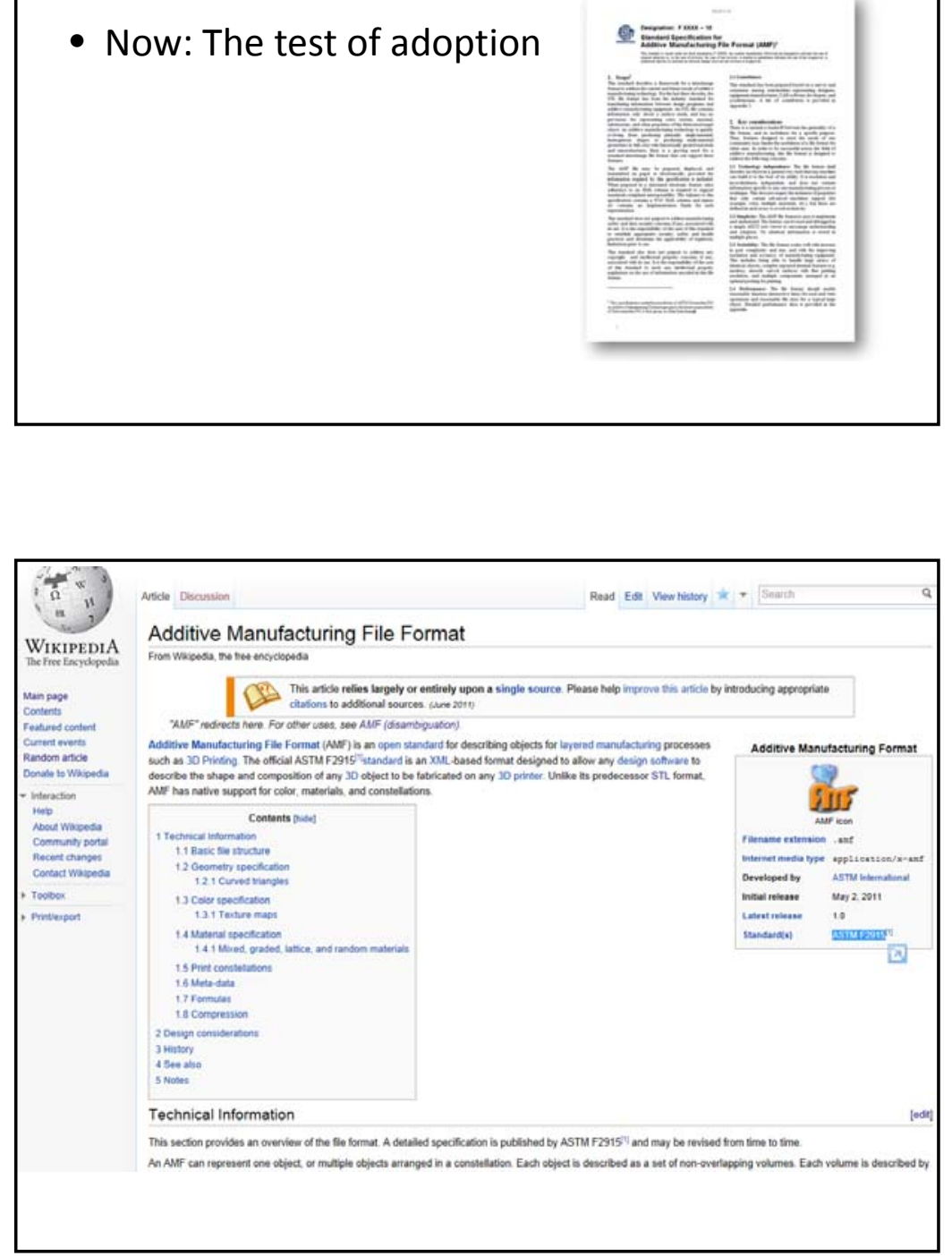


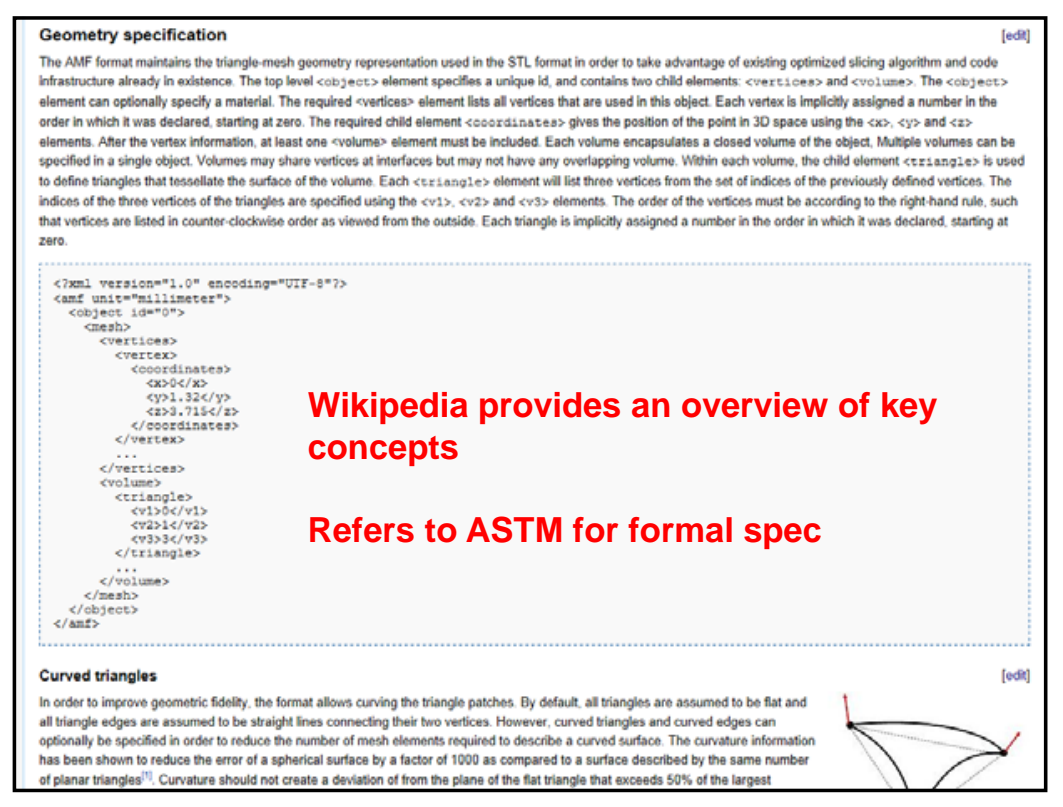

\begin{tabular}{|c|}
\hline $\begin{array}{c}\text { Join The Discussion } \\
\text { http://groups.google.com/group/stl2 }\end{array}$ \\
\hline Google groups \\
\hline$s_{s i}$ \\
\hline New since last time: 2 messages \\
\hline 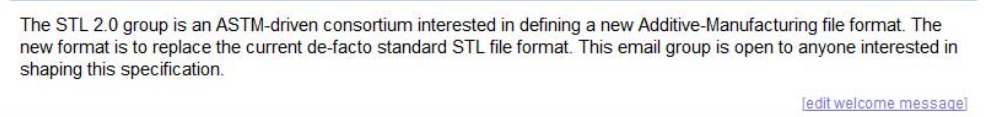 \\
\hline$\ominus$ Discussions 9 of 157 messages view all \\
\hline 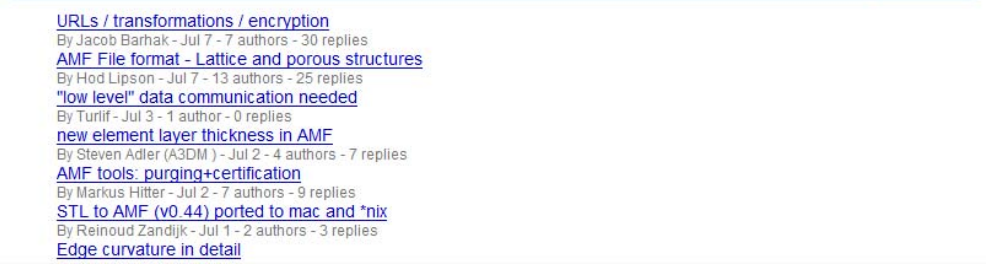 \\
\hline
\end{tabular}

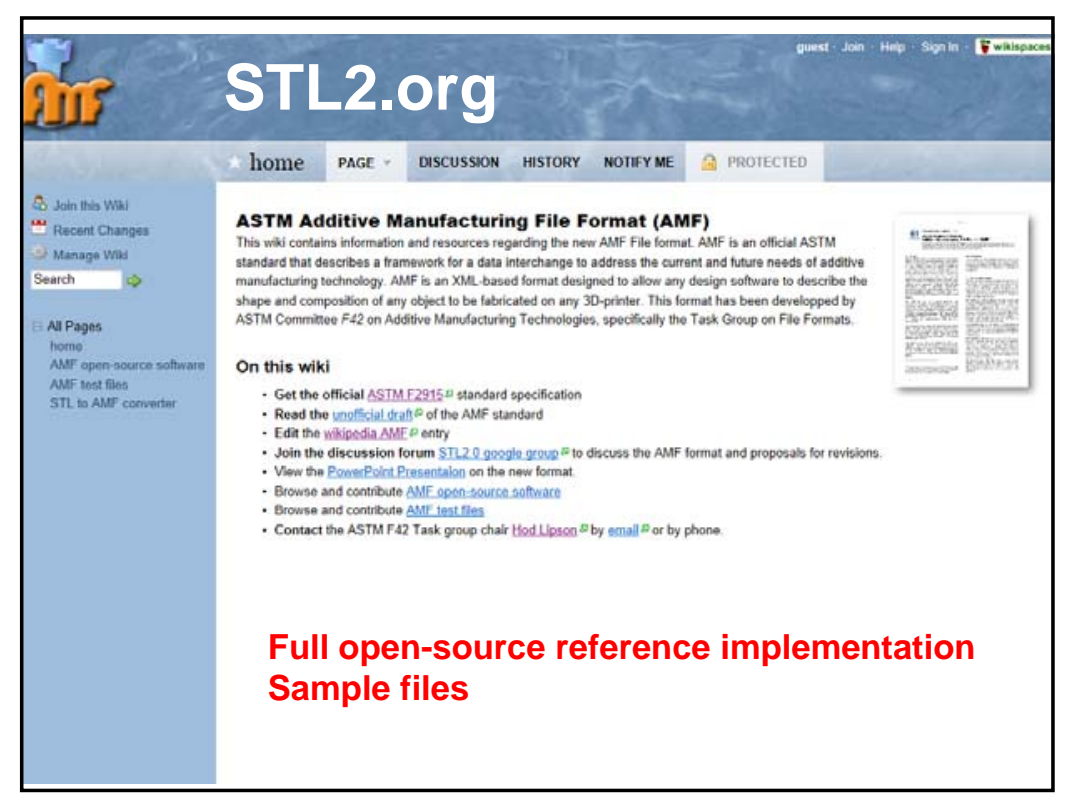


Appendix 6

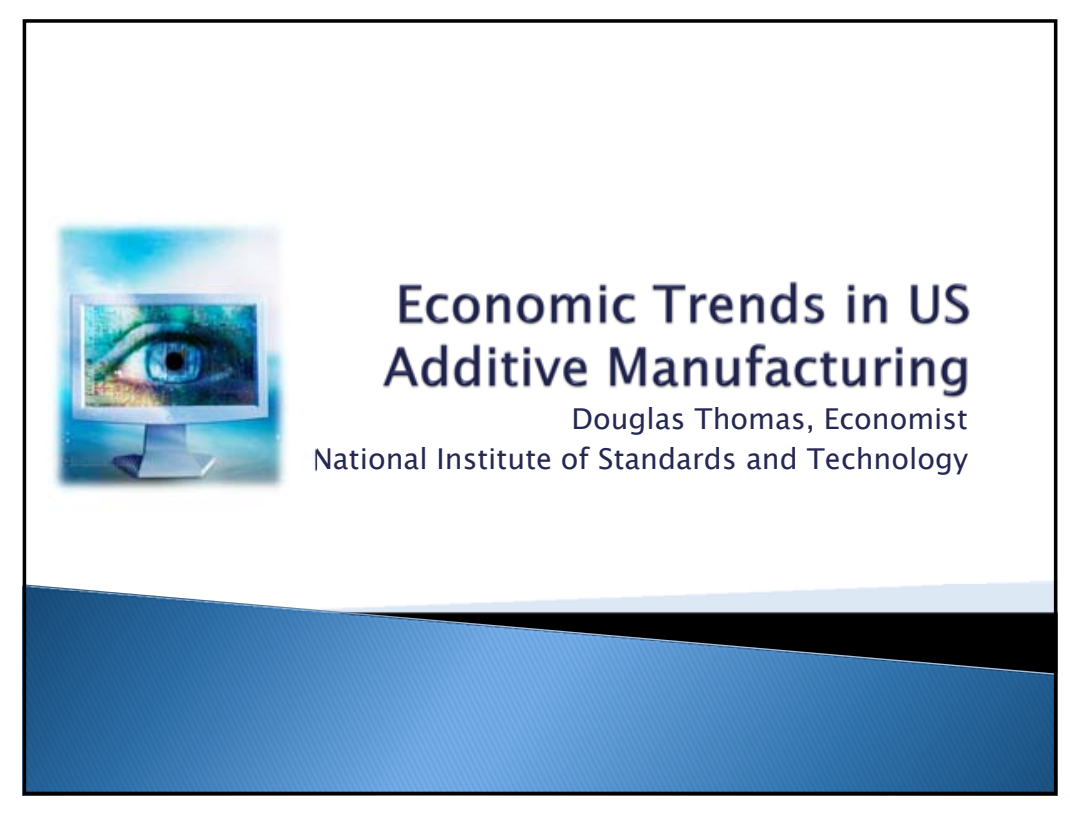

\section{Introduction: US Manufacturing}

- The U.S. produced approximately $18 \%$ of the world's manufactured goods in 2008

- The industry impacted $23 \%$ of U.S. output in 2009

- After controlling for price changes, the industry grew 26\% between 1985 and 2009

- Medium and high technology goods accounted for $56 \%$ of U.S. manufacturing value added in 2003

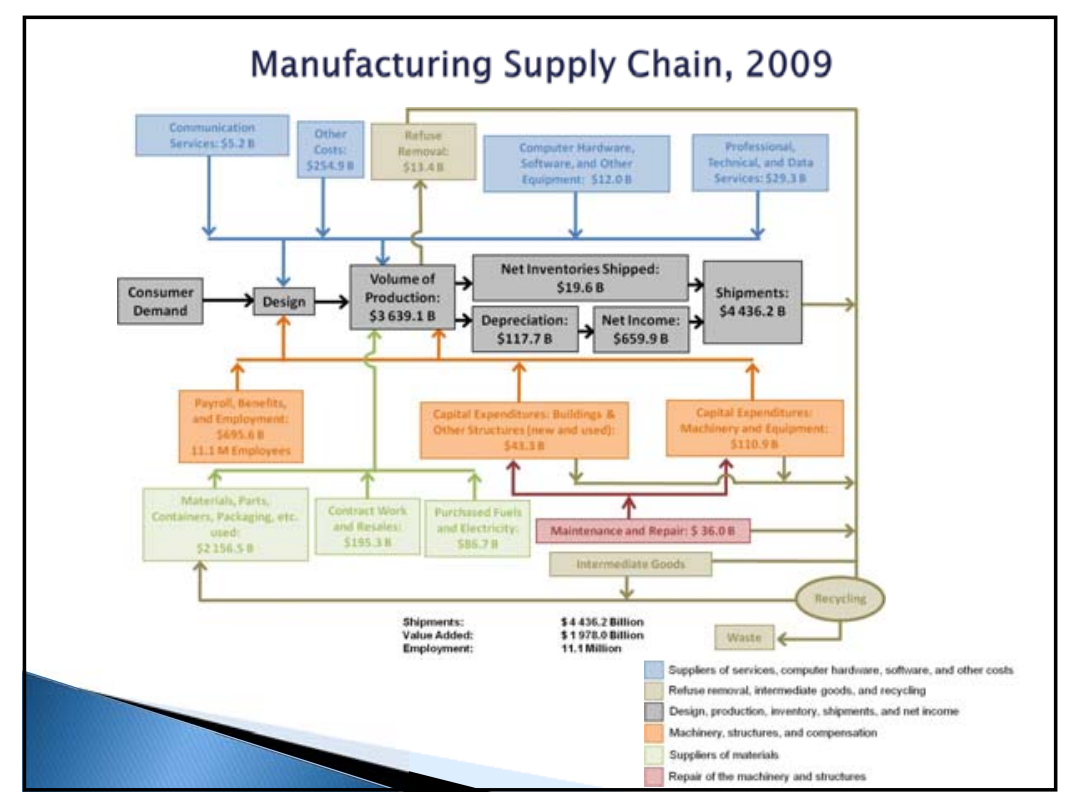

\section{Output and Value Added}

- Output (shipments) Net selling value

- Value added Value added is the difference between an industry's or an

establishment's total output and the cost of its intermediate inputs

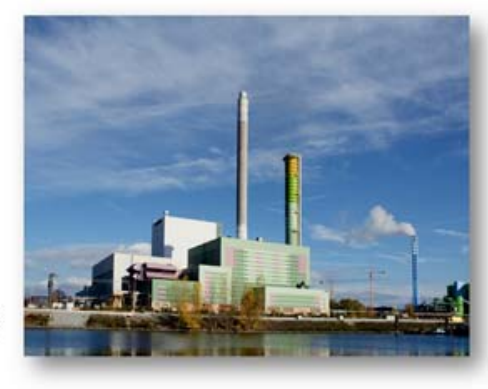



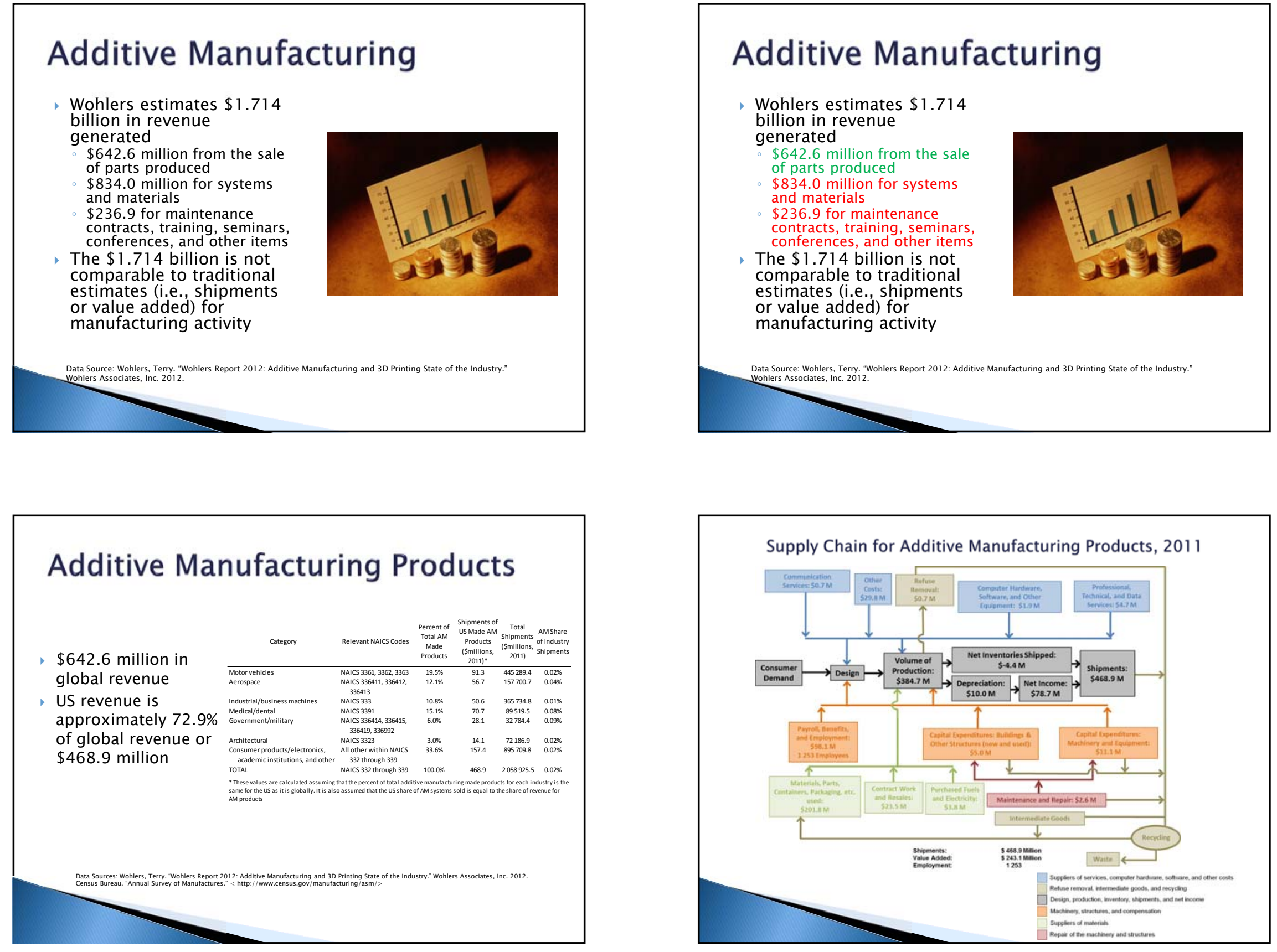


\section{Cost Distribution: Plastic Parts}

- A case study of a fluorescent lamp holder

- Machine and material costs are significant cost drivers
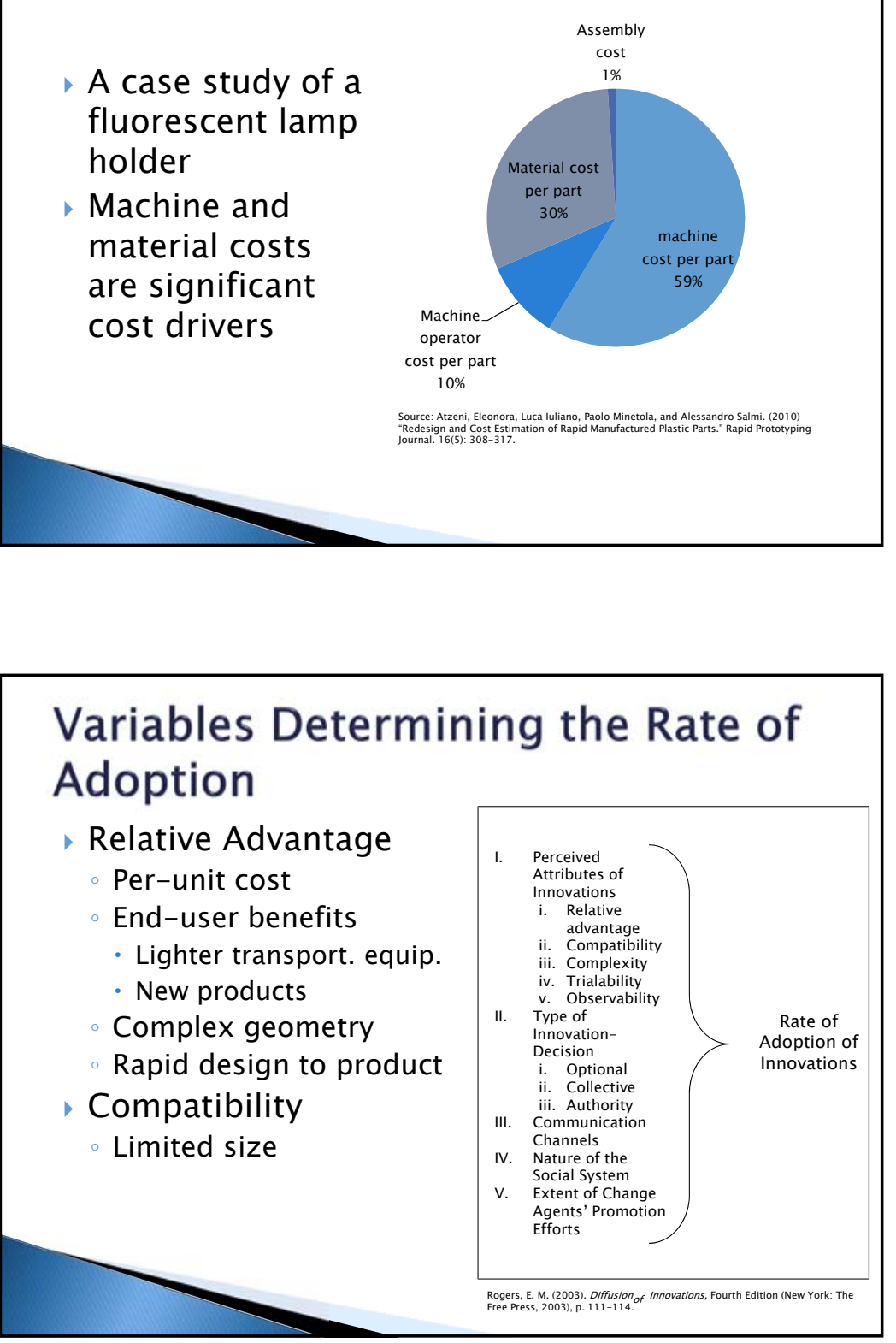

\section{Cost Comparison: Metal Parts}

- Additive

manufacturing is,

typically, competitive

for low to medium

volume production

- Case study of the

landing gear

assembly for a model

$1: 5$ scale of the P180

Avant II by Piaggio

Aero Industries S.p.A.

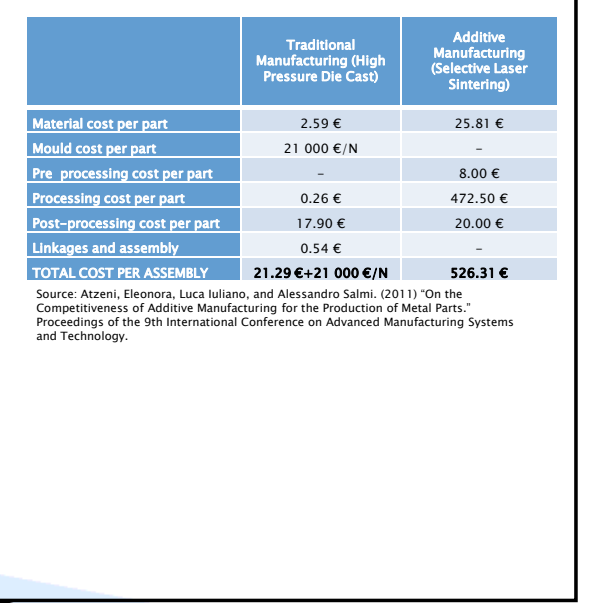

Below a lot size of 41

additive

manufacturing is

more cost effective

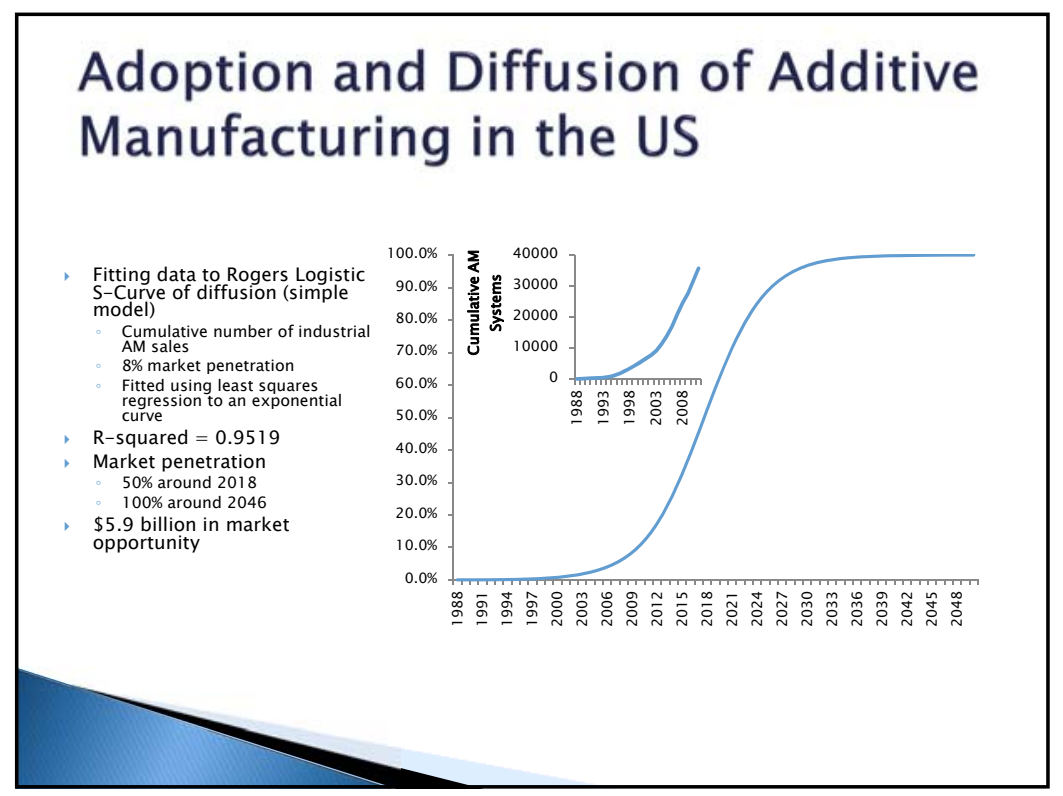



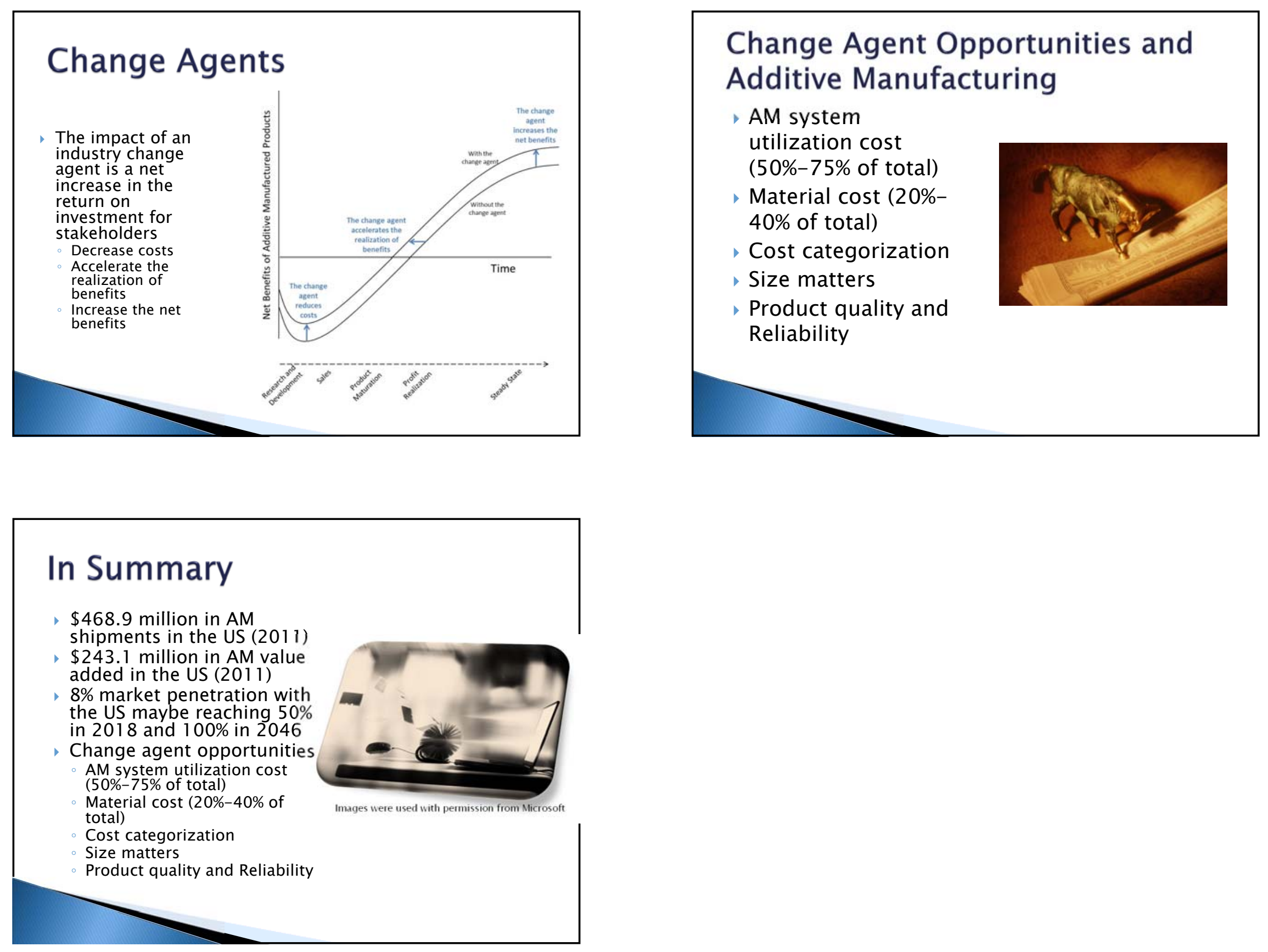